\title{
The Role of Alcohol, Marijuana, and Other Drugs in the Accidents of Injured Drivers \\ Volume 2-Appendices
}

National Highway

Traffic Satoty

K. W. Terhune

Calspan Field Services, Inc.

4455 Genesee Street

Buffalo, New York 14225

Contract No. DOT HS-5-01179

Contract Amount \$496, 165

This document is available to the U.S. public through the National Technical Information Service, Springfield, Virginia 22161 
This document is disseminated under the sponsorghip of the Department of Transportation in the interest of information exchange. The United States Government assumes no liability for its contents or use thereof. 
TECHNICAL REPORT STANDARD TITLE PAGE

\begin{tabular}{|c|c|}
\hline $\begin{array}{l}\text { 1. Report No. } \\
\text { DOT-HS-806 } 200\end{array}$ & 3. Recipienr's Catolog No. \\
\hline \multirow{2}{*}{$\begin{array}{l}\text { 4. Titlo and Subtitle } \\
\text { The Role of Alcohol, Marijuana, and Other Drugs in } \\
\text { the Accidents of Injured Drivers, Volume 2. Appendices }\end{array}$} & $\begin{array}{l}\text { 5. Report Date } \\
\text { January } 1982 \\
\end{array}$ \\
\hline & 6. Porforming Organieation Codo \\
\hline $\begin{array}{l}\text { 7. Author(s) } \\
\text { K. W. Terhune }\end{array}$ & $\begin{array}{l}\text { 8. Performing Organization Roport No. } \\
\text { ZS-5769-V-1 }\end{array}$ \\
\hline \multirow{2}{*}{$\begin{array}{l}\text { 9. Porforming Organization Name and Addross } \\
\text { Calspan Field Services, Inc. } \\
4455 \text { Genesee Street } \\
\text { Buffalo, New York } 14225\end{array}$} & $\begin{array}{l}\text { 10. Work Unir No. } \\
\mathrm{A} 03\end{array}$ \\
\hline & $\begin{array}{l}\text { 11. Contract or Grans No. } \\
\text { DOT-HS-5-01179 }\end{array}$ \\
\hline \multirow{2}{*}{$\begin{array}{l}\text { 12. Sponsoring Agency Name and Address } \\
\text { U.S. Department of Transportation } \\
\text { National Highway Traffic Safety Administration } \\
400 \text { Seventh Street, S.W. } \\
\text { Washington. D.C. } 20590\end{array}$} & $\begin{array}{l}\text { 13. Type of Report and Period Covered } \\
\text { Final Report } \\
\text { June } 1975 \text { - January } 1982\end{array}$ \\
\hline & 14. Sponsoring Agency Code \\
\hline
\end{tabular}

15. Supplamentary Notos

Report is in two volumes. Volume 1 is Findings.

16. Abstract Using samples of blood obtained from 497 injured drivers at a Rochester, $N Y$ hospital, this study determined the incidence rates of alcohol, THC (marijuana agent), and other drugs. Accident data (police reports, driver interviews) were also collected, and analyses determined driver culpability rates, collision types, and crash circumstances involving alcohol and certain drugs. Main substances found were alcohol $(25 \%)$, THC $(10 \%)$ and tranquilizers $(8 \%) ; 38 \%$ of the drivers had alcohol or some other drug tested for in their systems. Culpability rates were: $74 \%$ for intoxicated drivers, $53 \%$ for THC-only drivers, $34 \%$ for drugfree drivers, and $22 \%$ for tranquilizer-only. drivers. Alcohol-involved crashes were predominantly single vehicle accidents, followed by striking vehicles in head-on and rearend impacts. No unique THC or tranquilizer collision types were found. Circumstances overrepresented in alcohol crashes were curves, occurrence on weekends, occurrence between midnight-6AM, unlighted streets, and non-intersection locations. "Alcohol accident types" were identified, e.g. singledriver crash occurring midnight-6AM on a curve ( $95 \%$ alcohol involvement). Police reporting of alcohol involvement was also analyzed. Possible roadway and vehicle countermeasures to reduce impaired-driver accidents were suggested. Other recommendations addressed police alcohol detection and NASS or FARS monitoring of alcohol involvement. Further study clarifying the crash roles of THC and tranquilizers in fatal and non-fatal crashes was considered essential.

17. Key Words

Alcohol accidents; drug crashes; drinking drivers; alcohol countermeasures; driver culpability
18. Distribution Stotomont

Document is available through the National Technical Information Service Springfield, Virginia 22151
19. Socurity Classil. (of this ruport) None
20. Socurity Clussit. (ol this puyu) None

21. No. ol Pous
150




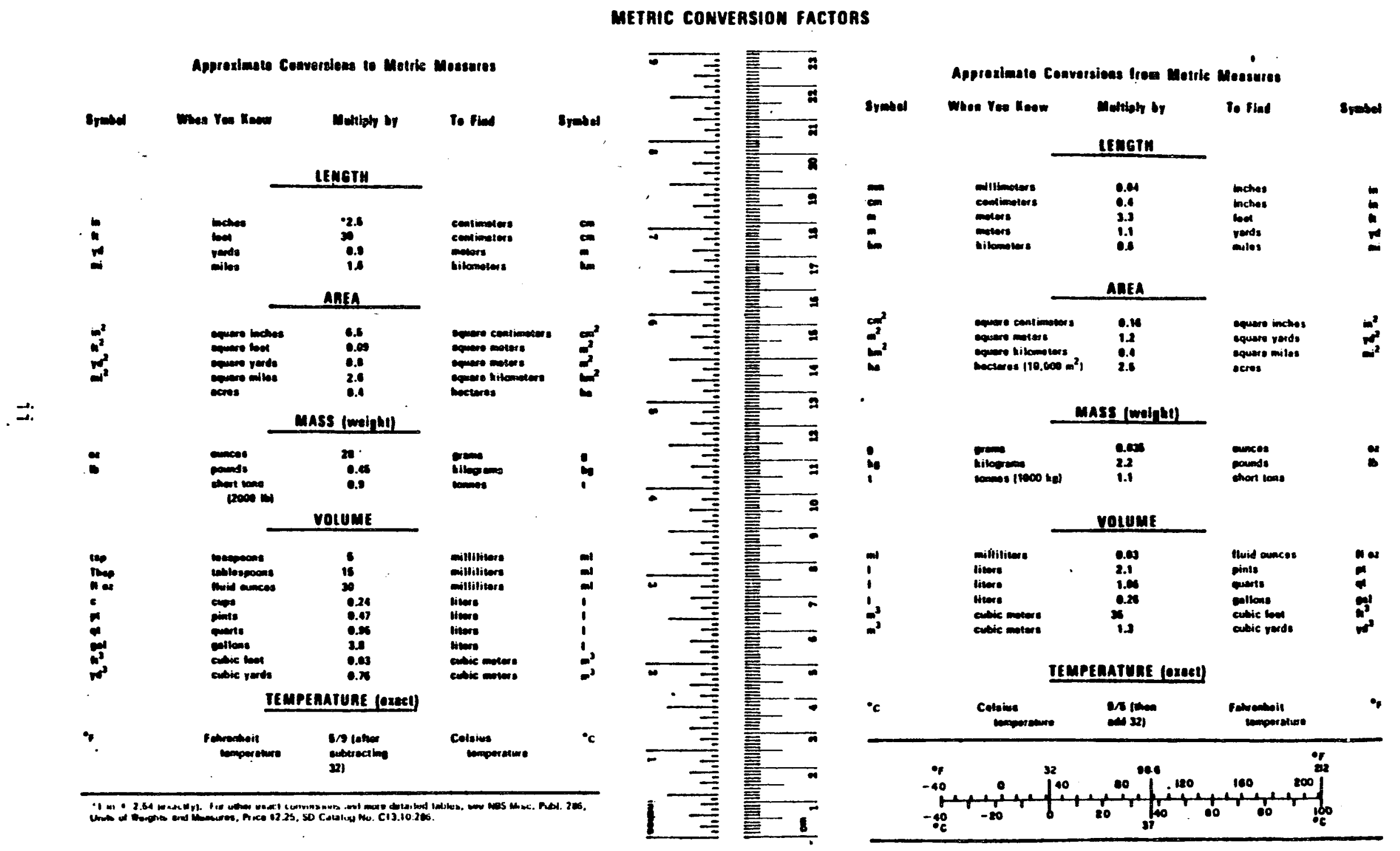


APPENDIX A

Data Forms 
DRIVER BEHAVIORAL ERRORS STUDY IIUMIN UAIA

U.S. DOT/NHTSA

CASE NUMBER

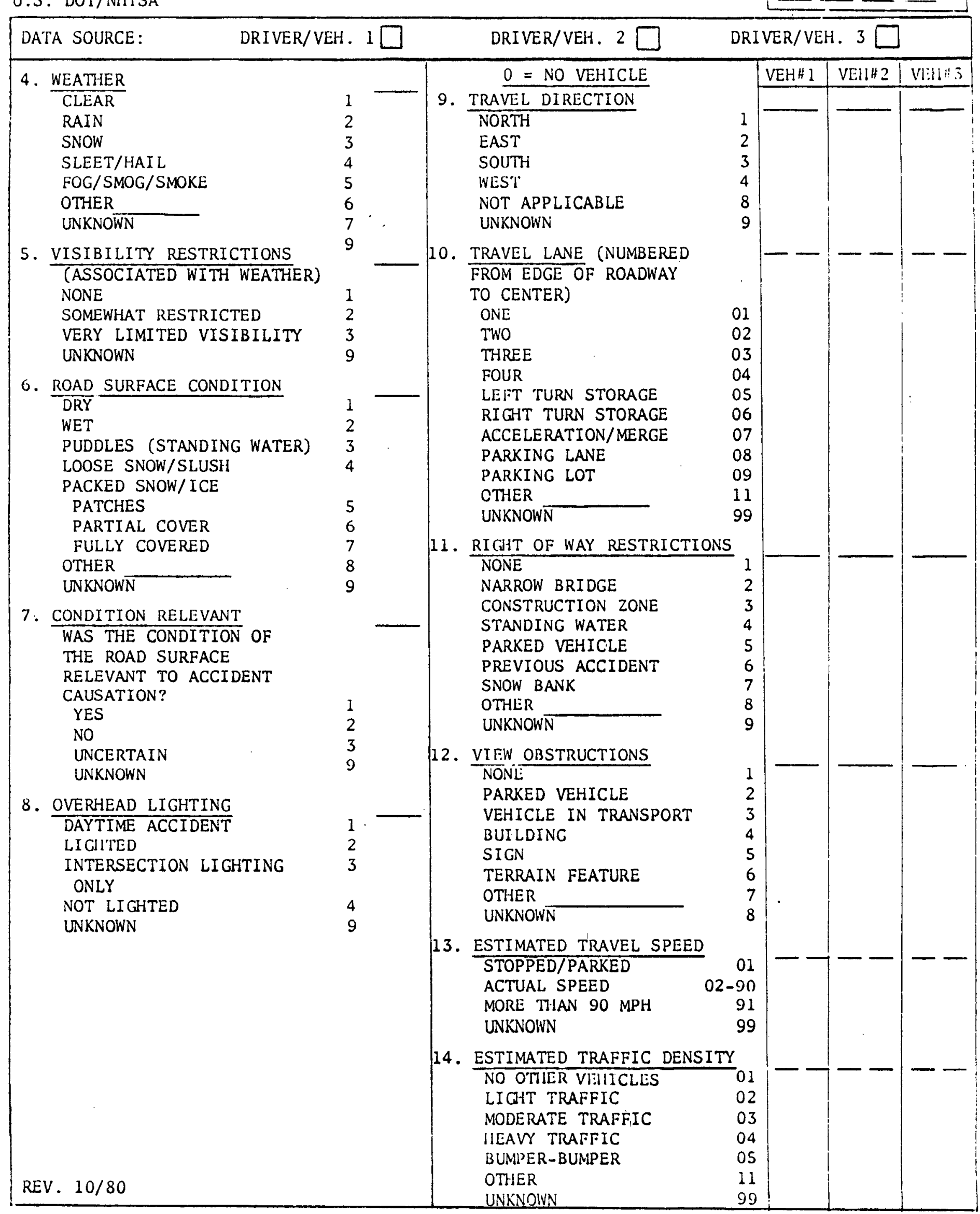

A-2 


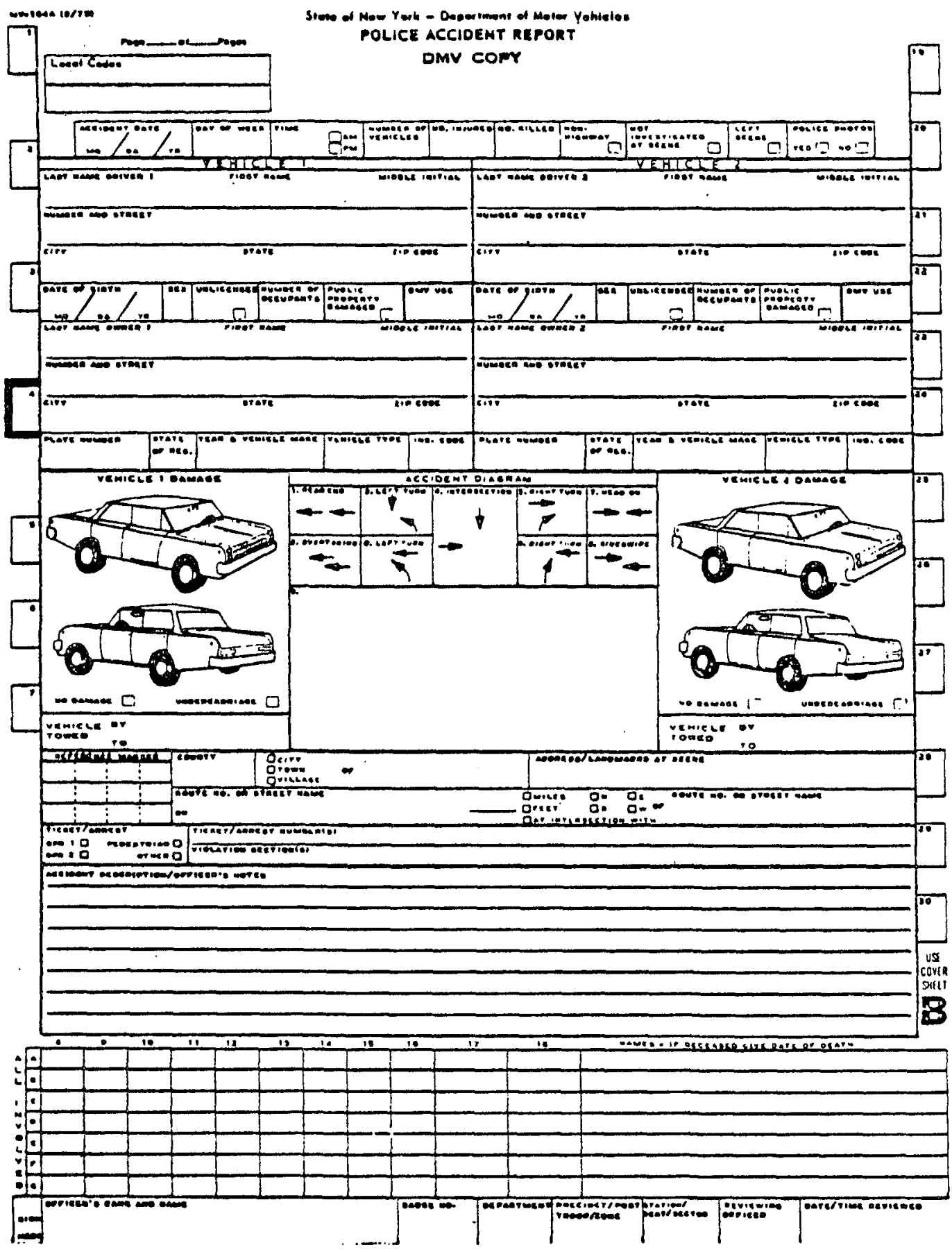




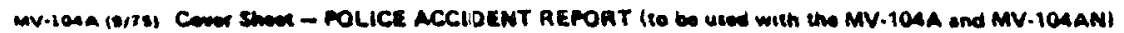

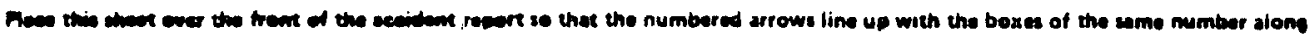

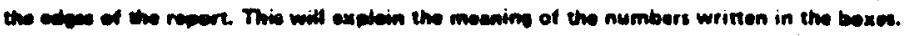

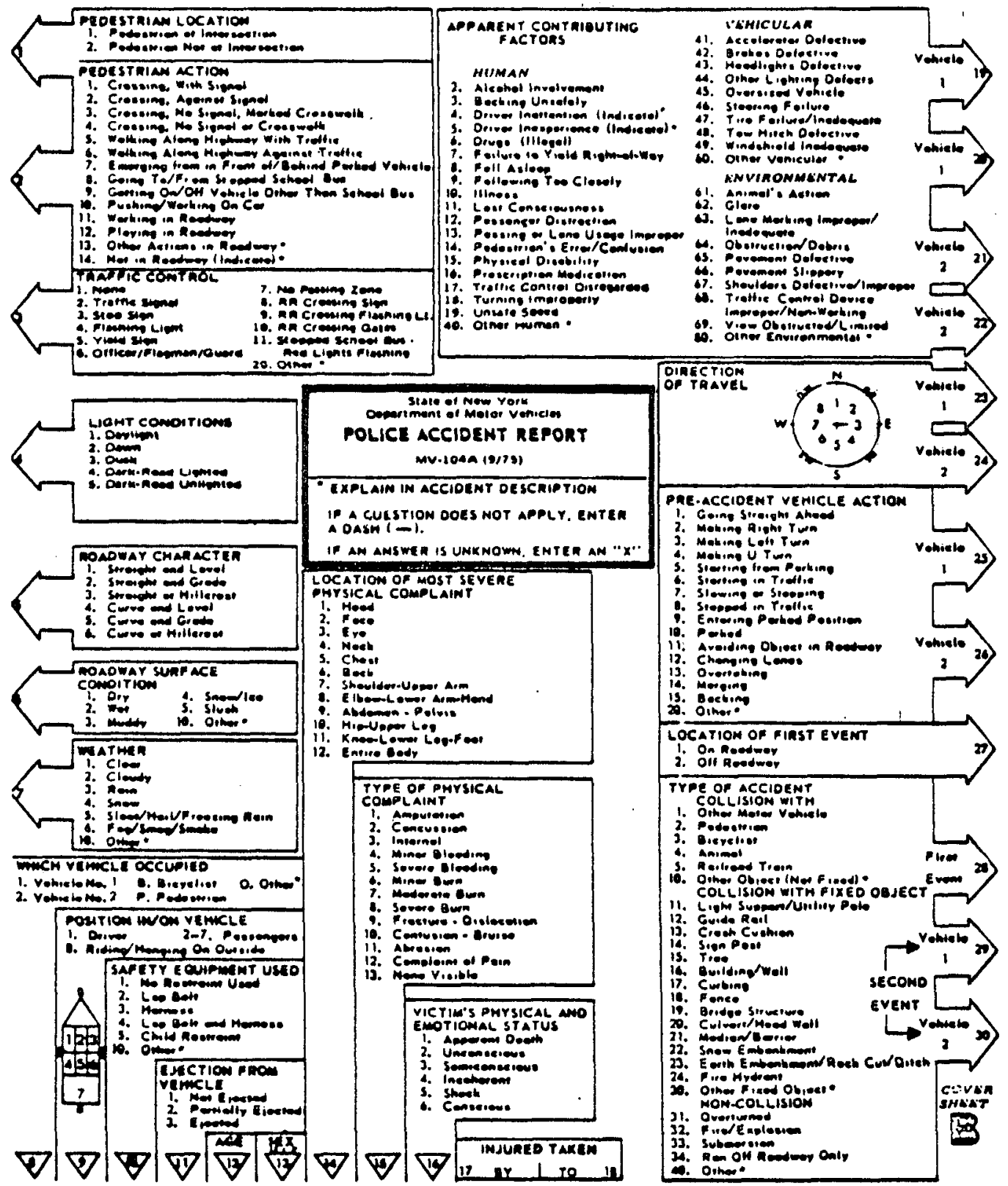




\author{
ROCHESTER GENERAL HOSPITAL \\ In Cooperation with \\ U.S. Department of Transportation
}

MOTOR VEHICLE SAFETY PROJECT

Consent

1. I authorize Rochester General to draw and use iny blood for research conducted under the U.S. Department of Transportation, Contract Number DOT-HS-5-01179.

2. I understand this is not a requirement for treatment at Rochester General.

3. I understand the results will be completely confidential and anonymous as provided by New York State Law.

Patient's Signature

Date

Witness

I authorize Rochester General Hospital to draw blood from the patient identified herein. This blood is intended for research purposes but will not be so used until the patient gives consent.

Authorizing Signature

A-5
Relationship

$2 S-5769-V-1$ 
CONSINAT/ROUTING I:ORM DIRI:CHLNS

Section 1

Cumplete Section l for
cvery person appearing
at bD who mects all four
conditions below:
(1) Driver
(2) Injured in motor
vehicle accident
(3) Monrue county
accident
(4) Accident occurred no
morc than four hours
previously.

Accident location (Identify Location with best availdill inforination)

Strect Location:

Town/City:

Police Agency:

Date of Accident:

Time of Accident:

i: $: i /:$

Time of Arrival at $1: \mathrm{D}: \ldots \ldots \ldots$. $\mathrm{Ni} / \mathrm{l}$

Secreting Initials:

TRIAGE NURSE: Your initials

(1) Result of Initial Request for

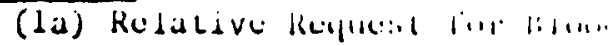
Consent (Check One)

Request patient's consent for drawing of blood; indicate result by checking appropriate box.

(A) Unable to request because of paticnt's condition (unconscious or incoherent) MARK (la)

(B) $\square$ Patient consent obtained

(C) $\square$ Patient consent refused Reason:

(2) Evidence of etham,

Your initials:

(d) $\square$ No request, other reason (explain):

For consenting drivers on $\overline{l y:}$

(3) Blood Drawn $\square$ Yes; Time AM/PM $\square$ No Problems, if any:

(4) Was patient given any medication prior to blood drawing? $\square$ Yes $\square$ No

Drug/Dose:

Time given: $N M / 1$

\section{Section 3} EN SECRETARTAI. STAFF:

Recurd lollow-up information from ED Admissions Form. Check appropriate box to indicate case disposition.

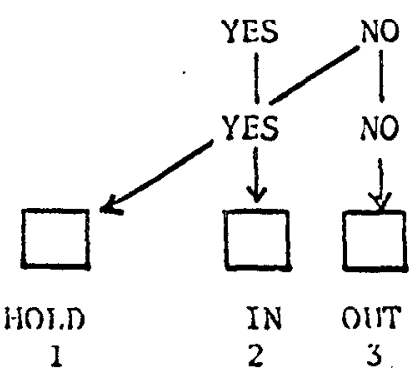

Ambulance Service:

Patient's Phone:

Next of Kin: Relation

Next of Kin Phone:

PATIENT CONSENT OBTAINED (see reversc side ful filliwi': signature). Circlc YES or NO

BLOOD DRAWN (Item (3), above, completed, requisiliur card removed). Circle YES or NO

DISPOSITION (check appropriate box and ented corresponding number into LOSi).

Initials: 
ADMINISTRATIVE DATA

DATE OF ACCIDENT (MONTH, DAY, YEAR)

DATE INFORMATION COLLECTED (MONTH, DAY, YEAR)

\section{VEHICLE DEFINITION}

VEHICLES DESCRIBED IN THIS FORM ARE IDENTIFIED

AS FOLLOWS:

$\left.\begin{array}{l}\text { VEHICLE \#1 } \\ \text { VEHICLE } \# 2 \\ \text { VEHICLE } \# 3\end{array}\right\}$ PROVIDE YEAR, MAKE, AND MODEL

\section{DATA SOURCE}

- DRIVER OF VEHICLE \#

SUBJECT \# (FROM CONSENT/ROUTING FORM)

\section{CONTACT RECORD}

\begin{tabular}{|l|l|l|l|l|}
\hline DATE & TIME & CONTACTED BY & $\begin{array}{c}\text { MANNER OF } \\
\text { CONTACT }\end{array}$ & RESULTS \\
\hline & & & & \\
\hline & & & & \\
\hline & & & & \\
\hline & & & & \\
\hline & & & & \\
\hline & & & & \\
\hline & & & & \\
\hline
\end{tabular}

SOMMENIS: (CO-OPERATION, DATA RELIABILITY, ETC.) 
CASE NUMBER

DRIVER BEHAVIORAL ERRORS STUDY

HUMAN DATA

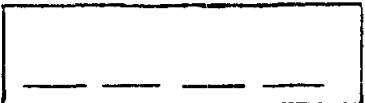

U.S. DOT/NHTSA

DATA SOURCE: $\quad$ DRIVER/VEH. $1 \square \quad$ DRIVER/VEH. $2 \square \quad$ DRIVER/VEH. $3 \square$

1. ACCIDENT SKETCH (DRAW AS DESCRIBED BY DRIVER)

2. ACCIDENT DESCRIPTION: (AS DESCRIBED BY DRIVER)

a. WHAT HAPPENED (DESCRIBE CRUCIAL EVENTS UP TO \& INCLUDING COLLISION) 
CASE NUMBER

DRIVER BEHAVIORAL ERRORS STUDY

HUMAN DATA

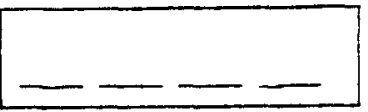

U.S. DOT/NHTSA

DATA SOURCE: $\quad$ DRIVER/VEH. $1 \square \quad$ DRIVER/VEH. $2 \square \quad$ DRIVER/VEH. $3 \square$

2b. WHY ACCIDENT HAPPENED (TRY TO ELICIT FROM DRIVER WHETHER PROBLEM WAS

SELF, ANOTHER DRIVER, VEHICLE, ENVIRONMENT.)

2c. WHY DRIVER UNABLE TO AVOID ACCIDENT

3. SPECIAL PROBES (CHECK 1 OF THE FOLLOWING; PROBE PER GUIDE SHEET)
口 ROAD DEPARTURE: CURVE
- I'SECTING PATH COLL.
$\square$ SIDESWIPE/CUTOFF
口 ROAD DEP . : STRAIGHT
- STATIONARY TARGET
$\square$ HEAD-ON COLLISION
口 REAR END COLLISION
$\square$ NONE OF THESE
(NO PROBE NEC.) 
CASE NUMBER

DRIVER BEHAVIORAL ERRORS STUDY

HUMAN DATA

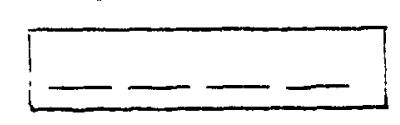

U.S. DOT/NHTSA

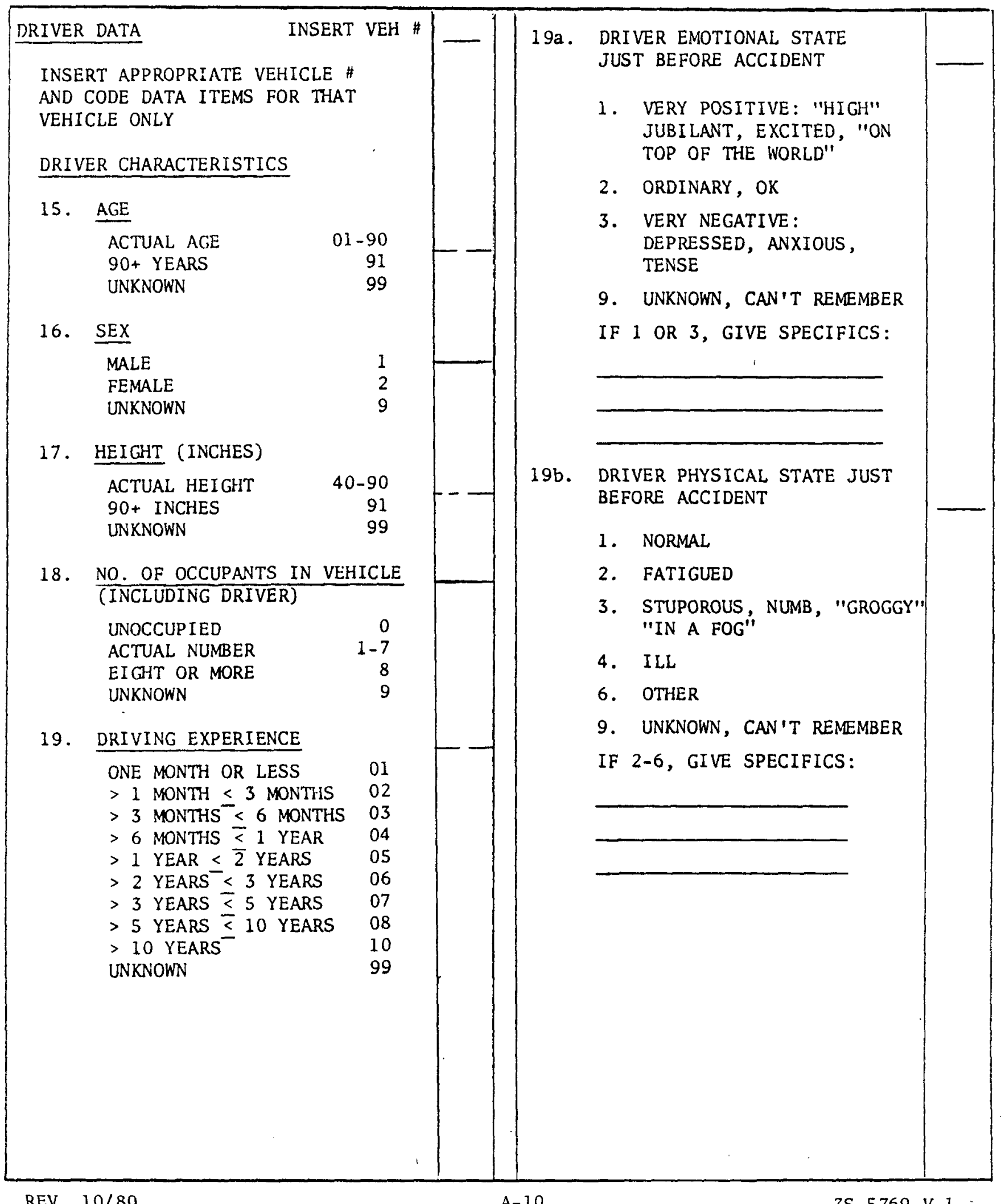




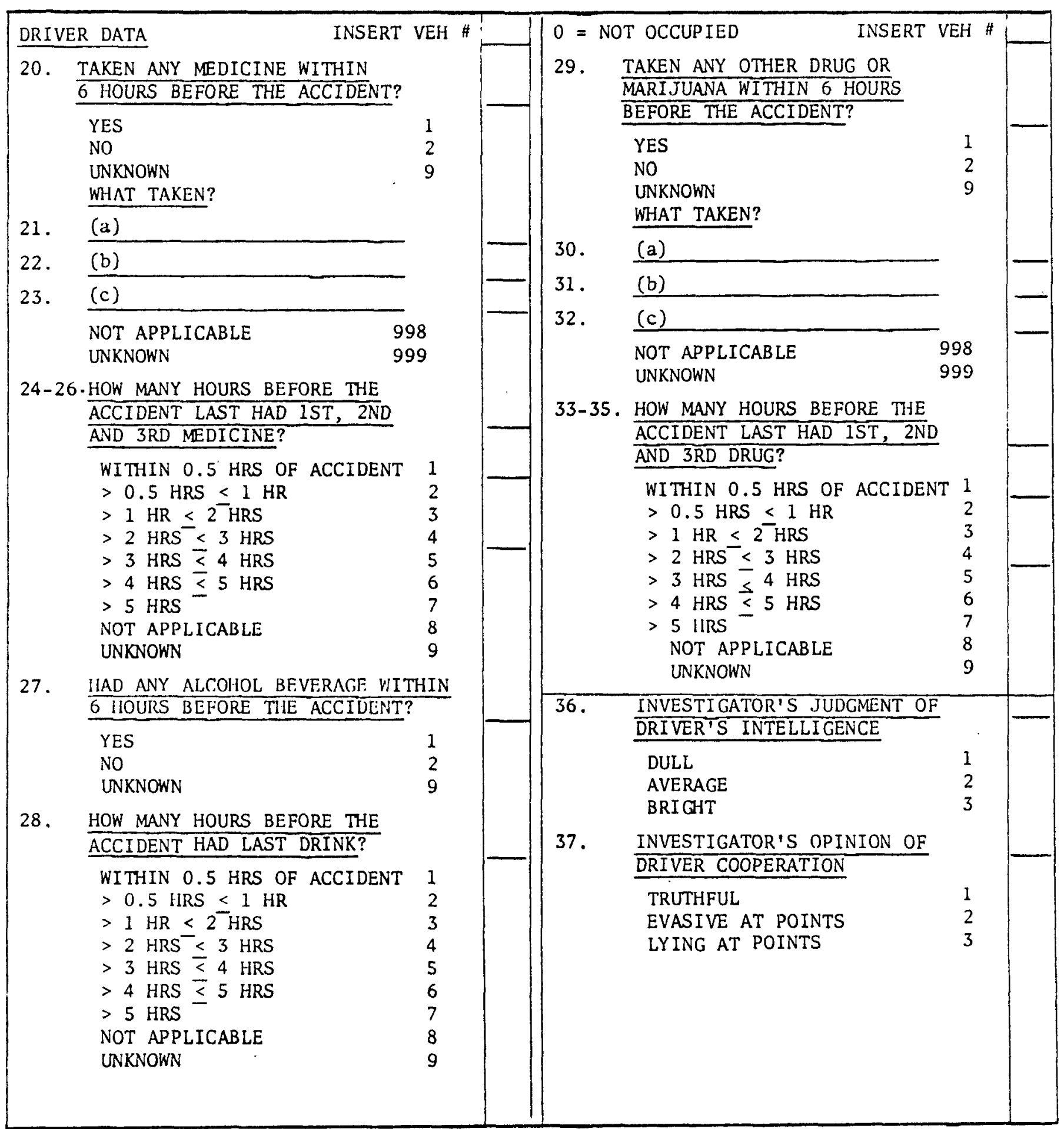

REV. $10 / 80$ 
DRIVER BEHAVIORAL ERRORS STUDY

HUMAN DATA

Guide Sheet for Special Probes -- Item 3 of 10/80 Form

a. Road departure on curve, or departing curve

Did driver see curve too late?

Was curve sharper than driver expected?

b. Road departure on straight road section

Was vehicle out of control, trying to avoid collision, or did it just drift off road?

If out of control, why?

If drift off road, did driver realize vehicle was departing road?

At what point?

c. Head-on collision (Any same-path, opposite direction collision)

Was passing maneuver or lane drift involved? Specify

If passing maneuver, what went wrong?

If lane drift, what was reason?

d. Intersecting path collision (Intersection, driveways, etc.)

Was either vehicle stopped before proceeding through intersection?

If yes, which one?

Did driver see the other vehicle coming?

Why did driver proceed through intersection?

e. Hit stationary target (Includes impact with parked vehicle)

Did driver see target ahead? If not, why not?

If nighttime, was target illuminated (lights on)?

f. Rear end collision

If driver of rear vehicle:

- Was forward vehicle stopped? If yes, did driver realize that?

- Was forward vehicle decelerating? If yes, did driver realize that?

- Was forward vehicle backing? If yes, did driver realize that?

If driver of forward vehicle:

- Was vehicle stopped? If yes, why? About how long?

If no, was driver braking before impact?

Was rear vehicle tailgating?

g. Sideswipe/cutoff (Paths parallel \& same direction, lateral move by one)

Why the lane change?

Did driver see the other vehicle? 
APPENDIX B

Blood Analys is Reports 
CALSPAN MOTOR VEHICLE STUDY: REPORT OF ANALYTICAL DATA

Center for Human Toxicology

University of Utah

Sait Lake City, Utah 84112

\begin{tabular}{|c|c|}
\hline Sample \# & $\begin{array}{c}\text { Drugs } \\
\text { Administered } \\
\end{array}$ \\
\hline 2 & \\
\hline 3 & Lidocaine \\
\hline 4 & Tetanus vaccine \\
\hline 6 & \\
\hline 7 & \\
\hline 9 & \\
\hline 13 & \\
\hline 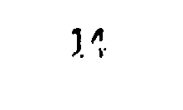 & $\begin{array}{l}\text { Mysoline and } \\
\text { Phenobarbital }\end{array}$ \\
\hline 15 & \\
\hline 17 & \\
\hline$\therefore 4$ & \\
\hline $25^{\prime}$ & Diazepam \\
\hline
\end{tabular}

Analytical Results

Phenobarbital less than $5 \mathrm{mcg} / \mathrm{ml}$. [Lidocaine present], $\Delta^{9}$-tetrahydrocannabinol less than $0.001 \mathrm{mcg} / \mathrm{ml}$. No other drugs detricled. No drugs detected. No drugs detected. No drugs detected. No drugs detected. Ethanol $0.2 \% \mathrm{w} / \mathrm{v}$, Cocaine $0.02 \mathrm{mcg} / \mathrm{mi}$, Benzoylecgonine $0.11 \mathrm{mcg} / \mathrm{ml}$. No other drugs detected.

[Phenobarbital $29 \mathrm{mcg} / \mathrm{ml}$, primidone $6 \mathrm{mcg} / \mathrm{ml}$.] phenyto in $10 \mathrm{mcg} / \mathrm{ml}$. No other drugs delecled. No drugs detected.

Ethano1 $0.17 \% \mathrm{w} / \mathrm{v}$. No other drugs detectroj. Diazepam and desmethyldiazepan less than 0.05 likcy 'm:

[Diazepam $0.29 \mathrm{mcg} / \mathrm{ml}$, desmethyl fiazepam less than $0.05 \mathrm{mcg} / \mathrm{ml}$.] No other drugs detected.

Diazepam $0.12 \mathrm{mcg} / \mathrm{ml}$, desmethyldiazepam $0.10 \mathrm{mcg} / \mathrm{m}$ ? No other drugs detected.

Phenobarbital $5 \mathrm{mcg} / \mathrm{ml}$. No other drugs detcclid. No drugs detected.

No drugs detected.

Etinanai $0.22 \% \mathrm{w} / \mathrm{v}$. No other drugs dentecled. No drugs detected.

Ethanol $0.23 \% \mathrm{w} / \mathrm{v}$, [lidocaine present].

No drugs detected.

Ethanol $0.06 \% \mathrm{w} / \mathrm{v}$, diazepam $0.84 \mathrm{mc} / \mathrm{m} / \mathrm{l}$, desmethyldiazepam 0.81 micg/mit. No other uruys: detected.

No drugs detected.

Ethanol $0.13 \% \mathrm{w} / \mathrm{v}$. No other drugs detected. No THC test.

No drugs detected.

[ ] = E.D.-administered substance 
Drugs

Saumle II Administered tetnus vaccine

64

65

73

76

81

83

84

86

89

97

100

104

106

107

110

120

121

125

127

129

130

131

133

141

\section{Analytical Results}

No drugs detected.

No druqs detected.

Propoxyphene $0.15 \mathrm{mcg} / \mathrm{ml}$, norpropoxyphenc $0.54 \mathrm{mcg} / \mathrm{ml}$. No other drugs detected.

Ethanol $0.05 \% \mathrm{w} / \mathrm{v}, \Delta^{9}$-tetrahydrocannabinol ress than $0.001 \mathrm{mcg} / \mathrm{mr}$, [positive Meperidine.] No other drugs detected.

Ethanol $0.11 \% \mathrm{w} / \mathrm{v}, \Delta^{9}$-tetrahydrocannabinul $0.001 \mathrm{mcg} / \mathrm{ml}$. No other drugs detected.

Diazepam, desmethyldiazepam, and desalkylflwi:nilli less than $0.05 \mathrm{mcg} / \mathrm{ml}$. No other urugs deleched.

No drugs detected.

Ethanol $0.20 \% \mathrm{w} / \mathrm{v}$. No other drugs detected.

Ethanol $0.28 \% \mathrm{w} / \mathrm{V}$, chlordiazepoxide and desmolliglchiordiazepoxide less than $0.1 \mathrm{mcg} / \mathrm{lil}$. No other drugs detected.

No drugs detected.

No drugs detected.

No drugs detected.

No drugs detected.

No drugs detected.

Codeine $0.06 \mathrm{mcg} / \mathrm{ml}$, phenobarbital $5 \mathrm{mcg} / \mathrm{lll}$, meprobamate $18 \mathrm{mcg} / \mathrm{ml}$, diazepam $0.9 \mathrm{mcg} / \mathrm{ml}$, desmethyldiazepam $0.4 \mathrm{mcg} / \mathrm{ml}$. No other drugs detected.

No drugs detected.

Ethanol $0.06 \% \mathrm{w} / \mathrm{v}$. No other drugs detected.

No drugs detected.

Ethanol $0.08 \% \mathrm{w} / \mathrm{v}, \Delta^{9}-$ THC $0.002 \mathrm{mcg} / \mathrm{m}$ ].

Ethanol $0.34 \% \mathrm{w} / \mathrm{v}$, cocaine less than $0.01 \mathrm{lic} \cdot \mathrm{g} / \mathrm{ml}$, benzoylecgonine drugs detected.

$\Delta^{9}-\mathrm{THC} 0.005 \mathrm{mcg} / \mathrm{ml}$. No other drugs detected.

No drugs detected.

Ethanol $0.17 \% \mathrm{w} / \mathrm{v}$. No other drugs detected.

No drugs detected.

No drugs detected.

No drugs detected.

$\Delta^{9}$-THC $0.0025 \mathrm{mcg} / \mathrm{m} 1$. No other drugs detected.

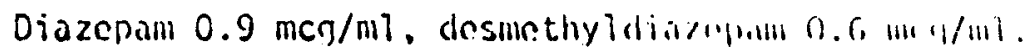
No ulher drug: delechled. 
Drugs

$\begin{array}{ll}\text { Sample If } & \text { Adiministered } \\ 143 & \text { Aspirin } \\ 149 & \\ 150 & \end{array}$

151

153

154

158

160

161

163

164

177

180

181 Tetnus vaccine

182

185

196

200

213

218

219

221

228

230

233

234

236

237

238

239

241

\section{Analytical Results}

No drugs detected.

$\Delta^{9}$-THC $0.0035 \mathrm{mcg} / \mathrm{ml}$. No other drugs detected.

Ethanol $0.07 \mathrm{w} / \mathrm{v}$, cocaine $0.024 \mathrm{mcg} / \mathrm{ml}$.

benzoylecgonine $0.013 \mathrm{mcg} / \mathrm{ml}$. No other drugs detected.

Ethanol $0.26 \% \mathrm{w} / \mathrm{v}$. No other drugs detected.

No drugs detected.

$\Delta^{9}-$ THC $0.0027 \mathrm{mcg} / \mathrm{ml}$. No other drugs detected.

Ethanol $0.17 \% \mathrm{w} / \mathrm{v}$. No other urugs delcelded. No THC test.

No drugs detected.

No drugs detected.

Chlordiazepoxide $0.7 \mathrm{mcg} / \mathrm{ml}$, desmethylchlordiazepoxide $0.7 \mathrm{mcg} / \mathrm{ml}$. No other drugs deleched.

Ethanol $0.12 \% \mathrm{w} / \mathrm{v}$. No other drugs delecled.

No drugs detected.

No drugs detected.

Ethanol $0.31 \% \mathrm{w} / \mathrm{v}$. No other drugs detected. No THC test.

Ethanol $0.14 \%, \Delta^{y}$-tetrahydrocannubinul 0.0012 $\mathrm{mcg} / \mathrm{ml}$. No other drugs detected.

Cocaine $0.01 \mathrm{mcg} / \mathrm{ml}$, benzoylecgonine less lhall $0.005 \mathrm{mcg} / \mathrm{ml}$. No other drugs detected.

No drugs detected.

No drugs detected.

No drugs detected.

Ethanol $0.13 \% \mathrm{w} / \mathrm{v}, \Delta^{9}$-tetrahydrocannabinol

$0.0016 \mathrm{mcg} / \mathrm{ml}$. No other drugs detected.

Diazepam $0.13 \mathrm{mcg} / \mathrm{m} 7$, desmethyidiazepam

$0.13 \mathrm{mcg} / \mathrm{ml}$. No other drugs detected.

Ethanol $0.26 \% \mathrm{w} / \mathrm{v}$. No other druys detected.

No drugs detected.

No druys detected.

No drugs detected.

$\Delta^{9}$-tetrahydrocannabinol $0.0013 \mathrm{mcg} / \mathrm{ml}$. No other drugs detected.

No drugs detected.

No drugs detected.

No drugs detected.

Elhanol $0.09 \% \mathrm{w} / \mathrm{v}$. No olncr diugs detected.

Ethanol $0.09 \% \mathrm{w} / \mathrm{v}$. No other drugs delcicled. 
No drugs detected.

No drugs detected.

No drugs detected.

Diazepam $0.1 \mathrm{mcg} / \mathrm{ml}$, desmethyldiazepam less than $0.05 \mathrm{mcg} / \mathrm{ml}$. No other drugs detected.

No drugs detected.

No drugs detected.

Ethanol $0.09 \% \mathrm{w} / \mathrm{v}$. No other drugs detected.

Ethanol $0.15 \% \mathrm{w} / \mathrm{v}$, diazepam $0.38 \mathrm{mcg} / \mathrm{mi}$, desmethyldiazepam $0.44 \mathrm{mcg} / \mathrm{ml}$. No other drugs detected.

Ethanol $0.18 \% \mathrm{w} / \mathrm{v}$. No other drugs detected.

Ethanol $0.16 \%, \Delta^{9}$-tetrahydrocannabinol 0.002 $\mathrm{mcg} / \mathrm{ml}$. No other drugs detected.

Ethanol $0.03 \% \mathrm{w} / \mathrm{v}, \Delta^{9}$-tetrahydrocannabinol $0.0017 \mathrm{mcg} / \mathrm{ml}$. No other drugs detected.

No drugs detected.

No drugs detected.

No drugs detected.

Ethanol $0.21 \% \mathrm{w} / \mathrm{v}$, lidocaine $0.3 \mathrm{mcg} / \mathrm{ml}$. No other drugs detected.

Diazepam and desmethyldiazepam less than 0.05 $\mathrm{mcg} / \mathrm{ml}$. No other drugs detected.

No drugs detected.

No drugs detected.

$\Delta^{9}$-tetrahydrocannabinol $0.0034 \mathrm{mcg} / \mathrm{ml}$. No other drugs detected.

No drugs detected.

No drugs detected.

No drugs detected.

No drugs detected.

No drugs detected.

No drugs detected.

Ethanol $0.09 \%, \Delta^{9}$-tetrahydrocannabinol

$0.0034 \mathrm{mcg} / \mathrm{ml}$. No other drugs detected.

No drugs detected.

No drugs detected.

$\Lambda^{9}$-tetrahydrocannabinol 0.0012 mcg/ml. No ot.hur drugs detected. 
Drugs

Sample Acministered 305

307

309

313

315

316

319

320

321

322

323

325

328

330

331

333

335

336

338

341

349

350

354

355

357

358

360

362

363
Analytical Results

Amobarbital $0.2 \mathrm{mcg} / \mathrm{ml}$, secobarbital $0.40 \mathrm{mc} \mathrm{cg} / \mathrm{iil}$, ethariol $0.07 \% \mathrm{w} / \mathrm{v}$. No other drugs detected.

No drugs detected.

Ethanol $0.16 \% \mathrm{w} / \mathrm{v}, \Delta^{9}$-tetrahydrocannabinol $0.0015 \mathrm{mcg} / \mathrm{mi}$. No other drugs detected.

No drugs detected.

No drugs detected.

Ethanol $0.12 \% \mathrm{w} / \mathrm{v}$. No other drugs detected.

Ethanol $0.13 \% \mathrm{w} / \mathrm{v}$. No other drugs detected.

Diazepam less than $0.05 \mathrm{mcg} / \mathrm{ml}$, desnicthyldiazrpin $0.09 \mathrm{mcg} / \mathrm{mi}$. No other drugs detected.

No drugs detected.

Ethanol $0.06 \% \mathrm{w} / \mathrm{v}$. No other drugs detected.

Ethanol $0.15 \% \mathrm{w} / \mathrm{v}$. No other drugs detected.

Ethanol $0.18 \% \mathrm{w} / \mathrm{v}, \Delta^{9}$-tetrahydrocannabinol $0.0014 \mathrm{mcg} / \mathrm{mi}$. No other drugs detected.

$\Delta^{9}$-tetrahydrocannabinol $0.0011 \mathrm{mcg} / \mathrm{ml}$. No other drugs detected.

No drugs detected.

No drugs detected.

No drugs detected.

No drugs detected.

No drugs detected.

No drugs detected.

Ethanol $0.16 \% \mathrm{w} / \mathrm{v}$. No other drugs detected.

Ethanol $0.24 \% \mathrm{w} / \mathrm{v}$. No other drugs detected.

No drugs detected.

Ethanol $0.15 \% \mathrm{w} / \mathrm{v}$. No other drugs detected.

Chlordiazepoxide less than $0.1 \mathrm{Ilc} / \mathrm{m} / \mathrm{ll}$, $\Delta^{9}$-tetrahydrocannabinol $0.001 \mathrm{mcg} / \mathrm{ml}$. No other drugs detected.

No drugs detected.

No drugs detected.

[Chlordiazepoxide $0.17 \mathrm{mcg} / \mathrm{ml}$, desmethyl ch]ordiazepoxide less than $0.05 \mathrm{mcg} / \mathrm{ml}$.] No other drugs detected.

No drugs detected.

No drugs detected.

$$
\text { B }-6
$$

$2 S-5769-V-1$ 
Drugs

Sample \# Administered

364

368

369

370

374

375

376

378

379

380

381

382

383

384

388

393

394

397

398

399

400

404

405

406

408

410

412

415

416

418

420

\section{Analytical Results}

No drugs detected.

Ethanol $0.12 \% \mathrm{w} / \mathrm{v}$. No other drugs detected.

Phenobarbital $11 \mathrm{mcg} / \mathrm{ml}$. No other drugs detected.

No drugs detected.

No drugs detected.

No drugs detected.

Ethanol $0.10 \% \mathrm{w} / \mathrm{v}$. No other drugs detected.

No drugs detected.

No drugs detected.

Cocaine less than $0.01 \mathrm{mcg} / \mathrm{mi}$, benzoylecgonine $0.014 \mathrm{mcg} / \mathrm{ml}$, diazepam and desmethyldiazcpan loss than $0.05 \mathrm{mcg} / \mathrm{ml}$. No other drugs detected.

No drugs detected.

Ethanol $0.11 \% \mathrm{w} / \mathrm{v}$. No other drugs detected.

No drugs detected.

Ethanol $0.12 \% \mathrm{w} / \mathrm{v}, \Delta^{9}$-tetrahydrocannabinol 0.003 $\mathrm{mcg} / \mathrm{ml}$. No other drugs detected.

No drugs detected.

$\Delta^{9}$-tetrahydrocannabinol $0.005 \mathrm{mcg} / \mathrm{mil}$. No other drugs detected.

No drugs detected.

Ethanol $0.12 \% \mathrm{w} / \mathrm{v}$. No other drugs detected.

Ethanol $0.26 \% \mathrm{w} / \mathrm{v}$. No other drugs detected.

Ethanol $0.08 \% \mathrm{w} / \mathrm{v}$. No other drugs detecled.

No drugs detected.

Ethanol $0.22 \% \mathrm{w} / \mathrm{v}$. No other drugs detected.

No drugs detected.

No drugs detected.

No drugs detected.

Ethanol $0.13 \% \mathrm{w} / \mathrm{v}$. No other drugs detected.

No drugs detected.

No drugs detected.

No drugs detected.

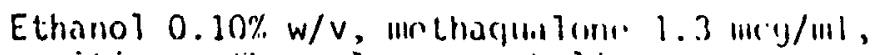
positive methaqualone metabolite.

$\Delta^{9}$-tetrahydrocannabinol $0.011 \mathrm{mcg} / \mathrm{ml}$. No olher drugs detected.

Diazepam and desnethyldiazepam less than

$0.05 \mathrm{mcg} / \mathrm{ml}$. No other drugs detected. 
Drugs

Sample Acministered

421

424

426

430

433

435

437

438

439

440

441

442

447

448

450

451

452

455

456

459

460

462

466

467

Codeine and acetaminophen

470

474

477

482

483

484

486

487

488

489

\section{Analytical Results}

No drugs detected.

Ethanol $0.14 \% \mathrm{w} / \mathrm{v}$. No other drugs detected.

No drugs detected.

No drugs detected.

Ethanol $0.07 \% \mathrm{w} / \mathrm{v}$. No other drugs detected.

No drugs detected.

No drugs detected.

No drugs detected.

No drugs detected.

Tetanus vaccine

No drugs detected.

Ethanol $0.15 \% \mathrm{w} / \mathrm{v}$. No other drugs detected.

No drugs detected.

No drugs detected.

Ethanol $0.10 \% \mathrm{w} / \mathrm{v}$. No other drugs detected.

No drugs detected.

No drugs detected.

Diazepam $0.08 \mathrm{mcg} / \mathrm{ml}$, desmethyldiazepam 0.08 $\mathrm{mcg} / \mathrm{mi}$. No other drugs detected.

No drugs detected.

No drugs detected.

Ethanol $0.13 \% \mathrm{w} / \mathrm{v}$. No other drugs detected.

No drugs detected.

No drugs detected.

No drugs detected.

No drugs detected.

No drugs detected.

No drugs detected.

No drugs detected.

No drugs detected.

Carbamazepine $2 \mathrm{mcg} / \mathrm{ml}$. No other drugs detected. $\Delta^{9}$-tetrahydrocannabinol $0.002 \mathrm{mcg} / \mathrm{ml}$. No other drugs detected.

No drugs detected.

Diazepam $0.21 \mathrm{mcg} / \mathrm{ml}$, desmethyldiazcpam less than $0.05 \mathrm{mcg} / \mathrm{ml}$. No other drugs detected.

Ethanol $0.08 \% \mathrm{w} / \mathrm{v}$. No other drugs detected. No drugs detected. 
Drugs

Sample \# Administercd

490

491

497

498

499

507
Analytical Results

Ethanol $0.22 \% \mathrm{w} / \mathrm{v}$. No other drugs detected. No drugs detected.

No drugs detected.

No drugs detected.

Ethanol $0.15 \% \mathrm{w} / \mathrm{v}$. No other drugs detecled. No drugs detected.

No drugs detected.

No drugs detected.

Ethanol $0.06 \% \mathrm{w} / \mathrm{v}$. No other drugs detected. No drugs detected.

Ethanol $0.12 \% \mathrm{w} / \mathrm{v}$. No other drugs detected.

Ethanol $0.19 \% \mathrm{w} / \mathrm{v}$. No other drugs detected.

No drugs detected.

Ethanol $0.24 \% \mathrm{w} / \mathrm{v}$. No other drugs detected.

No drugs detected.

No drugs detected.

No drugs detected.

No drugs detected.

No drugs detected.

No drugs detected.

Ethanol $0.18 \% \mathrm{w} / \mathrm{v}$. No other drugs detected.

Diazepam $0.16 \mathrm{mcg} / \mathrm{ml}$, desmethy ldiazepam $0.09 \mathrm{mcg} / \mathrm{m}$, $\Delta^{9}$-tetrahydrocannabinol $0.007 \mathrm{mcg} / \mathrm{ml}$. No other drugs detected.

No drugs detected.

No drugs detected.

No drugs detected.

No drugs detected.

No drugs detected.

No drugs detected.

No drugs cecected. 
Drugs

Sample \# Administered

547

548

549

553

554

555

563

566

569

570

571

573

574

575

576

579

580

582

584

589

590

591

592

593

594

596

598

599

602

603

609

613

615
Analytical Results

Ethanol $0.21 \% \mathrm{w} / \mathrm{v}, \Lambda^{9}$-tetrahydrocannal,inul $0.002 \mathrm{mcg} / \mathrm{ml}$. No other drugs detected.

No drugs detected.

Ethanol $0.18 \% \mathrm{w} / \mathrm{v}$. No other drugs detected.

No drugs detected.

Ethanol $0.11 \% \mathrm{w} / \mathrm{v}, \Delta^{9}$-tetrahydrocannabinol

$0.004 \mathrm{mcg} / \mathrm{ml}$. No other drugs detected.

No drugs detected.

No drugs detected.

No drugs detected.

No drugs detected.

Ethanol $0.09 \% \mathrm{w} / \mathrm{v}$. No other drugs detected.

No drugs detected.

No drugs detected.

Ethanol $0.12 \% \mathrm{w} / \mathrm{v}$. No other drugs detected.

No drugs detected.

No drugs detected.

No drugs detected.

Ethanol $0.20 \% \mathrm{w} / \mathrm{v}$, cocaine less than $0.01 \mathrm{mcg} / \mathrm{ml}$, benzoylecgonine $0.03 \mathrm{mcg} / \mathrm{ml}$. No other drugs detectc

No drugs detected.

No drugs detected.

No drugs detected.

No drugs detected.

No drugs detected.

Diazepam $0.06 \mathrm{mcg} / \mathrm{ml}$, desmethyldiazepam 0.07

$\mathrm{mcg} / \mathrm{ml}$. No other drugs detected.

Ethano. $0.13 \% \mathrm{w} / \mathrm{v}$. No other drugs detected.

Ethanol $0.08 \% \mathrm{w} / \mathrm{v}$. No other drurg cinlecilini.

No drugs detected.

No drugs detected.

No drugs detected.

No drugs detected.

No druns detected.

Ethanol $0.13 \% \mathrm{w} / \mathrm{v}$. No other drugs detected.

Phenobarbital $6.7 \mathrm{mcg} / \mathrm{ml}$. No other drugs detectud.

Ethanol $0.27 \% \mathrm{w} / \mathrm{v}$, chlordiazepoxide $0.83 \mathrm{mrg} / \mathrm{ml}$, desmethy ichlordiazepoxide $0.2 \mathrm{mcg} / \mathrm{ml}$, demusplim $1 \mathrm{mcg} / \mathrm{ml}$, desmethyldiazcpam less than $0.05 \mathrm{mcg} / \mathrm{ml}$. No otirer urigs detected.

$$
\text { B-10 }
$$


Drugs

Sample Administered

618 Tetanus vaccine

619

621

622

623

624

625

626

628

629

631

632

634

639

642

643

644

646

647

648

651

652

653

667

668

669

670

673

674

676

677

\section{Analytical Results}

No drugs detected.

No drugs cerected.

No drugs detected.

Ethanol $0.29 \% \mathrm{w} / \mathrm{v}$. No other drugs detected.

No drugs detected.

Ethanol $0.17 \% \mathrm{w} / \mathrm{v}$. No other drugs detected.

No drugs detected.

$\Delta^{9}$-tetrahydrocannabinol $0.002 \mathrm{mcg} / \mathrm{ml}$. No othim. drugs detected.

No drugs detected.

No drugs detected.

No drugs detected.

$\Delta^{9}$-tetrahydrocannabinol $0.011 \mathrm{mcg} / \mathrm{ml}$. No olher drugs detected.

No drugs detected.

No drugs detected.

Ethanol $0.29 \% \mathrm{w} / \mathrm{v}$. No other drugs detected.

No drugs detected.

No drugs detected.

Ethanol $0.17 \% \mathrm{w} / \mathrm{v}$. No other drugs detected.

No drugs detected.

No drugs detected.

No drugs detected.

Ethanol $0.04 \% \mathrm{w} / \mathrm{v}$, trichloroethanol $1.9 \mathrm{ncg} / \mathrm{ml}$. No other drugs detected.

No drugs detected.

Butalbital $1.1 \mathrm{mcg} / \mathrm{ml}$. No other drugs detecticd.

No drugs detected.

No drugs detected.

No drugs detected.

Ethanol $0.16 \% \mathrm{w} / \mathrm{v}$. No other drugs detected.

$\Delta^{9}$-tetrahydrocannabinol $0.008 \mathrm{mcg} / \mathrm{ml}$. No other drugs detected.

Ethanol $0.22 \% \mathrm{w} / \mathrm{v}$, diazepam $0.4 \mathrm{mcg} / \mathrm{ml}$, desmethyldiazepam $1.2 \mathrm{mcg} / \mathrm{ml}$. No other urugs detected.

No drugs detected. 
Orugs

Sample Aduinistered 678

679

680 Lidocaine

683

685

688

689

690

691

692

706

707

712

714

715

716

717

721

722

723

726

732

733

739

744

745
Analytical Results

$\Delta^{9}$-tetrahydrocannabinol $0.007 \mathrm{mcg} / \mathrm{ml}$. ilo olluer drugs detected.

Desaikyiflurazepam $0.03 \mathrm{mcg} / \mathrm{ml}$. No other drug', detected.

Ethanol $0.11 \% \mathrm{w} / \mathrm{v}, \Delta^{9}$-tetrahydrocannabinol

$0.005 \mathrm{mcg} / \mathrm{ml}$. No other drugs detected.

No drugs detected.

No drugs detected.

Ethanol $0.08 \% \mathrm{w} / \mathrm{v}$. No other drugs detected.

No drugs detected.

No drugs detected.

Methaqualone $0.87 \mathrm{mcg} / \mathrm{ml}$, positive methaqualonc: metabolite, [diazepam $0.06 \mathrm{mcg} / \mathrm{ml}$, desmethy] diazepam $0.29 \mathrm{mcg} / \mathrm{ml}$.] No other drugs detected.

Ethanol $0.12 \% \mathrm{w} / \mathrm{v}$, diazepam less than $0.05 \mathrm{micg} / \mathrm{ml}$, desmethyldiazepam $0.05 \mathrm{mcg} / \mathrm{ml}$. No other drugs detected.

No drugs detected.

Butalbital $0.5 \mathrm{mcg} / \mathrm{ml}$. No other drugs detected.

Ethanol $0.24 \% \mathrm{w} / \mathrm{v}$. No other drugs detected.

No drugs detected.

Ethano $0.32 \% \mathrm{w} / \mathrm{v}$. No other drugs detected.

Ethanol $0.15 \% \mathrm{w} / \mathrm{v}$, diazepam and desmethyldiazepan less than $0.05 \mathrm{mcg} / \mathrm{ml}$. No other drugs detected.

No drugs detected.

Ethanol $0.20 \% \mathrm{w} / \mathrm{v}$. No other drugs detected.

No drugs detected.

No drugs detected.

tetanus vaccine

Tetanus vaccine

Diazepam less than $0.05 \mathrm{mcg} / \mathrm{ml}$, desmethyldiazepam $0.18 \mathrm{mcg} / \mathrm{ml}$. No other drugs delected.

No drugs detected.

No drugs detected.

No drugs detected.

$\Delta^{9}$-tetrahydrocannabinol $0.003 \mathrm{mcg} / \mathrm{ml}$. No othor drugs detected.

No drugs detected.
$2 S-5769-V-1$ 


\begin{tabular}{|c|c|}
\hline Sample & $\begin{array}{c}\text { Drugs } \\
\text { Administered }\end{array}$ \\
\hline 747 & \\
\hline 748 & Tetanus vaccine \\
\hline 750 & \\
\hline 754 & \\
\hline 756 & \\
\hline 757 & \\
\hline 758 & Tetanus vaccine \\
\hline 759 & \\
\hline 760 & \\
\hline 762 & \\
\hline 764 & \\
\hline 765 & \\
\hline 768 & \\
\hline 769 & \\
\hline 771 & \\
\hline 772 & \\
\hline 774 & \\
\hline 777 & Meperidine \\
\hline 778 & Meperidine \\
\hline 780 & Tetanus vaccine \\
\hline 781 & \\
\hline 784 & \\
\hline 786 & \\
\hline 789 & \\
\hline 791 & \\
\hline 792 & \\
\hline 793 & \\
\hline 795 & \\
\hline 796 & \\
\hline 798 & \\
\hline 799 & \\
\hline
\end{tabular}

\section{Analytical Results}

No drugs detected.

Lidocaine $0.3 \mathrm{mcg} / \mathrm{m} 1$, lidocaine metabolile: 0.2 $\mathrm{mcg} / \mathrm{ml}$, ethanol $0.12 \% \mathrm{w} / \mathrm{v}$. No other drugs detcetes

No drugs detected.

No drugs detected.

No drugs detected.

Ethanol $0.21 \% \mathrm{w} / \mathrm{v}$. No other drugs detected.

$\Delta^{9}$-tetrahydrocannabinol $0.006 \mathrm{mcg} / \mathrm{ml}$. No other drugs detected.

No drugs detected.

No drugs detected.

No drugs detected.

Ethanol $0.06 \% \mathrm{w} / \mathrm{v}, \Delta^{9}$-tetrahydrocannabinol $0.002 \mathrm{mcg} / \mathrm{ml}$. No other drugs detected.

No drugs detected.

No drugs detected.

No drugs detected.

Ethanol $0.20 \% \mathrm{w} / \mathrm{v}, \Delta^{9}$-tetrahydrocannabinol $0.003 \mathrm{mcg} / \mathrm{ml}$. No other drugs detected.

No drugs detected.

No drugs. detected.

No drugs detected.

[Positive meperidine.] No other drugs detected.

No drugs detected.

No drugs detected.

No drugs detected.

No drugs detected.

Phenobarbital $3 \mathrm{mcg} / \mathrm{ml}$. No other drugs, doliccluil.

No drugs detected.

No drugs detected.

Ethanol $0.17 \% \mathrm{w} / \mathrm{v}$. No other drugs detected.

No drugs detected.

Diazepan and desmethyldiazepram lo:.: lhan

$0.05 \mathrm{mcg} / \mathrm{m} 7$. No other drugs detected.

Ethanol $0.12 \% \mathrm{w} / \mathrm{v}$. No other drugs detected. No drugs detected. 
Drugs

Sample \# Administered

801

803

807

814

818

819

821

822

823

824

825

826

827

828

829

831

833

835

837

841

842

845

846

847

848

850

852

Tetanus vaccine

853

\section{Analytical Results}

No drugs detected.

Diazepam $0.18 \mathrm{mcg} / \mathrm{m} 7$, desmethy ldiazepan $0.39 \mathrm{mc} / \mathrm{kin}$. No other drugs detected.

$\Delta^{9}$-tetrahydrocannabinol $0.002 \mathrm{mcg} / \mathrm{ml}$. No other drugs detected.

No drugs detected.

Butalbital $\& \mathrm{mcg} / \mathrm{ml}, \Delta^{9}$-tetrahydrocannabinol $0.003 \mathrm{mcg} / \mathrm{ml}$. No other drugs detected.

No drugs detected.

Ethanol $0.12 \% \mathrm{w} / \mathrm{v}$. No other drugs detected.

No drugs detected.

No drugs detected.

No drugs detected.

No drugs detected.

No drugs detected.

No drugs detected.

No drugs detected.

No drugs detected.

No drugs detected.

No drugs detected.

Ethanol $0.08 \% \mathrm{w} / \mathrm{v}$. No other drugs detected.

No drugs detected.

No drugs detected.

Ethanol $0.28 \% \mathrm{w} / \mathrm{v}$, cocaine less than $0.01 \mathrm{mcr} / \mathrm{mi}$, benzoy lecgonine $0.015 \mathrm{mcg} / \mathrm{m}$, $\Lambda^{?}$ - tecrulyurucannabinol $0.001 \mathrm{mcg} / \mathrm{ml}$. No other drugs detecteo.

Ethanol $0.28 \% \mathrm{w} / \mathrm{v}$, cocaine less than $0.01 \mathrm{mcc} / \mathrm{ml}$,

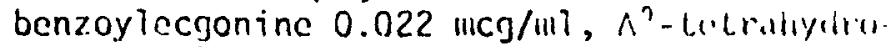
cannabinol $0.002 \mathrm{mcg} / \mathrm{ml}$. No other drugs detected.

No drugs detected.

No drugs detected.

Ethanol $0.24 \% \mathrm{w} / \mathrm{v}$, cocaine less than $0.01 \mathrm{lkc} / \mathrm{m} / \mathrm{ml}$, benzoy lecgonine $0.011 \mathrm{mcg} / \mathrm{ml}, \Lambda^{9}$-tetrahydrocannabinot $0.016 \mathrm{meg} / \mathrm{ml}$. No other drug:. de:Li:clent.

Ethanol $0.07 \% \mathrm{w} / \mathrm{v}$. No other drugs detected.

Ethanol $0.11 \mathrm{w} / \mathrm{v}, \quad \Delta^{9}$-tetrahydrocannabinol $0.001 \mathrm{meg} / \mathrm{mi}$. No other drugs delected.

No drigs detacted. 
Drugs

Sample \# Adninistered

854

858

860

861

863

867

868

869

871

874

876

878

879

881

885

891

895

896

898

902

903

906

912

913

914

916

919

920

921

\section{Analytical Results}

Ethanol $0.10 \% \mathrm{w} / \mathrm{v}$. No other drugs detected.

No drugs detected.

Diazepam $0.13 \mathrm{mcg} / \mathrm{m} 1$, desmethyldiazepam $0.49 \mathrm{mcg} / \mathrm{mi}$, phenobarbital $6 \mathrm{mcg} / \mathrm{ml}$, lidocaine less than $1 \mathrm{mcg} / \mathrm{mi}$ : No other drugs detected.

No drugs detected.

Ethanol $0.04 \% \mathrm{w} / \mathrm{v}$, phenobarbital $6 \mathrm{mcg} / \mathrm{ml}$. Mo other drugs detected.

No drugs detected.

No drugs detected.

Ethanol $0.24 \% \mathrm{w} / \mathrm{v}, \Delta^{9}$-tetrahydrocannaluinol $0.002 \mathrm{mcg} / \mathrm{ml}$. No other drugs detected.

No drugs detected.

No drugs detected.

Ethanol $0.12 \% \mathrm{w} / \mathrm{v}$. No other drugs detected.

Ethanol $0.07 \% \mathrm{w} / \mathrm{v}$, cocaine less than $0.01 \mathrm{mcg} / \mathrm{ml}$, benzoylecgonine $0.023 \mathrm{mcg} / \mathrm{ml}$. No other drugs detected.

No drugs detected.

No drugs detected.

No drugs detected.

No drugs detected.

No drugs detected.

Ethanol $0.23 \% \mathrm{w} / \mathrm{v}$. No other drugs detected.

No drugs detected.

No drugs detected.

Ethanol $0.14 \% \mathrm{w} / \mathrm{v}$, diazepam $0.24 \mathrm{mcg} / \mathrm{ml}$, desmethyldiazepam $0.28 \mathrm{mcg} / \mathrm{ml}$. No other drugs detected.

No drugs detected.

Ethanol $0.10 \% \mathrm{w} / \mathrm{v}$. No other drugs detected.

No drugs detected.

No drugs detected.

No drugs detected.

Ethanol $0.17 \% \mathrm{w} / \mathrm{v}$. No other drugs detected.

No drugs detected.

Methaqualone $0.81 \mathrm{mcg} / \mathrm{ml}$, positive methaquallons: metabolite. No other drugs detected. 
Drugs

Sample \# Adninistered

926

930

931

932

934

935

940

942

944

953

954

959

961

963

967

969

971

975

976

980

982

983

984

985

990

991

996

997

998

\section{Analytical Results}

No drugs detected.

Diazepam $0.39 \mathrm{mcg} / \mathrm{ml}$, desmethyldiazepain $1.1 \mathrm{mcg} / \mathrm{liil}$, desalkylf lurazepam $0.07 \mathrm{icg} / \mathrm{ml}$, ethanol $0.04 \% \mathrm{~W} / \mathrm{V}$. No other drugs detected.

Ethanol $0.18 \% \mathrm{w} / \mathrm{v}$. No other drugs detected.

Methaqualone $0.4 \mathrm{mcg} / \mathrm{ml}$, positive methaqualons: metabolite. No other drugs detected.

No drugs detected.

No drugs detected.

No drugs detected.

No drugs detected.

Ethanol $0.12 \% \mathrm{w} / \mathrm{v}$. No other drugs detected.

Ethanol $0.17 \% \mathrm{w} / \mathrm{v}$, diazepam $0.05 \mathrm{mcg} / \mathrm{mil}$, desmethyldiazepam $0.6 \mathrm{mcg} / \mathrm{ml}$. No other drugs detected.

No drugs detected.

No drugs detected.

No drugs detected.

No drugs detected.

Ethanol $0.13 \% \mathrm{w} / \mathrm{v}$. No other drugs detected.

No drugs detected.

No drugs detected.

No drugs detected.

No drugs detected.

Ethanol $0.15 \% \mathrm{w} / \mathrm{v}$. No other drugs delected.

No drugs detected.

No drugs detected.

Lidocaine less than $1 \mathrm{mcg} / \mathrm{ml}$. No other drugs dulecl:

Desmethyldiazepam $0.2 \mathrm{mcg} / \mathrm{ml}$. No other drugs deiect:

No drugs detected.

No drugs detected.

No drugs detected.

Diazepam $0.06 \mathrm{mcg} / \mathrm{ml}$, desmetr.yldiazepam $0.2 \mathrm{mc}: \mathrm{j} / \mathrm{ml}$. No other drugs detected.

No drugs detected.

No drugs detected. 
Drugs

Sample \# Administered

1002

1003

1009

1010

1012

1014

1015

1017

1019

1023

1029

1031

1032

1033

1040

1041

1043

1044

1045

1052

1053

1059

1060

1065

1066

1068

1069

1072

1079

1075

1079

1080

Tetnus vaccine

Tetnus vaccine

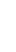

.


Drugs

Sample \# Administered

Analytical Results.

1085

1087

1088

1090

1092

1093

1100

1102

1103 Tetnus vaccine

1104

1105

1106

1113

1114

1115

1116

1117

1118

1125
No drugs detected.

No drugs dotacted.

No drugs detected.

No drugs detected.

Ethanol $0.08 \% \mathrm{w} / \mathrm{v}$. No other drugs detected.

$\Delta^{9}$-tetrahydrocannabinol $0.0018 \mathrm{mcg} / \mathrm{ml}$. No othrir drugs detected.

No drugs detected.

No drugs detected.

No drugs detected.

No drugs detected.

No drugs detected.

$\Delta^{9}$ tetrahydrocannabinol less than $0.001 \mathrm{mcg} / \mathrm{ml}$. No other drugs detected.

No drugs detected.

Ethanol $0.36 \% \mathrm{w} / \mathrm{v}$, chlordiazepoxide $2.3 \mathrm{mcg} / \mathrm{ml}$, desmethylchlordiazepoxide $0.08 \mathrm{mcg} / \mathrm{ml}$, domoxcpani $1.3 \mathrm{mcg} / \mathrm{ml}$, desmethyldiazepam $0.08 \mathrm{mcg} / \mathrm{ml}$. No other drugs detected.

No drugs detected.

No drugs detected.

No drugs detected.

No drugs detected.

No drugs detected.

Samples with plasma analysis onty:

265

273

443
No THC detected.

No THC detected.

No THC detected. 
APPENDIX C

ACCIDENT CAUSAL CODING SCHEME

CODING MANUAL

An Explication of Kenneth

Perchonok's "Causal Structure"

K. W. Terhune

With the Assistance of

J. M. Fletcher

T. A. Ranney

Revised February 1981

Calspan Field Services, Inc.

Buffalo, NY

C-1

ZS-5769-V-1 
Introduction . . . . . . . . . . . . . . . . 1

Primary event . . . . . . . . . . . . . . . 11

Critical event . . . . . . . . . . . . . . 12

Change speed: type . . . . . . . . . . 20

Change direction: type . . . . . . . . . . . 21

Direction . . . . . . . . . . . . . . 23

Subject path.................. . . 24

Target location . . . . . . . . . . . . 27

Target path. . . . . . . . . . . . . . . 29

Critical reason................ 31

Information failure: type . . . . . . . . . . 37

Control failure: type............. . 40

Logistic reason: type... . . . . . . . . . 41

Critical source . . . . . . . . . . . . 43

Critical reason basis . . . . . . . . . . . .45

Prior event . . . . . . . . . . . . . . 46

Change speed: type............. . 48

Change direction: type ............ 48

Direction . . . . . . . . . . . . . 48

Prior reason . . . . . . . . . . . . . . . 49

Prior reason basis... . . . . . . . . . . 49

Culpability . . ... . . . . . . . . . . 50

Culpable vehicle action . . . . . . . . . . . 52

Appendix A: Instructions - How to use the accident causal coding form........ . 56

Appendix B: Accident causal coding form . . . . . . . 59

Appendix C: How to determine coding reliability Accident causal coding scheme... . . 60 
Coding Manual

Accident C'ausal Coding Scheme*

The Accident Causal Coding Scheme is a set of categorical variables for describing the sequence of events and causes of a motor-vehicle accident. For each of the variables the category or item appropriate to the accident is assigned, providing data which can be analyzed statistically.

\section{Coding Perspective and Accident Model}

It is important for the coder to understand that coding of all variables is performed for each of the vehicles in the accident. This means that the entire accident is first coded from the perspective of one vehicle, then coded again from the perspective of a second vehicle (if any), and any others in turn. The coder will complete a separate coding sheet for each vehicle involved.

When doing coding from the perspective of a particular vehicle, that vehicle is referred to as the subject vehicle. In every accident, the subject vehicle has impacted something, and the first thing impacted is designated the target. In a single-vehicle accident, the target may be a pedestrian, a roadside object, or the road surface itself (in the case of a rollover). When the target is another vehicle, it is referred to as the target vehicle.

It is also important that the coder understand the model on which the coding scheme is based. A fundamental concept of the model is that of collision course. A collision course exists when the path (road lane being followed) and speed of all vehicles (or animals, pedestrians, moving objects) involved are such that, if unchanged, a collision will result. Every accident of necessity involves a collision course.

The model also conceives each accident in terms of two basic and sequential events, with a third added when appropriate. It helps to consider

*The Accident Causal Coding Scheme is an explication of the "causal structure" developed by Kenneth Perchonok, as reported in "Identification of Specific Problems and Countermeasure Targets for Reducing Alcohol Related Casualities." NHTSA, Contract No. DOT-HS-4-00945, 1978. 
these in the reverse order that they happen (they are also coded in that reverse order):

- Primary event -- The first impact between subject vehicle and target. Example: two vehicles collide head-on.

- Critical event -- The action of a vehicle momentarily before the crash and after which a crash was virtually unavoidable. Example (continuing the previous one): one vehicle crosses the road centerline into the path of an oncoming vehicle.

- Prior event -- Another action of vehicle just before the critical event that led into the critical event. An example will be given later.

To follow the discussion of these and other concepts, it may help to refer to Figure 1.

Every accident has one primary event and one critical event, but they may be described differently from the perspective of each vehicle in an accident. Note that by "event" is meant a vehicle or target action -- what it did. In addition to these actions, it is important to understand that the causal coding scheme divides the time preceding the primary event into three periods: the critical phase, the precritical phase, and the normal phase. (Here again, we are working backward from the most recent time period.)

- The critical phase (or condition or situation) is entered at that climactic moment in time after which a crash is virtually unavoidable -- the "point of no return", or critical point. The critical event occurs at this time. Every accident has a critical phase, and its essential defining characteristics are:

(a) A collision course exists between subject vehicle and target. 


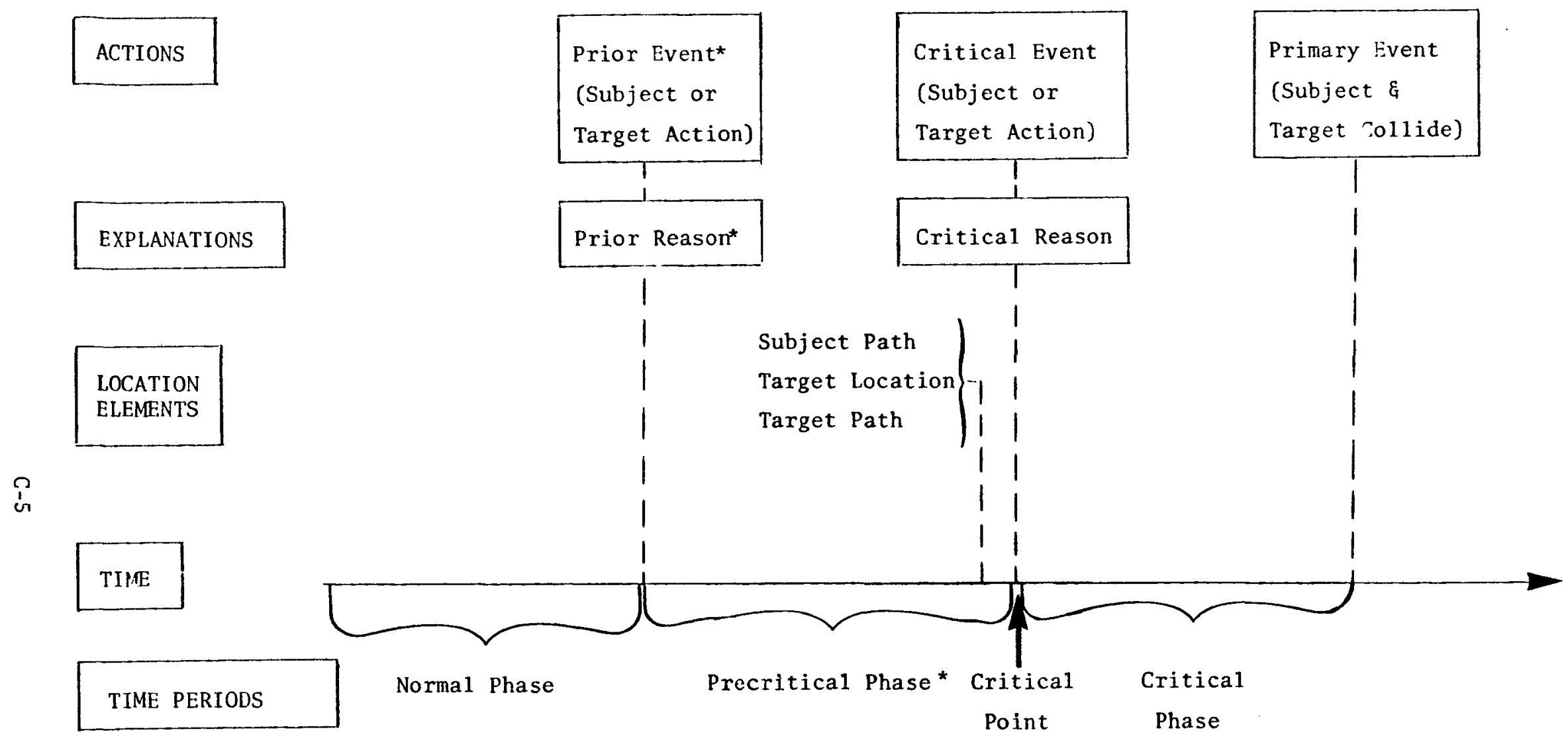

*Exists only in certain accidents 
(b) The vehicle dynamics (speed, momentum, etc.) are such that avoiding a crash is virtually a physical impossibility, for vehicles in satisfactory operating condition.

- The precritical phase (or condition or situation), when an accident has one, immediately precedes the critical phase. It is entered at that point that action to avoid an accident becomes appropriate, and it ends when such action is no longer possible. (Or, when successful avoidance action is taken). All drivers experience precritical situations regularly in driving, and adjustments in speed or direction are routinely taken to avoid a collision. Drivers differ in how soon they will take avoidance (precautionary) action, but only seldom is the situation allowed to develop to the critical point. Not every accident has a precritical phase, but when it occurs, it is defined by the following characteristics:

(a) A collision course exists

(b) Crash-avoidant action by at least one vehicle is possible.

(c) Crash-avoidant action by at least one vehicle is appropriate.

One example of entry of a precritical phase is when a vehicle approaching a sharp curve at a fast speed must slow down in order to avoid loss of control. ${ }^{* *}$ As another example, a vehicle on an expressway on-ramp may be on a collision course with a vehicle already on the expressway. The precritical phase is entered when it is appropriate for either vehicle to adjust its speed to insure a safe merger.

Just when a precritical phase is entered can only be specified approximately, for usually there is no precise point at which one can say that precautionary action becomes appropriate. As the precritical period comes to an end, however, avoidance action becomes increasingly necessary until it is absolutely essential. If the critical point is passed without successful avoidance action, the passing of the critical point is the critical event.

\footnotetext{
* The coder should avoid thinking of the critical event fatalistically; it is not some preliminary point after which an accident was "destined"to happen. Only physical inevitability is relevant here.

* This example shows that for a collision course to exist, the subject need not be heading directly at the target; prior to entering the curve, the speeding vehicle may not be heading towards the off-road target it will hit if the subject's path and speed are maintained.
} 
In some accidents there may be no observable precritical phase, as the situation is plunged almost instantaneously from normal to critical by the action of a driver-velicle, pedestrian, or some other agent. That action creates a collision course where there was none previously. The collision course is created either by a change of path or change of speed. Once the collision course is created, however, there is essentially no time for avoidance action, hence the precritical phase has in effect been bypassed. An example is the abrupt swerve of vehicle across the road centerline to collide immediately with a passing vehicle.

- The normal (or normal-driving) phase of an accident is that period of routine driving that immediately preceded the accident events. Activities of the normal phase generally are not relevant to the causal coding, except for understanding entry from the normal phase into a precritical phase or directly to the critical phase.

Every accident of necessity was preceded by a normal phase, for which the defining characteristics is the following:

For any collision course that may exist, the collision is so remote that avoidance action is inappropriate.

The latter characteristic is illustrated by the situation of two vehicles approaching the same intersection on different roads, but where each is still far from the intersection. Their speeds may be such that continuation would produce a collision, but the distance to the intersection is sufficiently far that "avoidant" action is premature.

\footnotetext{
* A moving vehicle is probably always on a collision course with something.
} 
Critical reason and prior event. For every critical event, there is a critical reason, which tells why the critical event occurred. Although there may be a chain of causes that led to the accident, the critical reason specifies only the last, most immediate one. Critical reasons are specified in terms of driver behavior, explaining why the driver did not control the vehicle so as to avoid the critical event. (No implication of fault is intended, for the driver may have been unable to control the vehicle safely.)

Not to be confused with the critical reason is the prior event, a concept introduced earlier. Whereas the critical reason explains vehicle action in terms of driver behavior, the prior event is another vehicle action that preceded the critical event. Specifically, the prior event is one that creates a precritical condition, just as the critical event creates the critical condition. To illustrate, consider a normal highway driving situation in which two cars are proceeding at the same speed in the same direction in the same traffic lane, and separated by a good distance. If the forward car slows down suddenly, a precritical condition will quickly develop: a collision course is created and avoidance action is in order. (The rear vehicle may slow down or pass the forward vehicle, the car ahead may speed up or pull off the road.) The sudden slowing down of the forward vehicle is the prior event, and it created the precritical condition. If neither vehicle took avoidance action, a critical event would occur as "the point of no return" was passed, and the crash would result.

Many accidents do not have a prior event because they had no precritical phase. For those that do have a prior event, it will be explained by the prior reason, similar in concept to the critical reason.

Review. The accident process is conceived of in the causal coding scheme by beginning with the most recent event -- the crash itself -- and working backwards in time. The crash is coded from the perspective of each vehicle in the accident, the one being coded at the moment being the subject vehicle. The crash itself is defined as the primary event, which takes place 
between the subject vehicle and the target, the first thing impacted by the subject vehicle.

The subject vehicle becomes involved in the accident in one of three ways :

(1) From a normal situation, the subject vehicle enters a precritical condition, wherein a crash is impending; insufficient corrective action is taken by the subject vehicle or the target (if animate), so the critical event is the passing of the critical point whereupon a crash is unavoidable.

(2) Out of a normal driving situation, the critical event is change of speed or direction by the subject vehicle, producing an immediately critical collision course and the resulting crash.

(3) Out of normal driving situation the critical event is a change of speed or direction by a mobile target, producing an immediately critical collision course and the resulting crash.

Underlying the critical event is the critical reason, while sometimes preceding the critical event is the prior event, which has its prior reason.

Locational elements. All the variables introduced so far describe what happened in the accident and why. Three more variables describe the where:

(a) Subject path -- Indicates the roadway of the subject vehicle, and the direction on it the subject vehicle is traveling.

(b) Target location -- Places the target with respect to the subject vehicle at the onset of the critical event. 
(c) Target path -- If the target is animate, its path is described in relation to the subject path. Inanimate targets like a bridge abutment have no path.

Summary. Every accident has these essential characteristics:

- Collision course

- Primary event

- Subject vehicle (at least one)

- Subject path

- Target

- Target location

- Critical phase

- Critical event

- Critical reason

- Normat práse

An accident may have (but not necessarily) the following:

- Target vehicle

- Target path

- Precritical phase

- Prior event

- Prior reason 


\section{General Coding Rules}

(1) Coding form. All coding will be recorded on the Accident Causal Coding Form. This form and instructions for its use are provided in Appendix A.

(2) Coding order. As indicated previously, the accident events are coded in the reverse order that they occur. All the elements (questions, variables) of the coding scheme are presented in this manual in the order they are to be coded, and the coding form follows that order (with skips of any inapplicable elements).

(3) Making coding judgments. For coding to be objective and reliable, it is necessary that you code only in relation to the reported facts of the accident, with one exception to be specified shortly. Now frequently you will not have all the information you would need to determine with certainty how each element should be coded. In such cases, the accident report should provide sufficient factual evidence to support your coding judgment as "most probably" true. You should always be able to point to that evidence. Lacking such evidence, you must use the "unknown" codes. Do not base your coding on mere suspicion of what happened or which driver was in error.

One problem situation that commonly arises is where drivers contradict each other. It is tempting to believe the driver whose explanation has the appearance of plausibility or which seems more honest. Examine the physical facts, including the areas of vehicle damage, skid marks, the road configuration, etc. for facts that help you to resolve the contradictions between drivers. If supporting evidence is lacking, you must code "unknown" or the code items that allow for two possibilities (such as items 6, 7, 8, and 96 under Critical Event).

Be wary of making coding judgments based solely on judgments of the reporting police officer. The officer may speculate on possible causes, but the speculations are not facts in themselves. Especially risky are speculations that the vehicle had been traveling too fast for conditions, that the driver lost 
control, or that the driver had been tailgating. Unless the reporting officer cites some factual basis for his judgments (e.g., skidmarks), you should make your judgment independently, based on the facts available to you. 


\section{PRIMARY EVENT}

This is the event that defines the occurrence of an accident. It is an impact between the subject vehicle and the thing struck, the target. If more than one of the following occurred, the primary event is whichever occurred first.

01-09 Collision with vehicle number - Each vehicle contacted in the accident is assigned a number with the first striking vehicle being number one, etc.

10 Collision with pedestrian/bicycle

11 Collision with train

12 Collision with animal

13 Road departure \& collision with offroad target (target: object; ground surface if rollover; ground or embankment). "Offroad" means off the road surface intended for driving vehicles. Includes hitting targets on shoulders or medians. Not included are accidents where vehicle crosses median, does not hit on-median target, but impacts vehicle on opposite lanes.

14 Rollover in road (target: roadway surface struck as vehicle rolls)

15 Collision with on-road stationary object e.g. bridge support (not on median); "men working" barrier.

$96 \quad$ Other

98 Unknown 


\section{CRITICAL EVENT}

The critical event is what the subject vehicle did, or was done to the subject vehicle, that made an accident virtually unavoidable. It is the event that creates a critical condition, during which nothing short of a highly skilled maneuver could prevent a crash. If there were several sequential events leading to the crash, the critical event is that one which, in the coder's judgment, made the crash essentially inevitable.

There is only one critical event, but as with all the coding categories, the critical event may be described differently from the perspective of each vehicle in an accident. Basically, there are three ways by which the critical event may be experienced by the subject vehicle. These are:

(a) An agent (vehicle, pedestrian, etc.) other than the subject vehicle changes the situation from normal to critical. The other vehicle is the imposer; the subject vehicle is imposed upon. Item 1 below indicates this event for the subject vehicle.

(b) The situation changes from normal to precritical to critical with no disruption of the collision course by the subject vehicle. The subject : vehicle has continued; if there is another agent, it too has continued. Items 2 and 3 below indicate this event for the subject vehicle.

(c) The subject vehicle changes the situation from normal to critical. If there is another agent involved, the subject vehicle is the imposer while the other agent is imposed upon. When the subject vehicle is the imposer, the specific form of imposition is coded, which will be one of items 4 or 5 below. 
01. Imposed upon - An animate target (vehicle, pedestrian, animal) changed its direction or speed to immediately change a normal condition into a critical one. There was no precritical condition (a collision course with avoidance action possible).

Note. The coder should avoid thinking that the imposer is the one at fault or responsible for the crash. Since Critical Event refers only to vehicle movements and not to such factors as signaling and perception, there is no necessary connection with driver responsibility.

Examples*

(a) An oncoming vehicle (target) in the opposite traffic lane suddenly swerves, crossing the centerline and impacting the subject vehicle in the side.

(b) A pedestrian (target), standing at the curb, steps into the road right in front of the subject vehicle.

(c) The subject vehicle is tailgating (closely following a vehicle) when the forward vehicle (target) brakes and is hit by the subject.

(d) Subject drives through traffic light that just turned red. Target starts up at green, runs into side of subject.

*Note in examples (c) and (d) that the subject appears at fault, but it is the target action that created the collision course. In all the examples, the subject is imposed upon. 
02. Continue - Subject vehicle continued whatever it was doing as the situation changed from precritical to critical. In other words, there was a collision course, crash avoidance was possible by subject or target, but neither took avoidance action.

Note 1. Ignore avoidance manuever made by subject vehicle after the crash was inevitable.

Note 2. Avoidance action may not have been possible for subject vehicle, although available to target.

Examples

(a) Subject vehicle and target vehicle approach an intersection. Neither stops, crash results.

(b) Subject vehicle stopped at red traffic signal. Target vehicle approaching from rear maintains speed and collides with subject. (Note that subject is not "imposed upon", since there was a precritical condition.)

(c) Subject vehicle stopped at red traffic signal. Target vehicle approaches from rear, brakes too late, runs into subject. (Note that braking occurred beyond the critical point, is therefore ignored.)

(d) Subject vehicle stopped at red traffic signal. Target vehicle approaches from rear, has brake failure, hits subject. (Assumes crash would be avoidable by vehicle in satisfactory operating condition.) 
(e) Target vehicle passes another vehicle on straight 2-lane road. Subject is approaching in opposite direction, but distance between subject and target is well more than sufficient for passing. Nevertheless, target and subject collide.

(f) Target vehicle passes another vehicle on blind curve of 2-lane road. Subject rounds curve in opposite direction, collides with target. (Note here that a crash may seem inevitable, suggesting that the subject was "imposed upon". But as long as it is physically possible to avoid the crash, the failure to do so renders the critical event as "continue".)

(g) Subject vehicle is following target vehicle with a good space between them. Target slows, is run into by subject. (A precritical condition is indicated, therefore continue is appropriate.)

(h) Subject vehicle goes straight ahead as path curves.

03. Change speed - Subject vehicle changed its speed to immediately convert a normal condition into a critical condition. There was no precritical condition. (Here, subject vehicle imposed on target.)

\section{Examples}

(a) Subject vehicle is following target vehicle at close distance. As driver adjusts seat, foot depresses accelerator. Speed increases, subject overtakes and impacts target.

(b) Subject vehicle is followed by tailgating target vehicle. Subject applies brakes and is hit by the target. 
(c) Subject vehicle waiting at red light, immediately moves forward as light turns to green. Already, however, vehicle from sidestreet is in intersection after trying to beat the light. Subject hits target in side*

04. Change direction - Subject vehicle changes its direction (angle of movement) to immediately convert a normal condition into a critical one. There was no precritical condition. (Again, subject vehicle imposed on target.)

Note: Most road departures have this Critical Event.

\section{Examples}

(a) The subject vehicle makes a left turn into the path of oncoming vehicle coming the opposite direction.

(b) The subject vehicle veers to the right, around another waiting to make a left turn. The subject vehicle hits a pedestrian standing in a crosswalk.

(c) The subject vehicle A tries to pass vehicle $B$ on a blind curve. Vehicle $C$ comes from around curve; $A$ and $C$ are in a head-on situation. Vehicle $A$ cuts right to avoid the head-on collision, but impacts vehicle $B$.

The three items below are used whenever the coder is uncertain as to whether or not there was a precritica 1 condition.

\footnotetext{
*Note that target may have been at fault but subject is the imposer.
} 
05. Continue/Imposed Upon - Used when it is clear that the subject vehicle did not initiate a critical collision course, but the target may have.

\section{Examples}

(a) Subject and target vehicle collide in intersection. Target vehicle had stop sign, subject vehicle did not, but it is not clear whether the target actually stopped at stop sign (which would produce Imposed Upon) or proceeded through without stopping (which would produce Continue).

06. Continue/Change Speed - Used when it is clear that a target agent did not initiate the critical collision course, but the subject vehicle possibly did so by a change in speed.

\section{Examples}

(a) Same as example 6(a), except with subject and target designations reversed.

(b) Rear end accident, in which the forward vehicle slowed down and was run into by the following vehicle, but it is not clear whether there was time for avoidance action after the lead vehicle slowed.

07. Continue/Change Direction - Used when it is clear that a target agent did not initiate the critical collision course, but the subject vehicle possibly did so by a change in direction. 
Examples

(a) Subject vehicle runs into a vehicle parked at side of road. It is not clear whether (a) parked vehicle jutted out in subject's forward path (continue) or (b) subject vehicle veered to right to impact target. Note: This is an important example.

(b) Subject vehicle, while passing, has a collision with an oncoming vehicle. It is not clear from the accident report whether the situation was immediately critical when the subject pulled out to pass, or whether there was a precritical phase. In any case, it is clear that the target vehicle did not initiate the collision course.

(c) Subject vehicle on a 4-1ane highway impacts a work zone barrier in far right lane. Driver reports changing lanes shortly before crash, but it is not clear whether there was a precritical phase.

08. Change Speed + Change Direction. The critical condition is created by a simultaneous change of speed and direction.

Examples:

(a) As Vehicle $A$ is passing Vehicle $B$ on a 2-1ane road, Vehicle $C$, which was stopped at a sideroad, starts up and turns into $A^{\prime} s$ path, resulting in a head-on crash between $A$ and $C$. Critical event for $C$ involves change of speed and direction.

(b) Subject vehicle is stopped in intersection, waiting for traffic to clear to make left turn. Subject starts turning, into path of oncoming vehicle, resulting in collision. 
96. Other - Use this item for crashes which do not fit the previous items. (There should be very few such instances.) One case that may arise is where it seems clear that a normal condition was changed directly to a critical one, but it is uncertain which of two vehicles did the imposing.

98. Unknown - Insufficient Information to determine

Example

The subject vehicle was in the passing lane of an expressway, and it was overtaking the slower vehicles (one behind the other) traveling in the right lane. The crash occurred as the rearmost of the two slower vehicles pulled out to pass the other, whereupon it was immediately impacted in the rear by the subject vehicle. The driver of the target vehicle claimed the crash occurred because the subject vehicle sped up, while the subject vehicle driver claimed he did not, but had been glancing down at a road map. (From the accident report it cannot be determined whether there was a precritical phase or not, and if not, which vehicle was the imposer.) 


\section{CRITICAL EVENT CHANGE SPEED: TYPE}

This variable specifies the particular way in which the subject vehicle change of speed was the critical event. In each of these items, a critical collision course was created from a normal situation.

1. Start forward

2. Stop

3. Accelerate

4. Decelerate

5. Start backward

6. Other

8. Unknown

$9 \quad$ Inapplicable - no speed change 


\section{CRIIIIAL EVENT CHANGE DIRECTION: TYPE}

This variable specifies the particular way in which the subject vehicle's change of direction was the critical event. In each of these items, a critical collision course was created from a normal situation.

01 - 05. Turns - At intersection, driveway, etc.

01. Normal turn

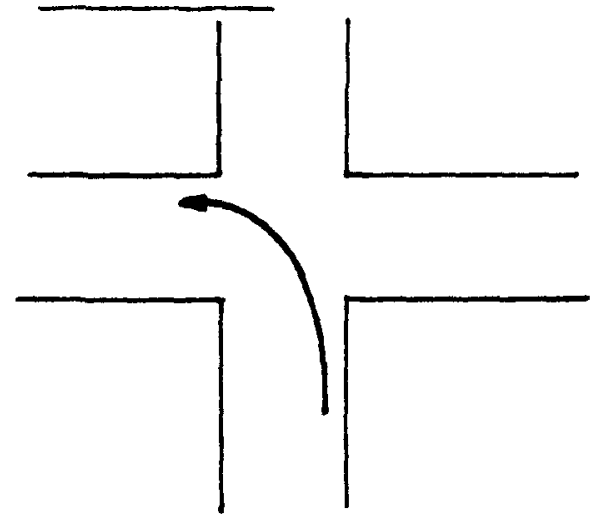

03. Cut turn short

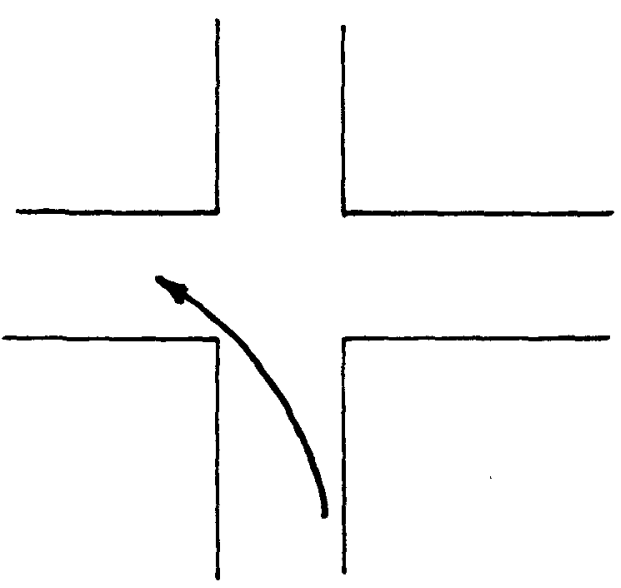

02. Wide turn

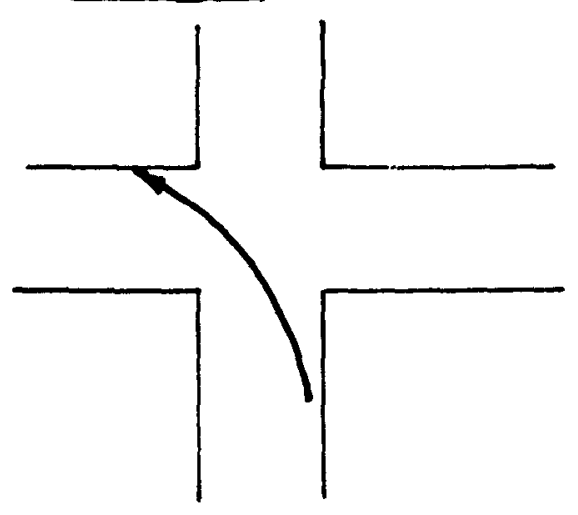

04. Protracted turn

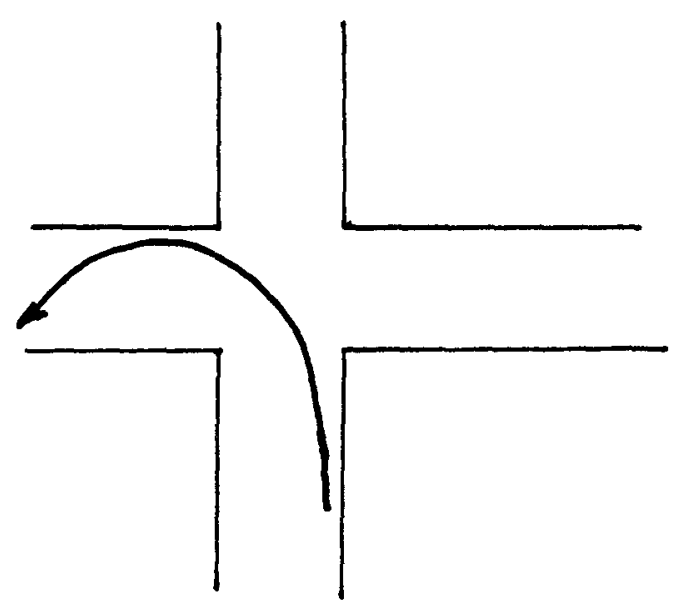


05. Turn, other or unknown kind - Includes U-Turn.

06. Lateral move

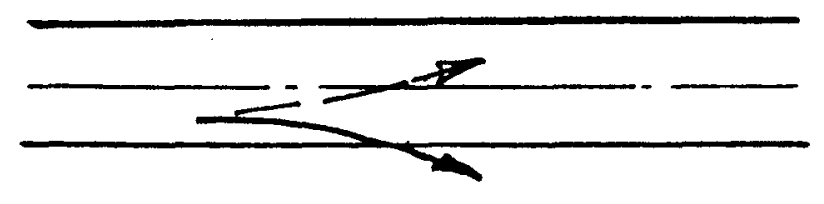

07. Parallel path

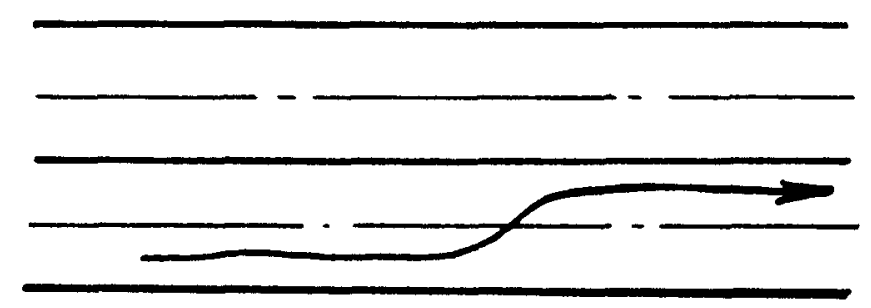

96. Other

98. Unknown

99. Inapplicable - No direction change 


\section{DIRECTION}

This variable specifies the general direction of movement when

"change direction" was the critical event. If vehicle was tuning, direction of turn is indicated.

1. Right - Subject vehicle turned, moved etc. to its right

2. Left - Change to left

8. Unknown - A change in direction was known to have been made, but its direction is unknown.

9. Inapplicable - No change in direction 
The subject vehicle path describes the road lane section the subject vehicle was on and the vehicle's motion, just prior to the critical event. The lane section is that in which the subject was traveling; it does not refer to the roadway ahead. The motion refers only to vehicle propulsion forward, backward, or none at all; it does not refer to the vehicle angle with respect to the roadway. (Whether the vehicle is crossing the road obliquely is irrelevant.) If the subject was changing to a lane on a different roadway, i.e. turning, that is coded. Caution: Take special note of how motionless vehicles are handled (items 13-15).

Special rules. (a) If the subject vehicle is in a parking lot, the direction of steer is used in place of roadway section.

(b) If the subject was in the process of changing lanes (other than turn) just prior to the Critical Event, code the iane it was changing from.

(c) If Critical Event for subject is turn, subject path designates path before the turn began. (See examples on page 26).

01 Forward; straight. Subject vehicle is proceeding forward on straight lane section.

02 Forward; right curve. Subject is on right-curve lane section, vehicle follows curve forward.

03 Forward; left curve

04 Forward; curve direction unknown

05 Forward; right turn. Subject is changing from its road section by making a right turn moving forward. Subject may be exiting into driveway, parking lot, expressway ramp or any other normal departure from its roadway.

06 Forward; left turn 
08 Forward; path ends. The road lane ends, as in dead end, "T" intersection, or lane drop. (Subject vehicle must be right on the lane terminus. This is not coded if subject turning before reaching the lane end.)

09 Rearward; straight/curve. Road lane section is straight or curved, vehicle is backing up.

10 Rearward; right turn. Vehicle moving rearward to its right side (driver's right).

11 Rearward; left turn

12 Rearward; other. Includes U-turn and path ends, with vehicle backing.

13 Motion imminent; any. Applies to any lane section. Vehicle is stopped momentarily, motor running.

Examples. Waiting for traffic light to turn green; waiting for traffic gap to make left turn; stopped at stop sign.

Caution. Does not include standing, e.g. waiting at curb for passenger, with motor running (Code item 15).

14 Motion imminent/forward; any. Unclear as to whether vehicle was fully stopped or in forward motion.

15 Motionless; any. Vehicle stopped, no motion was imminent. Examples. (a) Standing, e.g. waiting at curb for passenger, with motor running

(b) Vehicle broken down in road;

(c) Parked vehicle;

(d) Vehicle ahandoned by driver in road. 
96 Other

98 Unknown

Examples of when rule (c) does and does not apply:

(1)

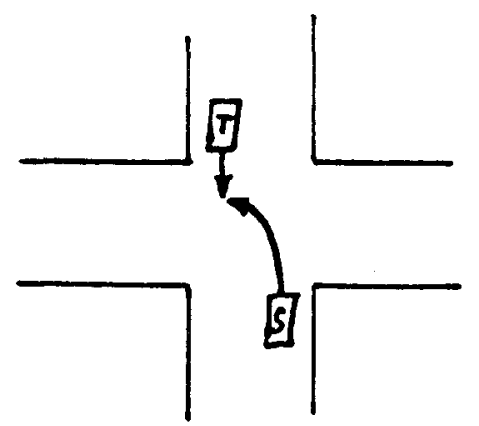

(2)

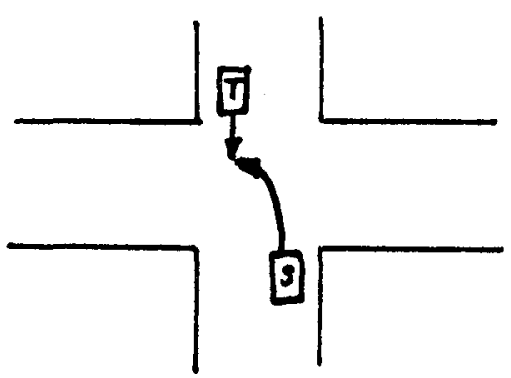

(3)

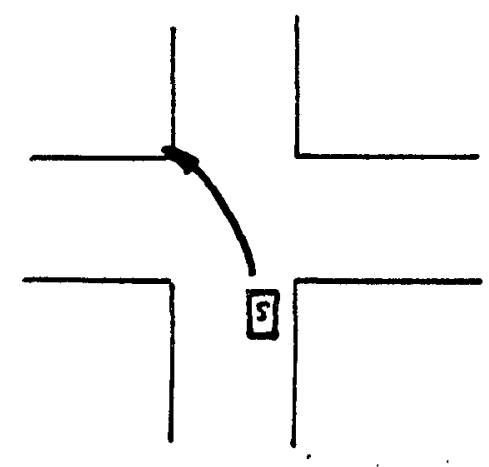

$S=$ Subject $\quad T=$ Target

$\mathrm{T}$ is proceeding through intersection (no stop) when $S$ makes turn across T's path. Critical Event is Change Direction (Normal left turn). Subject Path is Forward; Straight.

$S$ is making a left turn when $T$ starts forward (from stop) and impacts $S$. Critical Event is Imposed Upon. Subject Path is Forward; Left turn.

$S$ goes off road while attempting left turn. Critical Event is Change Direction (Wide turn) Subject Path is Forward; Straight. 


\section{TARGET LOCATION}

The target location is specified in relation to the subject vehicle's lane segment, just prior to the critical event. The target location is identified as one of the zones in the following diagram:

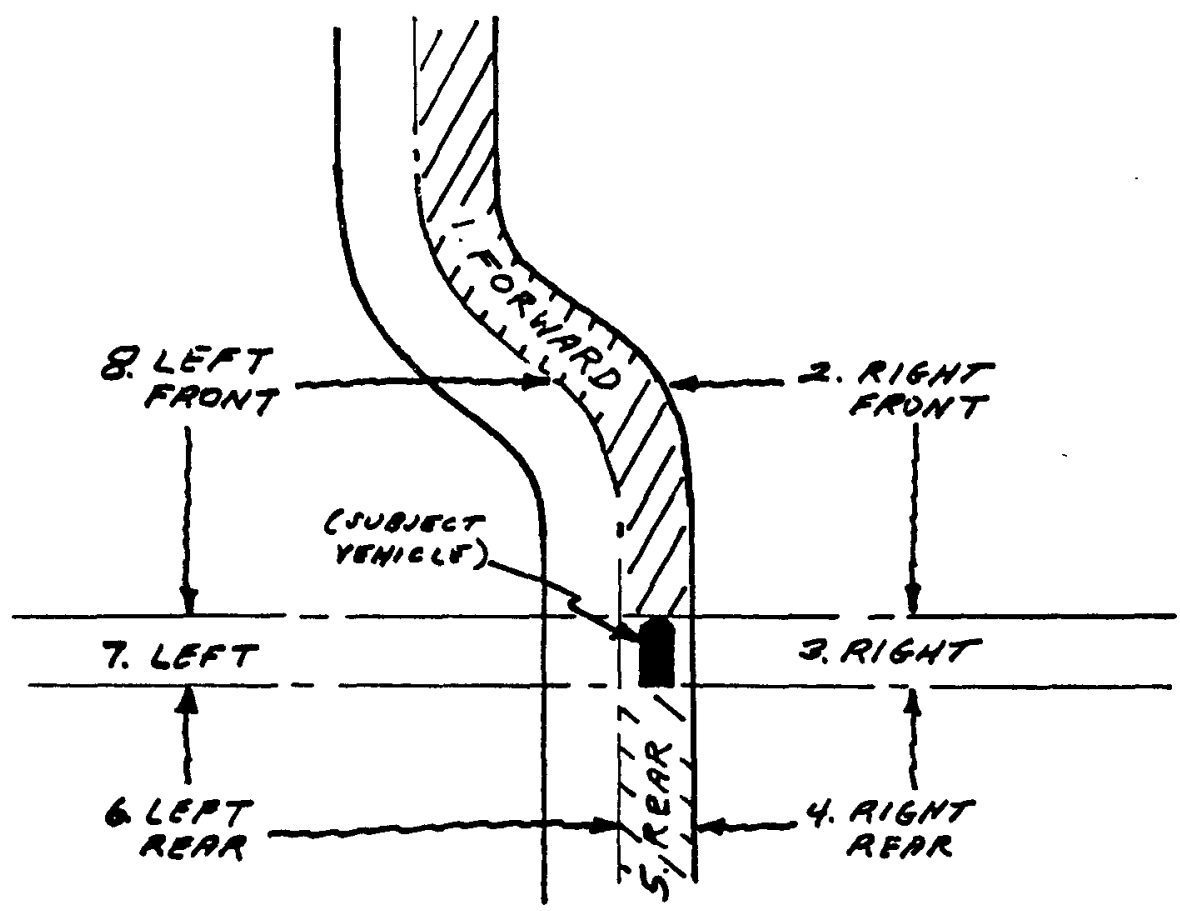

Note that the left and right boundaries of the subject vehicle's travel lane are the zone divisions laterally. The vehicle's front and rear determine the fore and aft boundaries. Note also that the exact position or attitude of the subject within the lane segment are irrelevant.

Special rules. (a) If the target overlaps the forward zone, code as "forward". In all other instances of overlap, code zone target is in predominantly.

(b) If subject vehicle was changing lanes or turning during critical event, code target location with respect to the lane segment subject was leaving. If target vehicle was changing lanes or turning during critical event, code target location with respect to the lane sequence target was leaving. 


\section{Examp̈le:}

Subject is making left turn, collides with target vehicle in opposite lane and traveling in the opposite direction. The target is located where it was just before the subject made its turn. The zone is "left front".

$01 \quad$ Forward

02 Right front

$03 \quad \underline{\text { Right }}$

$04 \quad$ Right rear

$05 \quad \underline{R e a r}$

$06 \quad$ Left rear

$07 \quad$ Left

$08 \quad$ Left front

$98 \quad$ Unknown 
This variable applies only to targets capable of locomotion, viz. vehicles, pedestrians, animals. Similar to subject path, target path describes the road lane the target was on and the direction the target was moving, just prior to the critical event. These are specified, however, in relation to the subject vehicle's lane and the subject's direction of movement. Caution: Take special note of how motionless vehicles are handled (Rules $c$ and $d$, and item 11).

\section{Special rules.}

(a) If subject vehicle is turning during the critical event, the target path is relative to the subject lane just before the turn. If the target vehicle is turning, the target path refers to its path before turning.

(b) If the target is a pedestrian or animal, target path refers not to a road lane but to its travel vector with respect to the subject path.

(c) If the target is a vehicle stopped but not parked, its path is the direction it is facing. Same for pedestrian or animal momentarily stopped.

(d) If the subject path is "motion imminent", the target path is in relation to direction subject is facing.

To determine target path direction, refer to the diagram below.

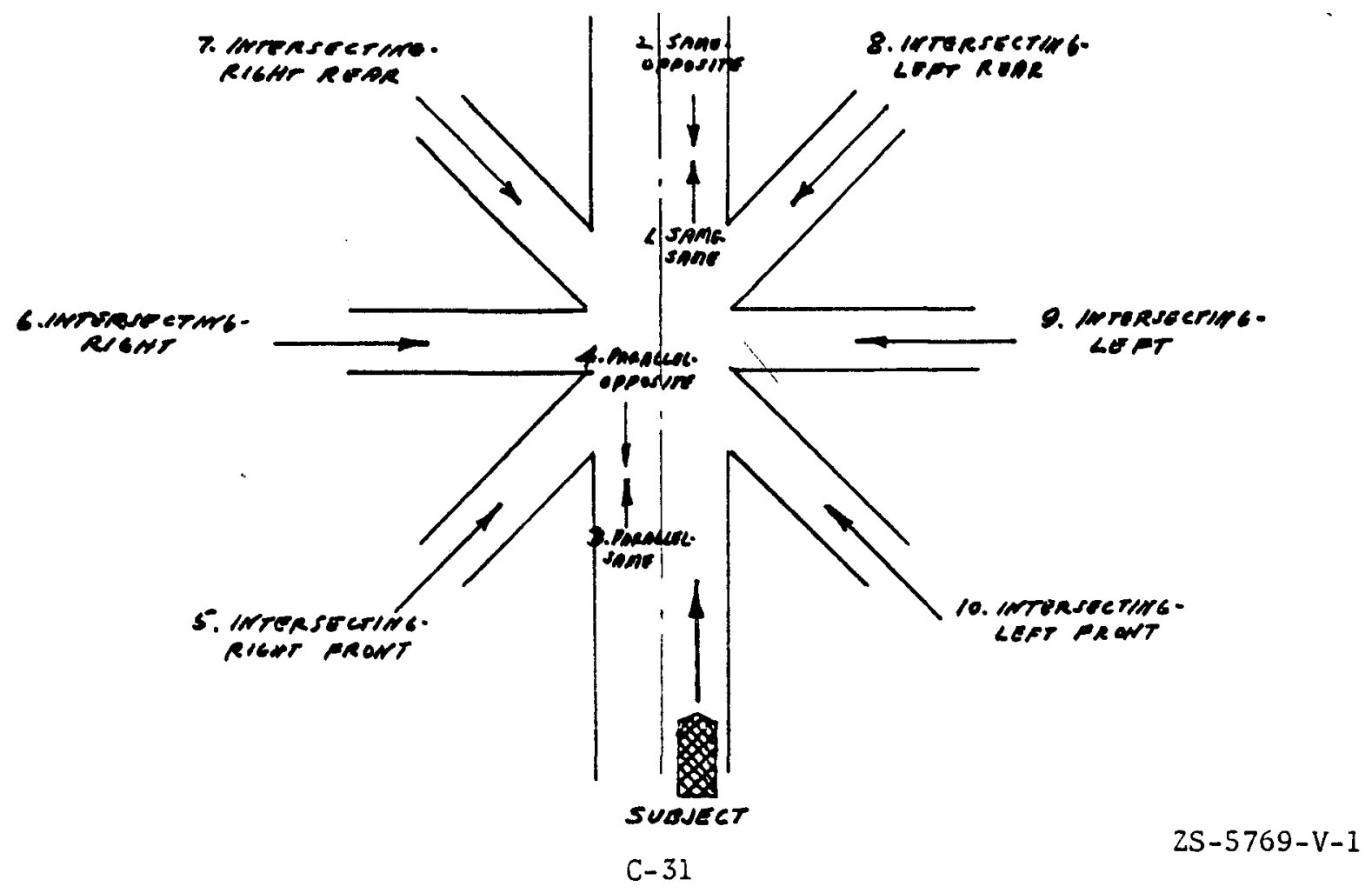




\title{
TARGET PATH
}

\author{
LANE DIRECTION \\ 01. Same - Same \\ Target is moving in same lane and same direction as \\ subject. (Includes curves, where vehicle ahead is \\ moving in same direction as the subject.) \\ 02. Same - Opposite \\ Target is on head-on collision course with subject. \\ 03. Parallel - Same \\ Target is un a parallel course with subject, going same \\ direction. \\ 04. Parallèl - Opposite \\ Target is on bypassing course with subject, e.g. Target \\ and subject are traversing opposite lanes of 2-1ane, \\ 2-directional road. \\ 05. Intersecting-right front \\ Target's path intersects subject's at a 7 to 8 o'clock \\ angle. \\ 06. Intersecting-right \\ Target's path intersects at $90^{\prime}$ clock. \\ 07. Intersecting-right rear Target's path intersects at 10 to 11 o'clock. \\ 08. Intersecting-left rear Target's path intersects at 1 to 2 o'clock. \\ 09. Intersecting-left Target's path intersects at 3 o'clock. \\ 10. Intersecting-left front Target's path intersects at 4 to $5 \mathrm{o}^{\prime}$ clock. \\ 11. None \\ Target capable of locomotion is at rest; motion not \\ imminent. Example. Parked vehicle.
}

96. Other

98. Unknown

99. Inapplicable

Target cannot locomote; immobile object. 


\section{CRITICAL REASON}

This is the explanation of why the driver of the subject vehicle did not control that vehicle so as to avoid the critical event. These reasons fall into three general categories:

(a) Influences apparently beyond the driver's control: Item 01-06.

(b) Problems of driver: Items 07-09. These are either information problems or control problems.

(c) Driver control without failure or errors: Item 10.

It is very important that the coder realize that the critical reason does not necessarily indicate fault nor even what may seem to be the main cause of the accident. This is well illustrated by the example of an accident resulting when Vehicle A tries to "beat the light," passing through the intersection just after the light turns red, and is hit by Vehicle $B$ just starting forward with the green light. The critical reason for Vehicle A does not attempt to explain why the driver went through the red light (which one might consider the "cause" of the crash), but why the driver did not avoid the critical event, which for Vehicle $A$ is "imposed upon." The critical reason (as explained below) is "external influence."

Whenever possible the coder should base the determination of critical reason on an explicit statement in the accident report. Only if such explicit information is lacking may the coder infer the critical reason, and there must be a reasonable basis for the inference. Lacking either explicit information or a reasonable inference, the critical reason should be coded "unknown".

01. External influence - Critical event was in response to external demands of another vehicle, traffic control, etc. Also used when critical event was "imposed upon" 
(with one exception: is "secondary" if collision is with vehicle already involved in an accident).

(Caution: Does not pertain to information

blockages, which belong in item 07).

Examples:

(a) The subject vehicle was hit from the rear by another vehicle as it was stopped for traffic light at an intersection (critical event: continue).

(b) As the subject vehicle was proceeding, it was cut off by a vehicle turning left in front of it (critical event: imposed upon).

02. Alleged external influence - Driver reported that critical event was in response to an external influence, which could have been true but is uncorroborated. (Does not apply to driver claims which are refuted by evidence or any witnesses.)

Examples:

(a) Driver claims he was forced off road by another vehicle. Presence of other vehicle unsubstantiated.

(b) Driver states he hit an adjacent vehicle when he swerved to avoid hitting a cat. Accident report does not provide any further evidence about cat.

03. External influence/passive - used when the critical event is "imposed upon/continue" (see examples in that category). 
04. Secondary - subject vehicle collided with target which was already involved in a previous collision, road departure, or rollover.

Examples:

(a) The subject, waiting for the light to change, was struck in the rear by Vehicle B (CE - imposed upon), which was pushed into the subject by vehicle $A$.

(b) As the subject was traveling in the lane adjacent to vehicle $A$, vehicle $A$ spun out of control, hit the guardrail, then hit the subject. (CE - imposed upon)

05. Vehicle breakdown - A sudden malfunction of the vehicle so that it responds abnormally to driver control inputs.

Examples:

(a) The subject was hit in the rear while parked in a traffic lane (CE - continue) because it was disabled.

(b) The subject ran off the road while negotiating a curve (CE - change direction) because its steering failed.

06. Driver breakdown - A sudden malfunction of the driver rendering him incapable of providing control inputs to the vehicle. Includes only acute changes in the driver's physical state as opposed to longer term conditions.

Note: Drunkenness by itself is not a driver breakdown. Drunkenness may create a driver breakdown, however, such as the driver passing out. 
Examples:

(a) The subject ran off the road (CE - change direction) because the driver fell asleep.

(b) The subject hit a light pole (CE - change direction) because the driver blacked out due to drinking.

07. Information failure - Driver did not validly process information about the vehicle, objects, and/or roadway in his vicinity. May have been due to blockage of information, misdirected attention, a failure to recognize, or a judgmental error. In all cases, driver's actions were based on a failure to comprehend the situation. Applies only to information regarding the environment outside the subject vehicle.

Examples:

(a) The subject made a left turn in front of an oncoming vehicle (CE - change direction).

(b) The subject departed the road by continuing to go straight on a curve (CE - continue steer angle).

(c) The subject unit, while stopped at a toll booth, backed into a vehicle stopped behind (CE changed speed).

08. Control failure - Driver lost control over vehicle, such as by (a) vehicle losing traction with road; (b) driver losing contact with vehicle controls (e.g. steering wheel, brake, accelerator); (c) excessive vehicle momentum; or (d) driver's inability to handle vehicle demands.

Inference guide: Gross vehicle path deviations may be used to infer Control Failure, in lieu or direct information. Be sure to code "Inferred" in Critical Reason Basis category. Caution: Police officer's statement that driver "lost control" is insufficient for coding Control Failure, without further evidence. 
Examples:

(a) Driver lost control of his vehicle while making a turn at high speed causing a departure from the road (CE - change direction)

(b) The subject vehicle slid into a bridge on the side of the road (CE - change direction) because he skidded on ice and lost control.

(c) As subject vehicle is turning into driveway, driver's foot slips off of brake pedal, vehicle goes off driveway into tree.

09. Information failure/control failure - Used where choice is not clear. Note: This is a commonly used item, particularly in cases of less severe path deviations, e.g. "drifting" off road or across lanes.

Examples:

(a) When the subject vehicle attempted to change lanes (CE - change direction), it struck a guardrail.

(b) The subject unit failed to move left when entering a construction area where cones narrowed the driving lanes. Vehicle drove straight into the cones. The road surface was slick (CE - cont SA).

10. Logistic - Subject driver's behavior was based solely on reasons relating to where he was going (destination) and how he wanted to get there. Driver behaved in reasonable way in accordance with environmental demands and his vehicle's right of way. Assumes no information failure has occurred and no other critical reasons apply. In summary: Driver apparently did nothing wrong, and there was no reason to drive differently. 
Examples:

(a) The subject unit was struck in the rear by another vehicle while parked (CE - continue) in the service area lane on the thruway.

(b) Subject vehicle slows down to make turn off roadway. Target vehicle is following at good distance, but driver's attention is distracted away from subject. Target runs into rear of subject. (CE - continue; Prior event - change speed; Prior reason - logistic).

96. Other - includes accidents with intentional involvement. Examples:

$$
\text { vandalism, suicide attempts }
$$

98. Unknown - No explicit information \& reasonable inference not possible. 
TYPE OF INFORMATION FAILURE

1. Presentation failure - Driver unable to perceive needed information. The information was reduced or obscured by something external to the vehicle. May not be used if information was available via rear view mirror. Also used if "signal-to-noise" ratio is so low a's to prohibit detection of signal.

Examples:

(a) Subject driver turned left in front of an oncoming vehicle that was traveling in the curb lane; that vehicle was obscured by other traffic in the inside lane.

(b) Subject vehicle collided with a pedestrian at night when pedestrian was obscured by the wearing of dark clothes.

(c) Subject vehicle pulled out from stop sign and collided with motorcycle when subject driver's vision was reduced by glare from setting sun.

2. Sensing failure - Information was transmitted to the general area of the driver, but driver did not see, hear or otherwise sense it.

Includes: driver did not look in correct direction; distraction; part of vehicle or its passengers blocked a source from view.

Examples:

(a) Subject collided with rear of a stopped vehicle because driver was glancing out the side window and did not notice the stopped vehicle until it was too late.

(b) Subject driver, starting up from a stop sign, collided with a vehicle passing through the intersection because he did not see the vehicle as a passenger's head was in the way. 
3. Recognition error - Driver perceived but did not take in the significance of the information. Information from a source in the driver's field of view (usually in his path) was sensed, but the driver remained unaware of it. Applies only to information about static conditions \& decisions whether another unit is moving or not. Can be thought of as "look but not see" error.

Examples:

(a) Driver states that he did not know where the vehicle he collided with came from; when he looked, the way was clear, so he proceeded to go through the intersection.

(b) Intersection accident occurring at night resulting when the driver looked both ways but was unable to discern the oncoming vehicle's lights from other lights.

4. Projection error - Error of judgment. Driver was aware of surrounding external conditions but did not appropriately process the information to draw valid conclusions about ensuing events. Normally involves speed/distance misjudgments.

Examples:

(a) Subject driver made a left turn in front of an oncoming vehicle because he thought he "had enough time".

5. Conflict error - Driver received misleading or conflicting information which provided some legitimacy for his actions.

Examples:

(a) The subject vehicle pulled out from a side street because an oncoming vehicle had slowed down and signalled a right turn; collision resulted when the oncoming vehicle actually proceeded straight. 
6. Other

8. Unknown

9. Inapplicable - no information failure 
TYPE OF CONTROL FAILURE

1. Primary control failure - Critical event resulted from driver losing control of vehicle leading to gross path deviations so as to precipitate an accident. Assumes intended path was available. (Leaving the road qualifies only if it can be assumed that the driver had information telling him the general location of the road.)

Example: See example (a) under Critical Reason -Control Failure.

2. Induced control failure - Path deviations due to traveling over road surface defects or foreign matter on the road surface.

Caution: Do not code Induced Control Failure simply because accident report indicates road was wet, icy, or the like. Report must provide other evidence, such as the driver's report, that the vehicle skidded. Without such evidence, "Unknown" must be coded.

Example: See example (b) under Critical Reason -Control Failure.

8. Unknown - whether primary or induced

9. Inapplicable - no control failure 
1. Proceed - passively continue along path with no relevant collision course.

Examples:

2. Before turn - usually refers to deceleration: Examples:

(a) Subject driver was slowing down to make a left turn. In the car following, the driver was looking out the window and struck the subject vehicle in the rear.

3. To pass - usually refers to direction change: parallel path

Examples:

4. Park - Either subject unit did not break off existing collision course because it was parked, or reason for critical event was pre-parking manuever.

Examples:

(a) Subject vehicle was hit in the rear end by another vehicle while subject was parked on the side of the road. 
6. Other

Examples:

(a) Subject vehicle was temporarily stopped in traffic with its flashers on while waiting to back into a driveway, when it was hit in the rear.

9. Inapplicable - reason was not logistic 


\section{CRITICAL SOURCE}

This category applies only to the following critical reasons.

(a) External influence, external influence/passive, and alleged external influence -- Source is the external agent to which the subject vehicle responded.

(b) Secondary -- Source is the target that vehicle struck.

(c) Information failure -- Origin of the information which was not properly utilized. (N.B. The critical sou.rce does not refer to a thing that blocked information.)

01-09 Vehicle number - A vehicle involved in the accident, but not the target for the subject vehicle. Code vehicle number. (See Codes 01-09 for Primary Event for explanation of numbering.)

10 Target - The critical source is the same as the target. Example: The driver saw vehicle in front of him too late to avoid an accident.

11 Non-accident vehicle

12 Pedestrian or bicycle - Human on foot, on bicycle, or a non-road vehicle.

13 Train

14 Animal

15 Traffic control signal 
16 Traffic control sign -

17 Road - Surface, or temporary surface cover, or path of road. Example: holes; oil; snow; gravel; bumps; traffic lane

96 Other

98 Unknown

99 Inapplicable - Critical reason was not external influence, secondary, or information failure. 


\section{CRITICAL REASON BASIS}

In this category the coder indicates whether the coding of critical reason was based on an explicit statement in the accident report or was inferred. from the nature of the accident.

I. Explicitly reported

2. Inferred

9. Inapplicable (critical reason unknown) 
PRIOR EVENT

The prior event is the creation of a precritical condition, i.e. initiation of a collision course in which avoidance action is possible and appropriate. Consequently, the prior event is coded only when the critical event is "continue".

Items in this category are nearly identical to those for critical event, the basic difference being that in the prior event, vehicle actions change the situation from normal to precritical.

1. Imposed upon - An animate target changed its direction or speed to change a normal condition into a precritical one. Example:

One vehicle is following another at a good distance on a highway. The lead vehicle stops to to make a left turn, well ahead of the rear vehicle. The rear vehicle is imposed upon.*

2. Continue - Subject vehicle continued whatever it was doing as the situation changed from normal to precritical. That is, a collision course for which avoidance action was inappropriate (premature) continued to the point where avoidance action was appropriate .

*In all examples for prior event, accident occurs when critical event is "continue". 
3. Change speed - Subject vehicle changed its speed so as to convert a normal situation into a precritical condition.

Example:

Same as previous example. Change speed is prior event for lead vehicle.

4. Change direction - Subject vehicle changed its direction to convert a normal situation into a precritical one.

Examp1e:

By pulling out to pass Vehicle $A$ on a 2-lane road, Vehicle $B$ enters a head-on collision course with oncoming Vehicle C. Avoidance action is necessary and possible.

6. Other

8. Unknown - Insufficient information to determine. In some accident reports there may be no indication of when the collision course was begun nor which vehicle initiated it.

9. Inapplicable - Critical event was not "continue" 


\section{PRIOR EVENT CHANGE SPEED}

PRIOR EVENT CHANGE DIRECTION

PRIOR EVENT DIRECTION

These categories provide the same kind of details about the prior

event as their counterparts do for critical event. The items within each have the same meanings as those counterparts. 


\section{PRIOR REASON}

This category explains prior event just as the critical reason explains the critical event. All items are essentially equivalent to those in critical event, except "extemal influence/passive" is not applicable to prior event.

PRIOR REASON BASIS

This category gives the coder's basis for coding prior reason, with the same kinds of items as critical reason basis. 
This category specifies how much responsibility the subject uriver had for the accident, in the coder's judgment. This is where the coder specifies whether the driver did something he shouldn't have, or failed to do something he should have, in either case creating a dangerous, high-risk situation.

1. Culpable - The subject vehicle was the first to create the dangerous situation. Clearly, there can be only one culpable driver per accident.

Rule of Thumb: Unless there are explicitly stated extenuating circumstances, drivers in road departure accidents are coded "culpable."

2. Contributory - While another vehicle or other source created the dangerous situation, the subject driver could readily have avoided involvement in the accident by a normal avoidance maneuver.

3. Culpable/contributory - The subject driver had some responsibility for the accident, but it is not clear whether he was culpable or contributory.

4. Contributory/neither - At most, the subject driver was contributory, and he may not have been even that.

5. Neither culpable nor contributory - Driver apparently had no responsibility for the accident; for him, the accident was virtually unavoidable. 
8. Unknown - The report evidence is insufficient to judge culpability.

Note: In some cases, the choice is between one drivervehicle being wholly culpable and the other not at all culpable, but it is unclear which is the culpable driver. These should be coded "unknown." 
This category specifies the vehicle action underlying the coder's judgment of culpability in the previous category. In other words, it is the vehicle action to which the accident is attributable and for which the driver is considered responsible.

The coder is to consider only the vehicle action, and not the driver's behavior nor intentions. Thus, all items in this category specify only observable vehicle actions.

Actions in this category are more descriptive and less abstract than those in Critical Event. Furthermore, the driver may be judged not responsible for the Critical Event, while by definition, the driver is responsible for Culpable Action.

Should more than one of the following items be applicable, select the one which seems most important to you.

As an aid to coding, the items below are organized into subgroups.

\section{Recklessness}

01. Police chase -

Running from police

02. High speed Over speed limit or too fast for conditions

03. High acceleration -

Excessive or erratic acceleration

04. Erratic lane changing -

Cutting in and out of traffic 
Chance-Taking

05. Tailgating -

Following too closely

06. Crossing too close

Crossing directly before oncoming vehicle

07. Turning too close -

Turning directly in front of oncoming vehicle

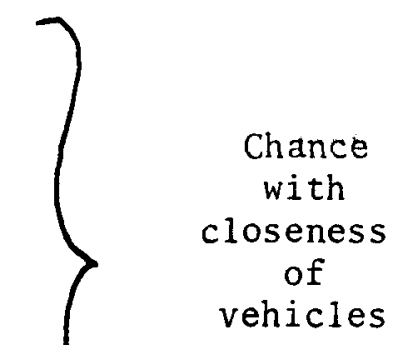

08. Passing too close -

Passing with close oncoming vehicle

09. Proceeding blindly -

Proceed despite view obstruction

10. Passing blindly -

Passing on blind curve/hill

11. Ignore vehicle defect -

Proceed despite vehicle defect (e.g., bald tires; defective windshield wiper; brakes deficient; lights not working)

\section{Illegal \& Dangerous Driving}

12. Disobey no-passing -

Passing in no-passing zone

13. Disobey right-of-way -

Not yielding right-of-way

14. Disobey stop sign/signal -

Disobeying stop sign or sígnal

15. Disobey yellow light -

Failure to stop on yellow, so that vehicle passes through red light

16. Disobeying red light -

Flagrant pass - through as well as premature start-up when green light is imminent

17. Disobeying other sign/signal - 
18. Over centerline

Driving over/on centerline

19. On median

Driving over/on median

20. Wrong way

Driving wrong way on 1-way street or entrance ramp

21. On shoulder

Driving on shoulder

22. Parking lane driving

Driving in parking lane

Obstacle - Presenting

23. Too slow -

Driving too slowly

24. Sudden deceleration

Slowing, braking rapidly and unnecessarily.

25. Dangerous stop -

Stopped in dangerous location (not vehicle breakdown)

26. Dangerous park -:

Parking in dangerous location (not vehicle breakdown)

\section{Lighting/Signalling Misuse}

27. No headlights -

28. No turn signal

Turn without signa 1

29. Misleading signal -

E.g., left turn signal on right turn

30. No hazard lights -

Nonuse of hazard lights 
Other

31. Critical event -

Culpable action was the critical event. To be used only when none of the above items apply.

32. Prior event -

Culpable action was the prior event. To be used only when none of the above items apply.

96. Other

99. Inapplicable Not culpable 


\section{APIPENDICT:S}

AA. Instructions - How to Use the Accident Causal Coding Form

BB. Accident Causal Coding Form

CC. How to Determine Coding Reliability - Accident Causal Coding Scheme 
How to Use the Accident Causal Coding Form

(1) For every question/item, one and only one answer is coded.

(2) Your selected answer is coded by circling its number on the coding form.

(3) The order in which questions are coded is as follows. Beginning with Primary Event (question 1), continue to code each question in the sequence they are listed unless the coding form instructs you to do otherwise. Thus, when there is no special instruction given to the contrary, you will always proceed from one question to the very next one in the sequence. You will be always "moving forward" through the form; instructions will not direct you backward until you reach question 23. That is the end of the "first pass".

(4) If you correctly follow the procedure in (3), the questions you have coded on the first pass will include all the questions with circled question numbers. If you reach question 23 and an answer is not coded for each of the circled questions, you have made a mistake; review your coding to find your error.

(5) As an added cue to direct your coding, double horizontal lines indicate that if you have coded the previous question, the next one is inapplicable and should be skipped in the "first pass".

(6) If you have followed the correct procedure by the time you reach item 23, the only unanswered questions will be those which were inapplicable to the accident sequence as you have judged it. Go back over the form and circle the "inap" answers, which always have a 9 or 99 code. 
(7) All questions should now have one and only one circled answer, except item 24. Circle the code which is your identifying number. The form is then complete. 
APPV:NDTX BB

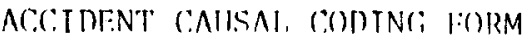

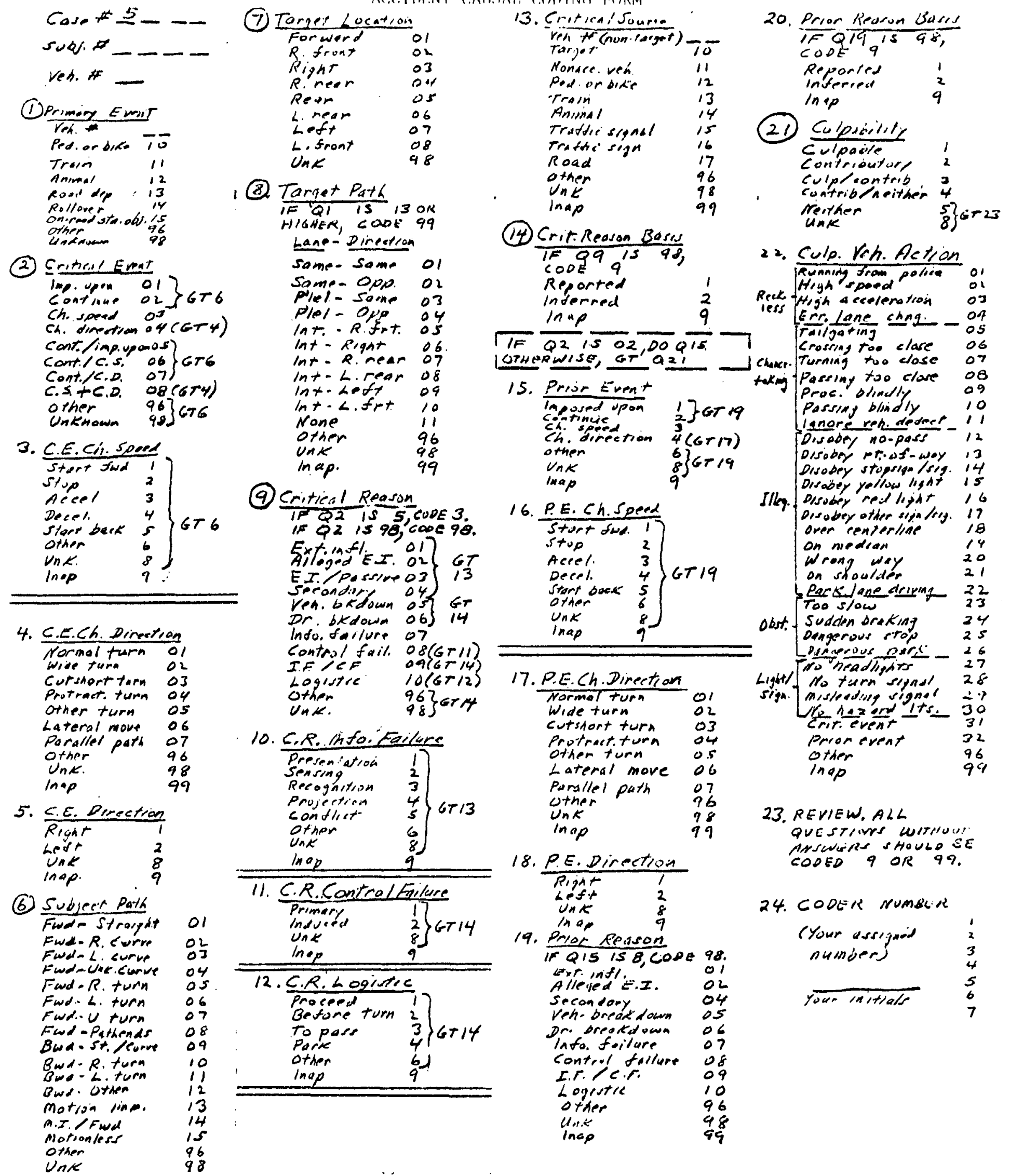

CIRCLES QUESTIONS= ALWATS CODED ON FIRST HOSS

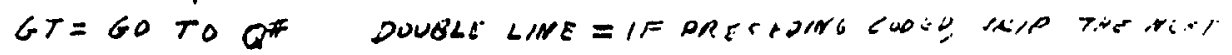

$\mathrm{C}-61$

$12-10-80$

xiv. $2-11-\delta 1$

ZS-5769-V-1 
How to Determine Coding Reliability

Accident Causal Coding Scheme

Coding reliability expresses in numerical form the degree of agreement between two coders in coding the same accident cases.

To assure statistical independence of coding reliability is to be done only on the \#1 (striking) vehicle from each case.

Coding reliability is to be determined (a) for individual categories, and (b) across all relevant categories:

(1) When determining reliability between two coders both using our coding manual, reliability is determined using all the categories;

(2) When determining reliability between one coder using our coding manual and another using Perchonok's original scheme, exclude all categories concerning Prior Event (Prior Event, P.E. Ch. Speed, P.E. Ch. Direction, P.E. Direction, Prior Reason, Prior Reason Basis.) These categories are not comparable across the two systems.

\section{Reliability Within Individual Categories}

When determining the reliability for an individual category use the following formula:

$$
R=
$$

$\frac{2 \text { (\# cases both coders judged applicable and agreed on specific code) }}{\text { (\# cases where coder } 1 \text { judged category applicable) }+} \times 100$ (\# cases where coder 2 judged category applicable)

$$
=\frac{2(A)}{C_{1}+C_{2}} \times 100=\text { Reliability (per cent) }
$$


Exception: For reliability of Critical Reason Basis in regard to Perchonok's "Category", determine reliability only for those cases where both coders considered the category applicable. Use formula [II].

Addition: For the Culpability category, also determine reliability using the Pearson product-moment correlation. Before doing so, however, recode the answers as follows:

$$
\begin{aligned}
\text { Culpable } & =1 \\
\text { Culpable/Contributory } & =2 \\
\text { Contributory } & =3 \\
\text { Contributory/Neither } & =4 \\
\text { Neither } & =5 \\
\text { Unknown } & =6
\end{aligned}
$$

Reliability Across Categories

An overall reliability figure is obtained by summing across all categories. The formula is

$$
R=\frac{2 j_{j}^{\Sigma} A j}{\sum_{j}\left(C_{1 j}+C_{2 j}\right)}
$$

where $j$ is a particular category. The formula simply sums numbers used in the reliabilities for individual categories.

$\underline{\text { Results }}$

For every set of cases used in determining reliability, there will be a reliability figure for each category and an overall reliability figure. These figures will express degrees of agreement between two particular coders. 
APPENDIX D

Programming Rules for the Perchonok Collision Types 


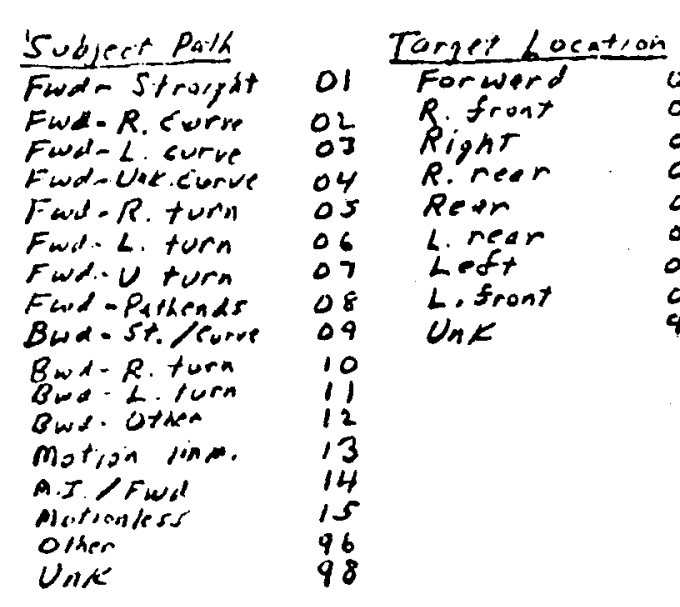

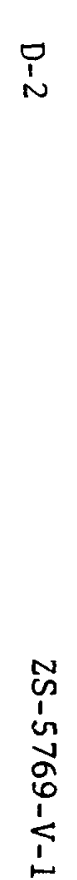

Configuration Designation
1. Class $R$
2. Rear End
3. Stationary Target Ahead
(STA)
4. Intersecting Path-
Continue (IP-C)
5. Intersecting Path -
Start (IP-S)
6. Parallel Opposite -
Lateral Move (PO-LM)
7. Parallel Opposite -
Left Turn (PO-LT)
8. Parallel Same - Lateral
Move (PS-LM)
9. Rearward

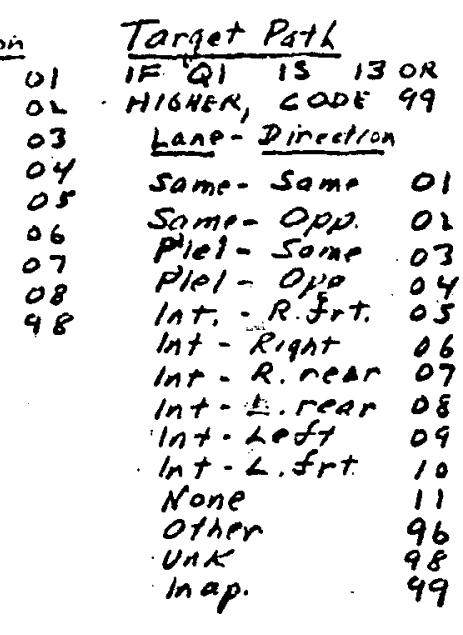

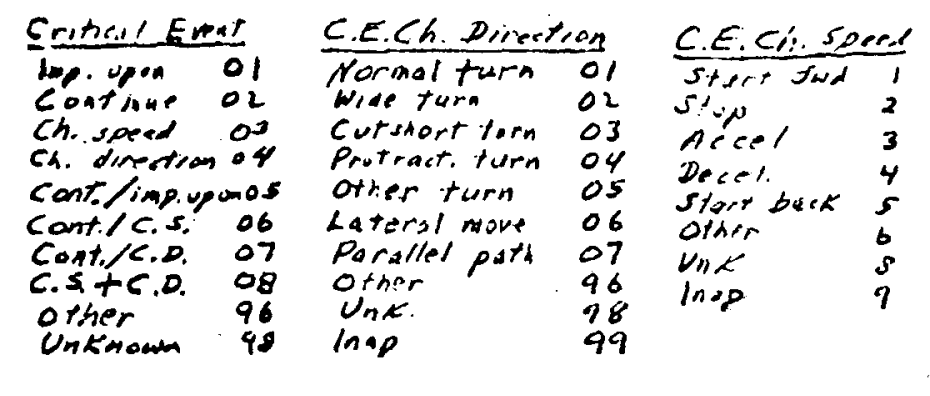

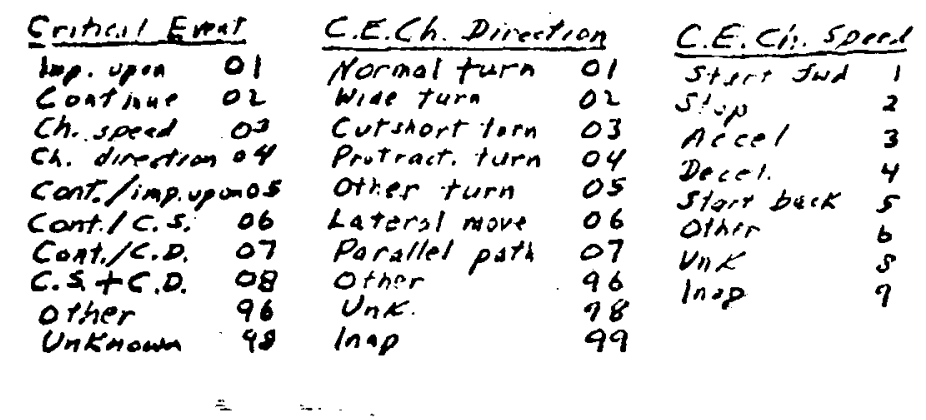

\begin{tabular}{|c|c|c|c|c|c|}
\hline $\begin{array}{c}\text { Subject } \\
\text { Path } \\
\end{array}$ & $\begin{array}{c}\text { Target } \\
\text { Location } \\
\end{array}$ & $\begin{array}{c}\text { Target } \\
\text { Path } \\
\end{array}$ & $\begin{array}{c}\text { Critical } \\
\text { Event } \\
\end{array}$ & $\begin{array}{c}\text { Change } \\
\text { Direction } \\
\end{array}$ & $\begin{array}{l}\text { Change } \\
\text { Speed }\end{array}$ \\
\hline $1,2,3,4$ & 2,8 & 11,99 & 4 & 6 & - \\
\hline $1,2,3,4$ & 1 & 1 & 2 & - & - \\
\hline $1,2,3,4$ & 1 & 11,99 & 2 & - & - \\
\hline $1,2,3,4$ & 2,8 & $5-10$ & 2 & - & - \\
\hline 13 & 2,8 & $5-10$ & 3 & - & 1 \\
\hline $1,2,3,4$ & 8 & 4 & 4 & 6 & - \\
\hline $1,2,3,4$ & 8 & 4 & 4,8 & 1 & - \\
\hline $1,2,3,4$ & $3,4,6,7$ & 3 & 4 & 6 & - \\
\hline$, 10,11,12$ & $4,5,6$ & $5-11,99$ & 2 & - & - \\
\hline
\end{tabular}


APPENDIX F:

\section{Procedures to Increase}

Driver Inclusion

The experience and discussions held on this project led to insights on methods to increase the rate of driver inclusion in studies where blood samples are needed. These insights are conveyed as the following recommendations.

(a) Ideally, use a hospital that routinely obtains blood samples. Hospital reịmbursement systems in Michigan, Texas, Illinois, and Perinsylvania make it more likely that such hospitals will be found there.

(b) If a driver consent is needed:

- Have a member of the research team on standby at or near the hospital(s) used: that individual should be exclusively responsible for asking drivers for a blood , sample.

- Provide copies of letters from the local Police Chief, Mayor, etc. assuring that the blood analyses will not be used to prosecute the driver, and encouraging his cooperation.

- Provide the driver with a signed statement assuring him of the confidentiality of the data.

(c) Well in advance of the data collection, prepare the emergency department staff for the study and solicit their ideas on the ways to make it most effective; if any staff members have major roles in the study, an incentive program or other form of payment should be considered. 
(d) Concentrate on developing the driver recruitment process before starting any other data collection; a pilot phase to do that is recommended.

(e) A menber of the research team should keep. in daily contact with the emergency department staff, with frequent contact of all shifts. Provide positive feedback and solicit suggestions. Do not neglect the night shift, which will be critical to the inclusion of alcohol-involved drivers.

(f) Determine in advance whether the cooperating hospital has any problems which would interfere with the study, such as excessive caseloads, high staff turnover, staff morale problems, etc. If serious, perhaps consider another hospital.

(g) Intrude as little as possible in the normal operations of the emergency department, and convey in advance understanding that medical needs take priority over research needs.

(h) Obtain in advance the endorsement of the hospital administration, including the chief executive, making sure they understand and approve of the research procedures. 
APPENDIX F

Drug Analysis Procedures

Michael A. Peat, Dennis J. Crouch, and Bryan S. Finkle

\author{
Center for Human Toxicology \\ University of Utah \\ Salt Lake City, Utah
}




\section{Analytical Plan:}

For the analytical procedures described below it is necessary that the protocols described be strictly followed. Briefly, these are:

1. Collection of at least $15 \mathrm{mls}$ of blood in the tube provided.

2. Remove $5 \mathrm{ml}$ of blood immediately, centrifuge, collect the plasma and freeze.

3. Shipment of samples to the Center for Human Toxicology by Federal Express.

If this protocol is followed a suitable sample will be available for testing. The analytical scheme to be used must cover three major areas: screening, confirmation of presumptive positives, and quantitation of the drugs detected.

Section A: Volatile compounds.

A GLC-FID screen for ethanol, methanol, acetone, and isopropanol. This procedure is used routinely at CHT.

Section B: Benzodiazepines, trichloroethanol, and ethchlorvynol screen.

1. Benzodiazepines: GLC-ECD will be used to screen for these drugs.

By this procedure the following benzodiazepines will be detected: diazepam, desmethyldiazepam, flurazepam, desalkylflurazepam, chlordiazepoxide, prazepam and flunitrazepam.

2. Trichloroethanol and ethchlorvynol: The extract from the benzodiazepine screen will be used. Sample will be screened on a $10 \%$ SP 1000 using GC-ECD.

Section C: Radioimmunoassay screens. "Abuscreen" radioimmunoassay kits developed and produced by Roche Diagnostics will be used to screen the samples for barbiturates, morphine, codeine and related narcotics, phencyclidine, and cocaine and its metabolites. These procedures are widely used by practicing toxicologists, including those at $\mathrm{CHT}$. 
In addition to using immunoassay for screening for these compounds, plasma samples will be tested for $\Delta^{9}$-tetrahydrocannabinol ( $\Delta^{9}-T H C$ ) using a similar technique.

Section D: Basic drug screen. If a detailed survey of drugs in injured drivers is to be carried out, it is imperative that there be a suitable screening technique for basic drugs. Recent procedures have been published (3) utilizing nitrogen phosphorous detector. Although these workers (Pierce, et al.) quoted a lower limit of $500 \mathrm{ng} / \mathrm{ml}$ for the drugs studied, further work has shown that with an increase in sample size this can be reduced by a factor of approximately five for most drugs.

Section E: : Anticonvulsants, glutethimide, and carbamate screen.

1. Anticonvulsants and glutethimide: These agents will be detected by high pressure liquid chromatography. Recently a procedure for the quantitation of anticonvulsants in serum samples using HPLC has been published (4). This method has been modified for the screening of blood samples to include both this group of drugs and glutethimide.

2. Carbamates: Approximately $25 \%$ of the residue available after HPLC screening will be examined for the carbamates (meprobamate and carisprodol) by thin layer chromatography (TLC). Although a number of workers have used GLC-FID for these compounds, experience at CHT has shown that TLC is a more reliable screening technique avoiding thermal decomposition problems encountered with meprobamate by GLC.

Section F: CNS stimulant screen. As outlined above, RIA will be used to test for cocaine and its metabolites. The remainder of the commoniy encountered stimulants, eg., amphetamine and methamphetamine will be screened by GLC-NPD.

Confirmation of Presumptive Positives

Section B: Benzodiazepines, trichloroethanol and ethchlorovynol.

1. Benzodiazepines: The procedures used to screen for the basic drugs will also detect the commonly encountered benzodiazepines and wi7l, therefore be used as a confirmatory technique in the majority of cases. 
2. Trichloroethanol and ethchlorovynol: Gas chromatographyelectron impact mass spectrometry (GC-EIMS) will be used to confirm these compounds.

Section C: Radioimmunoassay screen. GC-MS will be used to confirm the presence of morphine, codeine, phencyclidine, $\Delta^{9}-T H C$, and cocaine and its metabolites.

The barbiturates will not be confirmed by GC-MS; a combination of HPLC and GLC will be used. The modification of the HPLC procedure developed at CHT resolves the commonly encountered barbiturates from the anticonvulsants and will, therefore, be used to confirm the former. Unfortunately, the HPLC solvent system does not resolve amobarbital from pentobarbital; the residue from the Section $E$ screen will be used to differentiate these drugs.

Section D: Basic drugs. GC-CIMS will be used to confirm any presumptive positives detected in this group. The extract from the NPD screen will be used without further treatment and, in a similar manner to Section $C$, a positive identification made on the basis of retention time and the molecular ion generated, using ammonia as reagent gas. The gas chromatographic column packing used will be $3 \%$ OV-17 on Gas Chrom Q $100-120$.

Section E: Anticonvulsants, glutethimide and carbamates.

1. Anticonvulsants: A GLC-FID procedure will confirm any presumptive positives.

2. Glutethimide and carbamates: GC-EIMS will be used to confirm these compounds and the residue from the Section $E$ screen used, provided no amobarbital or pentobarbital have been detected. If either of these are present, a separate extract will be set up for this confirmation. 
Section F: CNS stimulants. The extract from the GLC-NPD screen will be used to confirm this group of drugs. A GC-CIMS procedure has been developed for this.

Quantitation. The techniques to be used are shown in Table 1. All of the procedures involve the addition of internal standards before extraction. In the GC-CIMS procedures these will be deuterated analogs of the drugs to the quantitated. Each method will meet the necessary sensitivity, accuracy, and precision requirements.

Summary. The analytical scheme detailed above was developed to satisfy certain sensitivity requirements and to minimize sample volume. Table 2 shows the important drug classifications that will be detected and quantitated using this scheme and the sensitivity 1 imits that will be obtained for each classification.

Listed in Table 3 are some drugs that are not included together with the reason for leaving them out of the analytical scheme. Assays are available for most of these drugs; however, the cost in both sample and development time greatiy outweighs any possible benefits. It is for this major reason that these drugs have been excluded. 
Table 1: Quantitation Procedures

\section{Section}

A. 1. Ethanol and related volatiles
Procedure

GLC-FID

Internal Standard

n-propanol

B. 1. Benzodiazepines

GLC-ECD

Flunitrazepam

2. Trichloroethanol

GLC-ECD and ethchlorvynol

C. 1. Barbiturates

HPLC

GLC-NPD

(for amo and pentobarbital)

2. Morphine and codeine

GC-CIMS

Deuterated analogs

3. Phencyclidine

GC-CIMS

Deuterated analogs

4. Cocaine and

GC-CIMS

Deuterated analogs benzoylecgonine

D. Basic drugs

GLC-NPD

SKF-525A, (for

example)

GC-CIMS

(tricyclic antidepressants)

\section{E. Anticonvulsants \\ Glutethimide \\ Carbamates}

F. CNS stimulants
HPLC

HPLC

GLC-FID

GLC-NPD

Propylamphetamine 
Table 2: Drug Classifications and Sensitivity Limits.

\begin{tabular}{|c|c|c|}
\hline Classification & Examples & Sensitivity \\
\hline Volatile compounds & $\begin{array}{c}\text { ethanol, methanol, } \\
\text { ethylene glycol }\end{array}$ & $10 \mathrm{mg} \%$ \\
\hline Benzodiazepines & $\begin{array}{l}\text { diazepam, desmethyldiazepam } \\
\text { desalkylflurazepam }\end{array}$ & $0.05 \mu \mathrm{g} / \mathrm{ml}$ \\
\hline Barbiturates & $\begin{array}{l}\text { amobarbital, pentobarbital } \\
\text { phenobarbital }\end{array}$ & $1.0 \mu \mathrm{g} / \mathrm{ml}$ \\
\hline $\begin{array}{l}\text { Non-barbiturate } \\
\text { sedative hypnotic }\end{array}$ & $\begin{array}{l}\text { trichloroethanol and } \\
\text { ethchlorvynol }\end{array}$ & $1.0 \mu \mathrm{g} / \mathrm{ml}$ \\
\hline & glutethimide & $1.0 \mu \mathrm{g} / \mathrm{ml}$ \\
\hline & meprobamate & $5.0 \mu \mathrm{g} / \mathrm{ml}$ \\
\hline & methaqualone & $0.1 \mu \mathrm{g} / \mathrm{ml}$ \\
\hline Narcotic analgesics & $\begin{array}{l}\text { morphine, codeine } \\
\text { methadone, } \text { LAAM }^{2} \\
\text { meperidine, propoxyphene, } \\
\text { pentazocine }\end{array}$ & $\begin{array}{l}0.025 \mu \mathrm{g} / \mathrm{ml} \\
0.1 \mu \mathrm{g} / \mathrm{ml}\end{array}$ \\
\hline Antidepressants & $\begin{array}{l}\text { amitriptyline, nortriptyline } \\
\text { imipramine, desipramine, } \\
\text { doxepin }\end{array}$ & $0.1 \mu \mathrm{g} / \mathrm{ml}$ \\
\hline Antipsychotics & chlorpromazine, trifluoperazine & $0.1 \mu \mathrm{g} / \mathrm{m} 1$ \\
\hline Antihistamines & $\begin{array}{l}\text { diphenhydramine, } \\
\text { chlorpheniramine }\end{array}$ & $0.1 \mu \mathrm{g} / \mathrm{ml}$ \\
\hline CNS stimulants & $\begin{array}{l}\text { cocaine } \\
\text { amphetamine, methamphetamine }\end{array}$ & $\begin{array}{l}0.025 \mu \mathrm{g} / \mathrm{ml} \\
0.05 \mu \mathrm{g} / \mathrm{ml}\end{array}$ \\
\hline Anesthetic agents & lidocaine & $0.1 \mu \mathrm{g} / \mathrm{ml}$ \\
\hline Anticonvulsants & $\begin{array}{l}\text { phenytoin, phenobarbital } \\
\text { primidone, carbamazepine }\end{array}$ & $1.0 \mu \mathrm{g} / \mathrm{ml}$ \\
\hline "Drugs of abuse" & $\begin{array}{l}\text { phencyclidine } \\
\Delta^{9} \text {-tetrahydrocannabinol }\end{array}$ & $\begin{array}{l}0.012 \mu \mathrm{g} / \mathrm{ml} 1 \\
0.001 \mu \mathrm{g} / \mathrm{m} 7\end{array}$ \\
\hline \multicolumn{3}{|c|}{$\begin{array}{l}\text { The sensitivity limit will depend upon the technique used; for example } \\
\text { RIA is more sensitive than GLC-NPD as a screening technique. } \\
2 \text { If this drug is indicated, then a more sensitive GC-CIMS procedure will } \\
\text { be used. }\end{array}$} \\
\hline
\end{tabular}


Table 3: Drugs That Have Been Omitted.

$\begin{array}{ll}\text { Drug } & \begin{array}{c}\text { Available Anaiytical } \\ \text { Techniques }\end{array}\end{array}$

\begin{tabular}{|c|c|c|}
\hline Methylphenidate & $\begin{array}{l}\text { GC-CIMS (for meta- } \\
\text { bolites) }\end{array}$ & $\begin{array}{l}\text { 1. Extensive metabolism. } \\
\text { 2. Cost of developing assay. } \\
\text { 3. Require extra sample. }\end{array}$ \\
\hline
\end{tabular}

\begin{tabular}{lll}
\hline Antidiabetic & HPLC & 1. A non-routine procedure. \\
agents & 2. Require extra sample. \\
& 3. Cost of developing assay.
\end{tabular}

$\begin{array}{ll}\text { Nicotine GC-CIMS } & \begin{array}{l}\text { Study does not ask the required } \\ \text { questions. }\end{array}\end{array}$

$\begin{array}{ll}\text { Carbon monoxide GLC-FID } & \begin{array}{l}\text { Study does not ask the required } \\ \text { questions. }\end{array}\end{array}$

Haloperidol GLC-ECD An "in-hospital" drug.

\begin{tabular}{lll}
\hline $\begin{array}{l}\text { Phenelzine } \\
\begin{array}{l}\text { Digoxin and } \\
\text { digitoxin }\end{array} \\
\text { RIA }\end{array}$ & Tas been withdrawn fron the market. \\
\hline
\end{tabular}

Lithium AA Test could be arranged.

\begin{tabular}{ll}
\hline Propanolo1 HPLC, GLC-ECD & 1. A non-routine procedure. \\
& 2. Cost of developing assay. \\
& 3. Require extra sample.
\end{tabular}




\section{Key References}

1. B.S. Finkle, K.L. McCloskey, L. Kopjak, and J.M. Carrol1. Toxicological analyses in cases of sudden infant death: A national feasibility study. J. of For. Sci. In press.

2. M.A. Peat and L. Kopjak. The screening and quantitation of diazepam, flurazepam, chlordiazepoxide and their metabolites in blood and plasma by electron capture gas chromatography and high pressure liquid chromatography. J. of For. Sci. 24:46-57, 1979.

3. W.O. Pierce, T.C. Lamoreaux, F.M. Urry, L. Kopjak, and B.S. Finkle. A new, rapid gas chromatogrpahy method for the detection of basic drugs in postmortem blood using a nitrogen phosphorous detector. Part1. Qualitative analysis. J. of Ana 1. Tox. 2:26-31, 1978.

4. R.F. Adams, G.J. Schmidt, and F.L. Vandemark. A micro liquid chromatography procedure for twelve anticonvulsants and some of their metabolites. J. of Chromat. 145:275-284, 1978. (Biomedical Applications)

5. L. Kopjak, T.C. Lamoreaux, W.0. Pierce, F.M. Urry, and B.S. Finkle. A new, rapid gas chromatography method for the detection of basic drugs in postmortem blood using a nitrogen phosphorous detector. Part II. Quantitative analysis. J. of Anal. Tox. In press.

6. D. Chinn, T. Jennison, D. Crouch, M.A. Peat, and G.W. Thatcher. Gas chromatographic chemical ionization mass spectrometric analys is of the tricyclic antidepressants. Submitted to $C l i n$. Chem.

7. R.L. Foltz, A.F. Fentiman, Jr., and R.B. Foltz. GC/MS assays for abused drugs in body fluids. 1980.

8. D.M. Chinn, D.J. Crouch, M.A. Peat, B.S. Finkle and T.A. Jennison: Gas chromatography-chemical ionization mass spectrometry of cocaine and its metabolites in biological fluids. J. of Anal. Tox. 4:37-42, 1980. 


\section{APPENDIX G}

Special Rules for Identifying Certain Parent Drugs and

Drug Groups 


\section{Programming Rules for Parent Drugs and Drug Groups}

Special rules were programmed for the identification of certain parent drugs, based on the substances actually found in the blood samples. They are not intended to be more generally applicable. The rules were as follows :

1. Chlordiazepoxide
a. Presence of CHLORDIAZEPOXIDE = presence of:
chlordiazepoxide or desmethylchlordiazepoxide or demoxepam.
b. Absence of CHLORDIAZEPOXIDE = absence of:
all above three drugs.
c. Else, CHLORDIAZEPOXIDE presence is unknown.

2. Chlordiazepoxide/Diazepam/Chlorazepate/Prazepam (C/D/C/P)
a. Presence of $\mathrm{C} / \mathrm{D} / \mathrm{C} / \mathrm{P}=$
presence of: desmethyldiazepam
and
absence of: chlordiazepoxide and diazepam
b. Unknown presence of $C / D / C / P=$ unknown presence of:
all above three drugs.
c. Else, $C / D / C / P$ is absent.

The special rules for identifying drug groups are as follows:

1. Analgesics
a. Presence of ANALGESIC group = presence of: codeine or propoxyphene.
b. Absence of ANALGESIC group = absence of: both drugs above.
c. E1se, ANALGESIC group presence is unknown.

2. Anticonvulsants
a. Presence of ANTICONVULSANT group = presence of:
carbamazepine or phenobarbital or phenytoin.
b. Absence of ANTICONVULSANT group $=$ absence of:
a11 above three drugs.
c. Else, ANTICONVULSANT group presence is unknown. 


\section{Sedative-hypnotics}

a. Presence of SEDATIVE-HYPNOTIC group = presence of:

amobarbital or butalbital or desalkylflurazepam or meprobamate or methaqualone or secobarbital or trichlorethanol.

b. Absence of SEDATIVE-HYPNOTIC group = absence of:

all above seven drugs.

c. Else, SEDATIVE-HYPNOTIC group presence is unknown.

\section{Tranquilizers}

a. Presence of TRANQUILIZER group = presence of:

chlordiazepoxide or demoxepam or desmethylchlordiazepoxide or desmethyldiazepam or diazepam.

b. Absence of TRANQUILIZER group = absence of:

all above five drugs.

c. Else, TRANQUILIZER group presence is unknown. 
APPENDIX $\mathrm{H}$

Data Code Sheets

$\mathrm{H}-1$

2S-5769-V-1 
ACCNENT CTUSAL LaOWA FORM

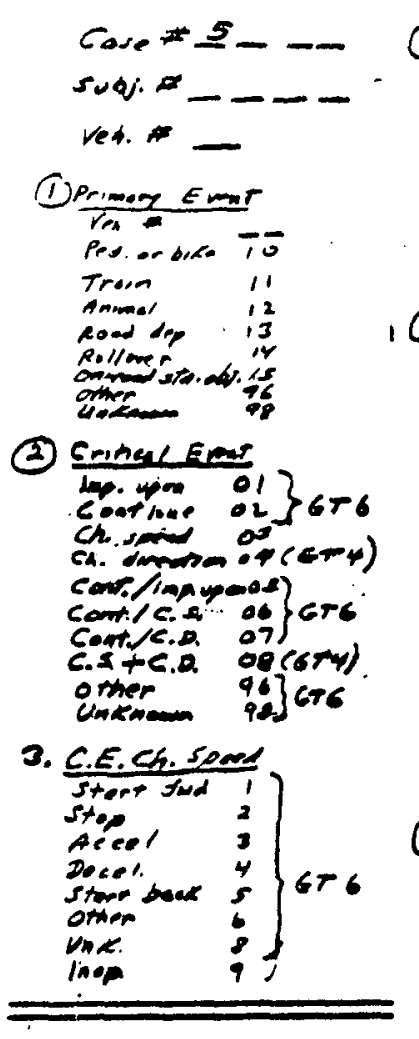

4. Cis.Ch. Diverion Toroal turn ol Nove tume of Cursiomptim os Curshomptirn o3 other turm os Lateral mow of Piralled pats o7 ortar $\lim _{\ln \rightarrow \infty}$

\section{(9)}

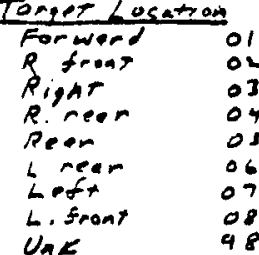

(d) Target Path IF Q1 13 is on Hiswer, cooe 99

sem- semer of

spme- Opa or

Mrod- som ol

Plpl-or :4

lat. - R.Frt :s

lat - Rigar is

Inr - R. near of

intikiferer of

inte sofer of

vane : ii

vex

in ap.

96

Sritical Reoson

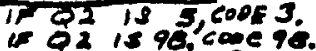
$5 \times 1$.ncl 017 Axtinged Es. or 67 EI. Pasen of 13 specondey of 4 rea. breman of in Pri. defluma of contal fail

IE Pes beqistic 10(6512) Otham. 96$\}$ Gror

10. G. R Info. Filuee

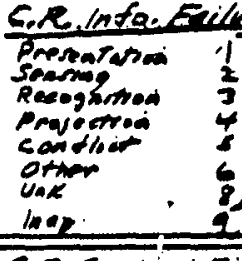

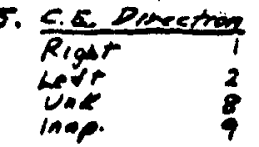

6) Subject Antk Fund straoglo 01 Pude- R. Com Fud- L. Surve Fudacion Cume Fand - R. Turn Fud. L. Aura Fwd. U turn Fud - Pltomds Bud - Str. lewe Bud-R. twrm Ourd. orm motion indo. A.I. Find morimiess Orther 98

CIRCLED QUESTIONS= ALWATS CQOEA ON FIRST PASS

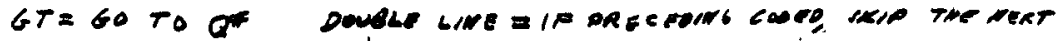

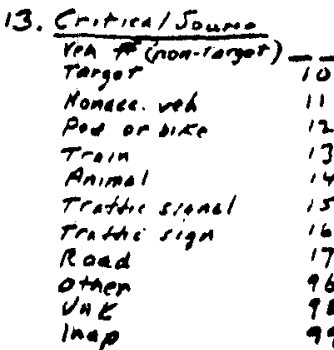

10
11
12
13
14
15
16
17
96
18
99

20. Prom Rearon Bases

Reported

insior.ed 9

(21) Supuititis

Conipudere !

cuipliantris,

cuatribolaciones \&

restien $\quad$ s\}aren

(14) Critrkewin Bards

$\operatorname{Tim}_{\cos 9} 9^{15} 94$

24 Culp. Vh. Actian Fuanty Jrom pectican of Reporred
laterred
lacp lorwerwese or ane

15. Prier Ermt

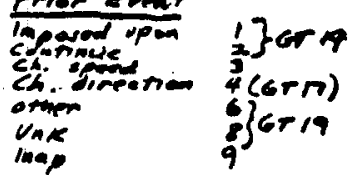

16. P. E. Ch. Spend stort dim. Stup Acelel. Decel.

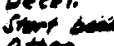
Sace linep

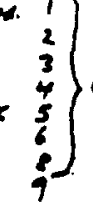

17. P.E.Ch. Dimeetion Wrice turn of of curtuert turA o3 protreartion on otwen tuan hatreal mave Panullel parth other Unte anderas

ies tur jA a coolemotmin of

res Ger.lene cang. - of croseng 70 elare of chmo. Tuming the clase of

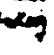
Pree. aliaidy Passias bladiy lengre not dow 11 Dosaby a-pass - 12

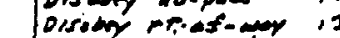

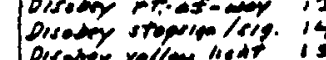

IIL. Arsody red ligdt 16 oisator ether sepaten. 19 omer rearer hio an mededen. Wroug wey

encenedrume 22

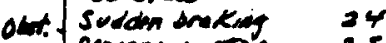
Dangerous rrop 25

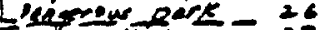

culy. rinediptior - 27

sign. 28 mistoeding riged 29 ce 147 and $1+30$ pmonemat 32 other

latp

23. RFVIEW. ALL

QVESTIUN wirmu ur

answower smovts

18. P E. Direction Ripar I Lete vace

19. Pyor fiason if Q15 158,0000 onrindl. Allewd $z . x$. secondory ven-buteledan

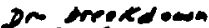
lafo. foilure contrel farlure of E.F. The oq Logerte other Under cosfo 9 or 99.

24. coper rumara

CYour essigon numbers

rout inthats 96

99

10.
01
02
04
05
06
07
08
09
10
96
98
99

$12-10-80$

Riv. $2-11-8$

ZS-5769-V-1 


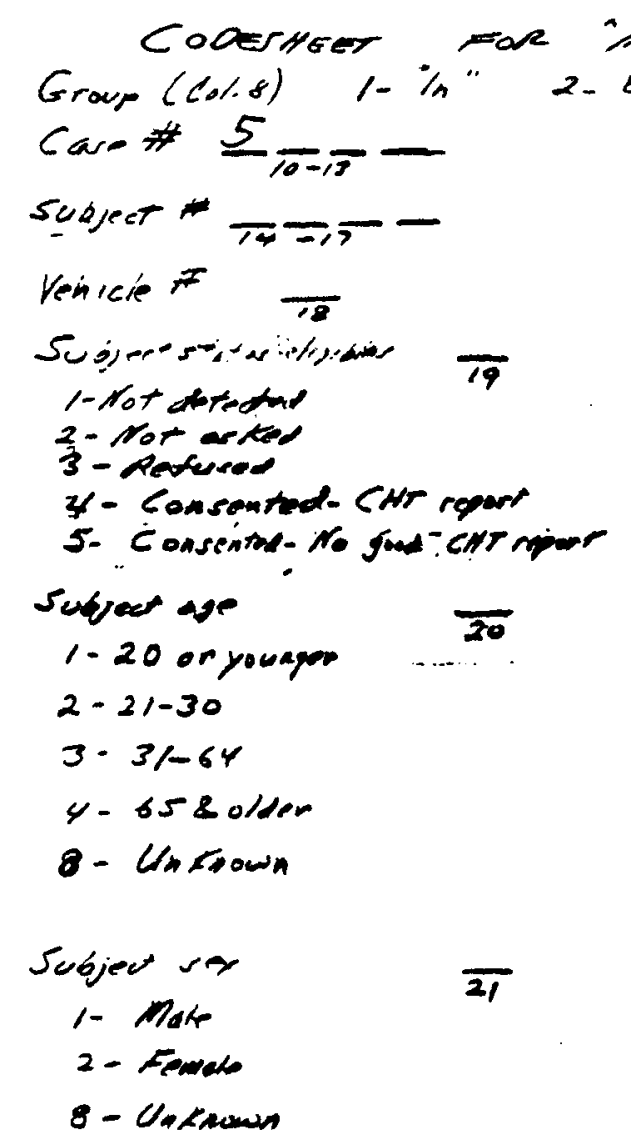

Time of dy

1. bziol Am-zi00 am

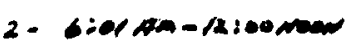

3 - 12:01 m - 6:00 PA

4. 16:01 $\mathrm{mm}-12=00 \mathrm{~m} / \mathrm{ar}$.

8- Uatriand

$\overline{22}$
Subject's redicate type 1- Auto
2-Preferp, rea, wieldy vor.
3 - monim/lawe truck
$4 x-$ moraceyde
- Order
8- Unkpoma

$\overline{25}$

Accideat type

(see guidester)

$$
\begin{aligned}
& \text { "ours Cumperon - ADDE,R }
\end{aligned}
$$

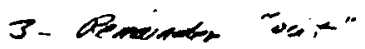

$$
\begin{aligned}
& \text { Cupoobiley (as in cousel cuding) } \frac{}{47} \\
& \text { 1- Coipsile }
\end{aligned}
$$

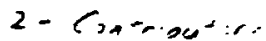

$$
\begin{aligned}
& \text { 3- Calp lcontis; } \\
& \text { 4. Contrib. /nertan. } \\
& 5 \text { - Meithen } \\
& 8 \text { - Untrowan }
\end{aligned}
$$

Roadway type for subiest path * $\frac{}{28 .-4}$

$$
\begin{aligned}
& 01 \text {-Linuted ecears } \\
& 02 \text {-Other dinided } \\
& \text { O3-Other mattilear (>2) } \\
& \text { roaduay; 2-cury } \\
& \text { 0.4-2 tawe, 2-woy rood }
\end{aligned}
$$

os - One-way roed

06. Road, type waknom

07 - Drireway /alley

of. Panking lot

09 - Raw

48 - Undeacan.

Polrereradicioted alcodol involuemert $\overline{30}$

$$
\begin{aligned}
& 1 \text { - Ner } \\
& 2-N o \\
& 8 \text { - Unkaown }
\end{aligned}
$$

Eenroosentel typ (See guedentery)

$$
\begin{aligned}
& \text { 1- Urbea } \\
& \text { 2- Sobarban } \\
& 3 \text { - Pural } \\
& 8 \text { - Uaknown }
\end{aligned}
$$

$\overline{31}$

Coder namber

$\overline{32}$

Your metsib:

*Is turn, rodwey subpex wer

tarning from 


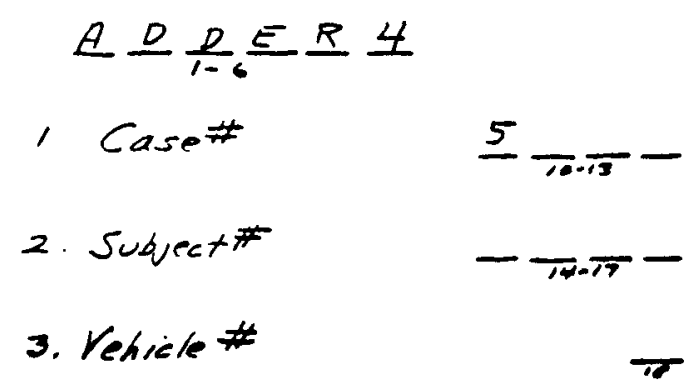

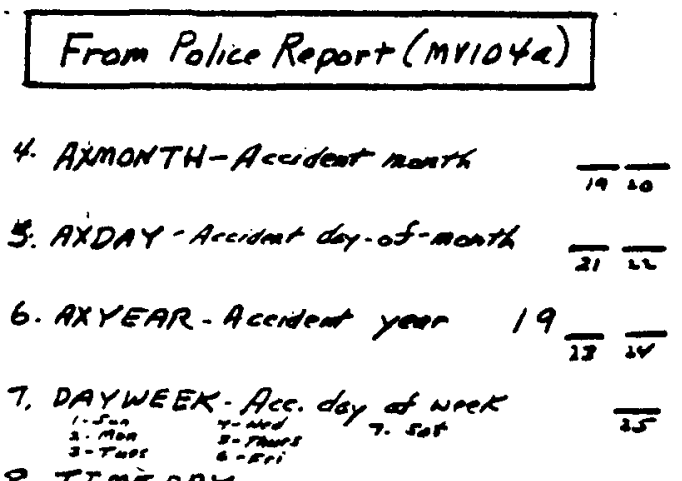

8. TIME DAY

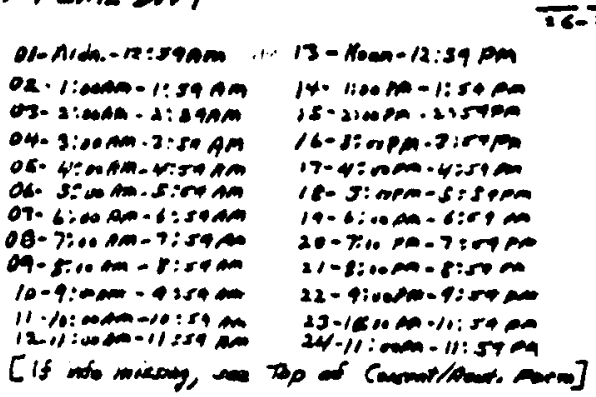

9. Nrancles- Ho.reticks in ace.

10. NOREVERS-No.drimers in ece.

11. SUGJMOB - Subj. no. of birk

12. SUBJDOB - subj: dy of birt T.

13. suBJyOB-sudv. yr. at binth $19 \overline{34.28}$

14. $(0 \leq 6<-00)$

76.77
15. ROADCON (BOX S Of MYIOXA)

$$
\begin{aligned}
& \text { 1-Dry 4-snowlice } \\
& \text { 2- Wet 5. Sinsin } \\
& \text { 3-muddy 7-otner }
\end{aligned}
$$

16. WeATHER (Bow 7 of mvioka)

1- Clemen 5. Sleet/hail/trme.rman

Not 10!

2- Cloudy 6-Fag/smog/smake

3- Rem

7 - othen

4. Snaw

[IS no Mrlokn, conmert code from

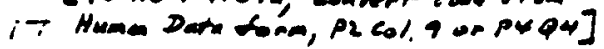

17. Ax<DCATX-Cxy, tom village Caidel of mvidxa. Soe cuive for coder.)

\section{$\overline{39}$}

Not 10!

उ9

From Furiranmentel Form (E.E)

12. Intsetr (Pl, cal. 7)

1- Mon-intonsection (N.Z.)

Not $9 !$

2- N.T., drinumy rolated

$3-N .3 .$, alley noleres

4. Intrweetion

5- intersection- relater

[ if ne F.F., ar coded 9 an E.F., noter. to mriokd midrection. See Guide.]

19. LIGATSTG (P.1, Col. 9)

Not 9!

1- Deytine aceident

2- Ligited

3-Intenearian ligatrog and

4- Hot ligdtod

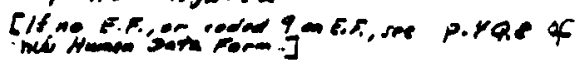

20. HORALYN - Homizontal aliganar

$\left(P_{2}\right.$, col. $4 A 43$, ace. to rehicte $\left.\#\right)$

40. $\frac{}{41}$

1. Straiget

2. Curve loot

3. Cunve rigdt

8- Unkinum

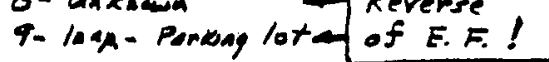

[if ha E.F., on coded $q$ on E.F., refex to Mrioya dereription. See Guide. ] 
Cowbuation Miscellowous Dore Coling Form - MDDER

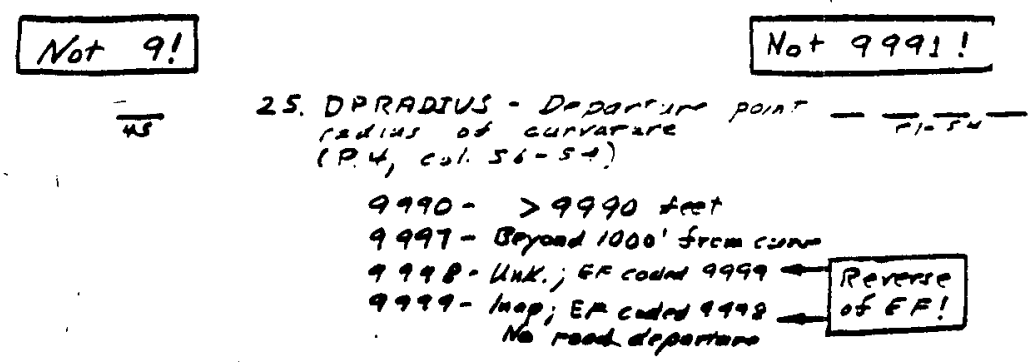

[If no E.F. or eoded 9 on E. F.,

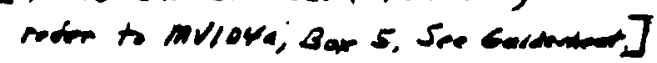

21. VRTALYN - Vertical alignment

(P. 2, cul. 4.4-46, ace. to venicle \#)

1. Level $(<2 \%$ grade)

2-Upgrade

3-Dowagrade

4- Crest of hill

5-Sag at hill bottom

\section{Not $1 !$}

22 DPDIRCTN - Roed dyetore diroution $(P, 3, \mathrm{Col}$ a 9$)$

$\overline{76}$

2- Letet side

3- Ripdr ride

8- Unthom (EF- a)

9- $\lim (\varepsilon,-1) ; n$

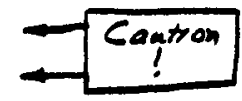

[If noE.F., refer to Mrlova. Sne Guide.]

23. DEPANGLE-Departure lagte

(P.3, C०/. 32- 37)

$\overline{-10}$

$91->10^{\circ}$

98. Uaknamon/to E.F.

99. laqp.; to road deportwe - of EF!

99. Map.jito road deportwe L of E...

24. DPDISTNC - Deanrame parer

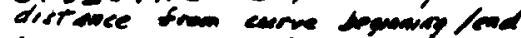

(P. 3 cod. $3(-39)$

$02-0-200$ dont

03. $201-400$ At.

04. 401-600 \&4.

$05.601-800$ st.

$06-101-1000$ -

$07-1000+24$.

91 - No withen 0.5 miller

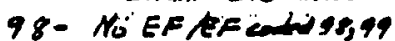

99 . MQP; EF $=01$

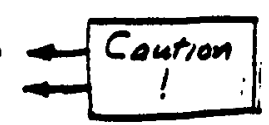

From Integrative Report 26. INVSPEED - Invertigator-estindted
spopd of sudjeet nohicle. (P.2)

01- Stopped lported

02-90. Actial speed

91 - More then $90 \mathrm{mpd}$

\section{From Human Data Form*}

27 DVRSPEGO-Drime-artiveted

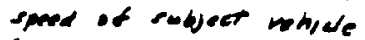
(.P. sed.2503; 44 Q13)

Kor $99 !$ 01- rropand/pertind

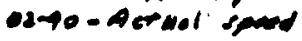
91- mone than bood

$\overline{19}-\overline{80} \cdots$

28. TAAFDENS- Trout dmeity (ino form only; $P$ Y Q w)

Not 11 or 99 !

1- No other wdictir

2. Light tractic

3-moderate trateici

Y- Heary trostre

5- Bumper to- duaper

7. Other

[If no new tha form, See integ.

Repeno. :R, Part A.]

-7.<smiles>[3H][3H]</smiles>

27. DPVEXPER - Driming experience
( $A$ T Ad. 15-16, P.5 Q 19 )
O1- One manth or les
ax- > Imo $\leq 3 \mathrm{ma}$.
03- > $3 \mathrm{~mol}^{\circ} \leq 6 \mathrm{mo}$.
04. > 1 mo. $\leqslant 1$ yeer
05. $>1$ yre $\leq 2$ years
$06 .>2$ yrs $\leqslant 3$ years
$07 .>3$ yrs $\leq 5$ yeurs
$08 .>5$ yrs. $\leq 10$ years
$10 .>10$ years

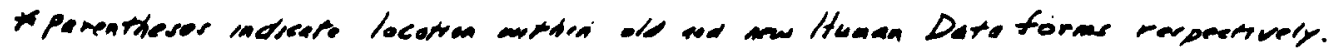


Contincearion - Misenllaneous Dato COdin FOrm - ADDER

$$
\text { Not } 9 !
$$

30. AnYMEU's (P.4 Cal.33; 1.6920$) \quad \frac{1}{62}$
- Yes

$2-N_{0}$

31$. TYMDREKK (P.96.147; .6928$)$

01 - Withm $0.5 \mathrm{An}$ of Ceceldow $\overline{c 3} \cdot \overline{\mathrm{Cr}}$

$02 .>0.5 \mathrm{hr} \leq 1 \mathrm{hr}$.

$03->1 \mathrm{hr} \leqslant 2 \mathrm{hr}$

04. > 2 hr. $\leq$ s hr

$05->3 \mathrm{hr} . \leqslant 4 \mathrm{hr}$.

$06 .>4 h r .5 \mathrm{hr}$.

$07 .>5$ Ar

98- Unktanatho H. D. form

94- $\ln a p(\theta$ an H.D. form)

os - Aftir acaidert

32. RECRDRUG (P.9 C01.48.57; P.6Q29.32)

O- None

1- Marijuena, by itrelt or in

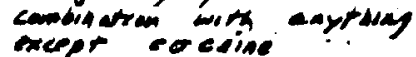

2. Cocasive; by itrels... in combenesson' unta captom eresper manijusua

3- Marijuena + cocorose (t eny ether substaece)

7- Any etter drug on ? areg condiantrom

8- Un kacaun 7 Revense

1. Inap Of H.A.F!!

\section{From Hospital on Poluee Records}

33. BACALT - Podice /Anppita/. promided

$B A C$. (It botx, we ervenge)

98 - Not provided

$0 \cdot \frac{-6.67}{60}$ 
APPENDIX I

Circumstance Variables for SUBSAMPL Groups 
TABLE I-1 - - AGE GROUP BY SUBSAMPL

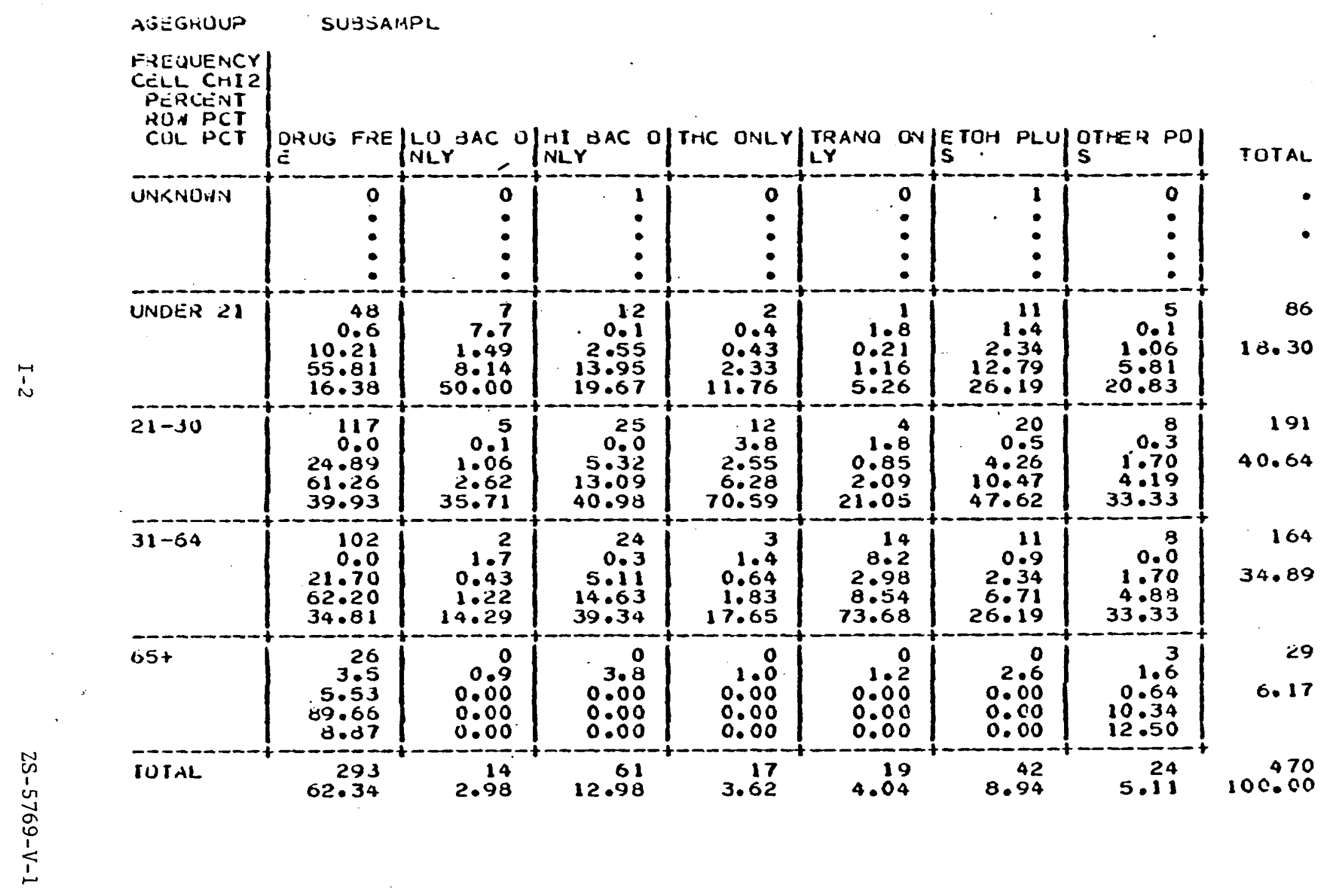


TABLE 1-2 - ENVIRONMENT BY SUBSAN!PL

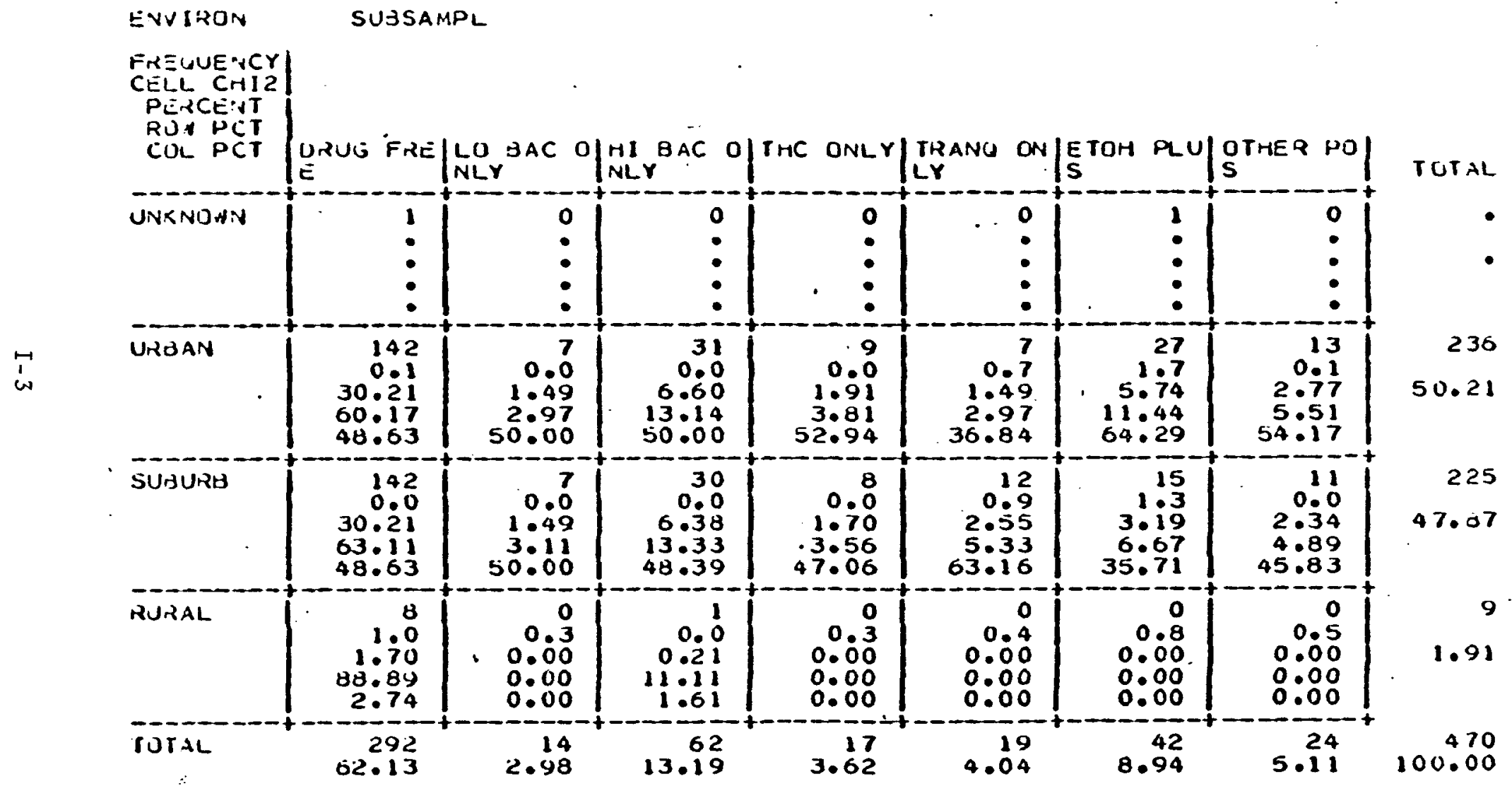


TABLE I-3. - HORIZONTAL ALIGNMENT BY SUBSAMPL

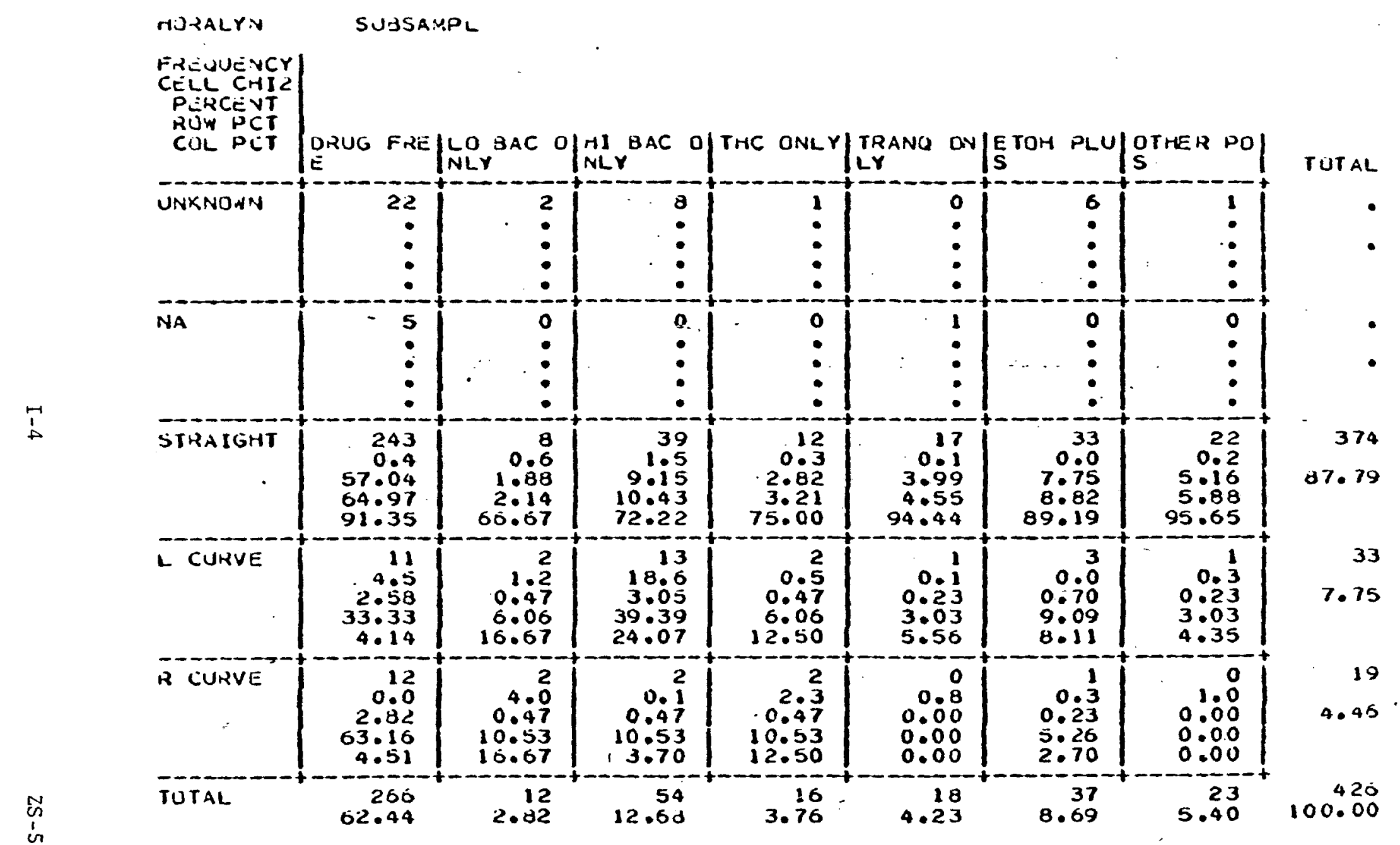


TABLE I-4 - LIGHTING BY SUBSAMPL

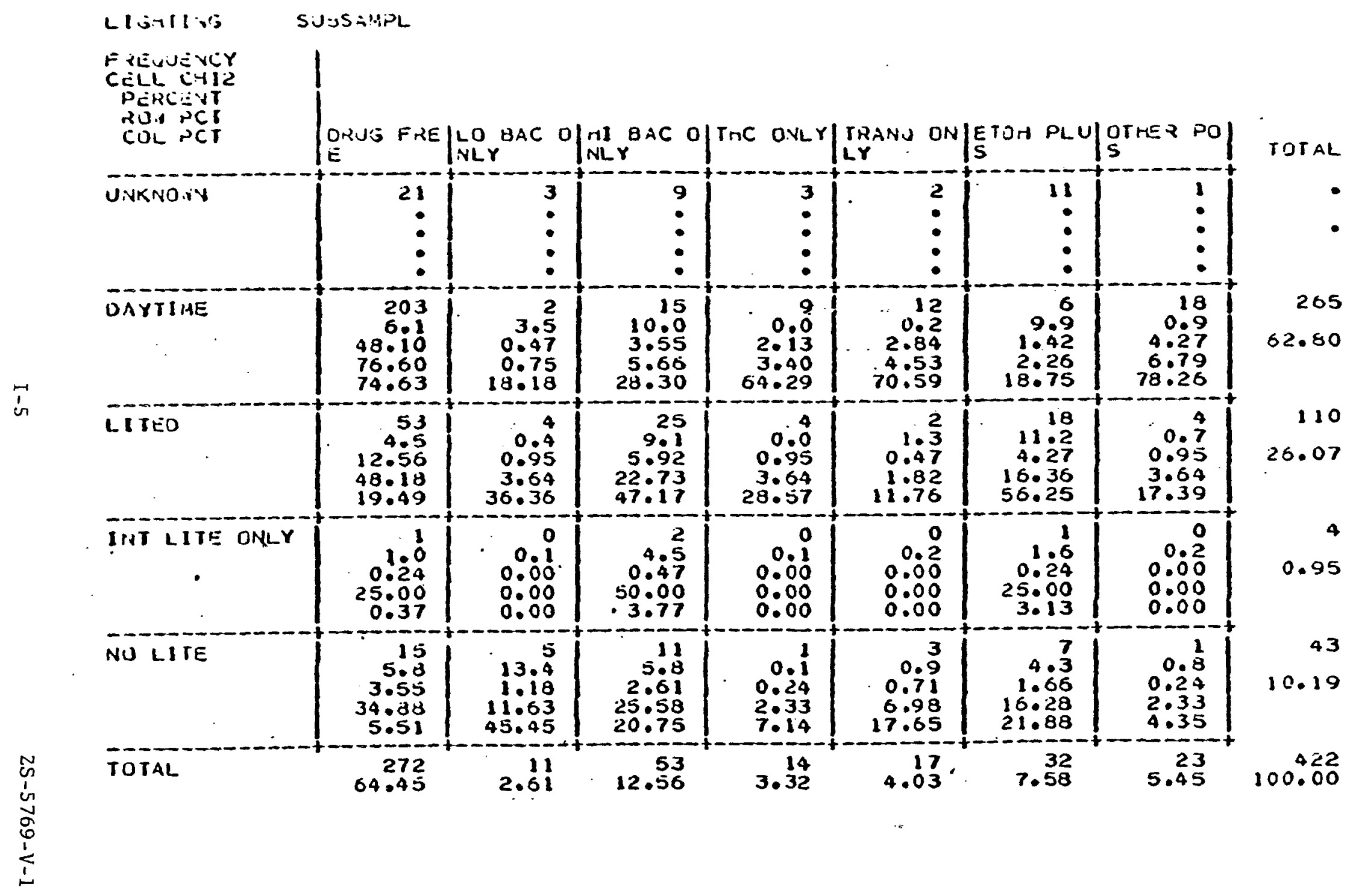


TABLE I -5. - ROAD CONDITION BY SUBSAMPL

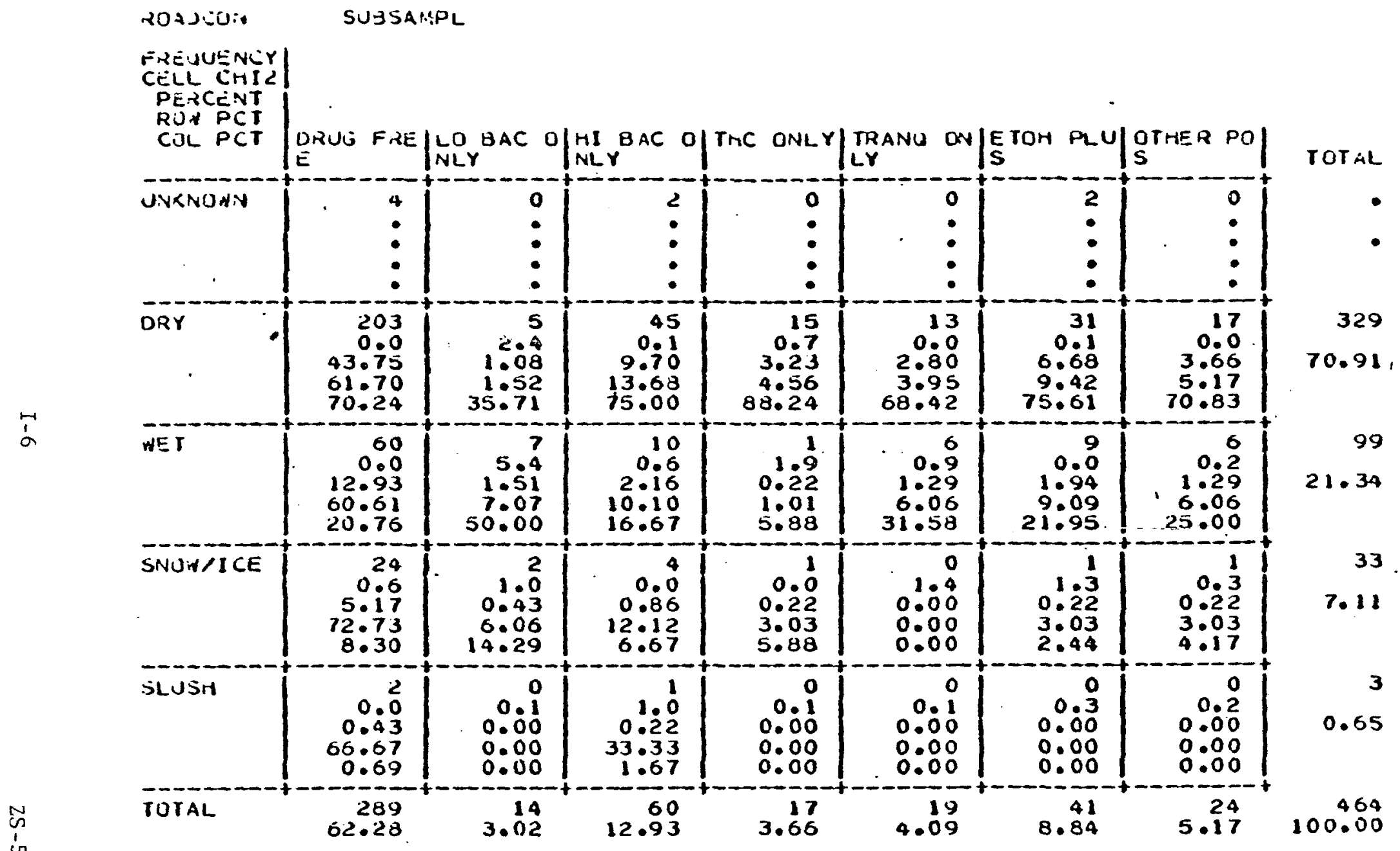


TABLE I-6. - ROAD SECTION BY SUBSAMPL

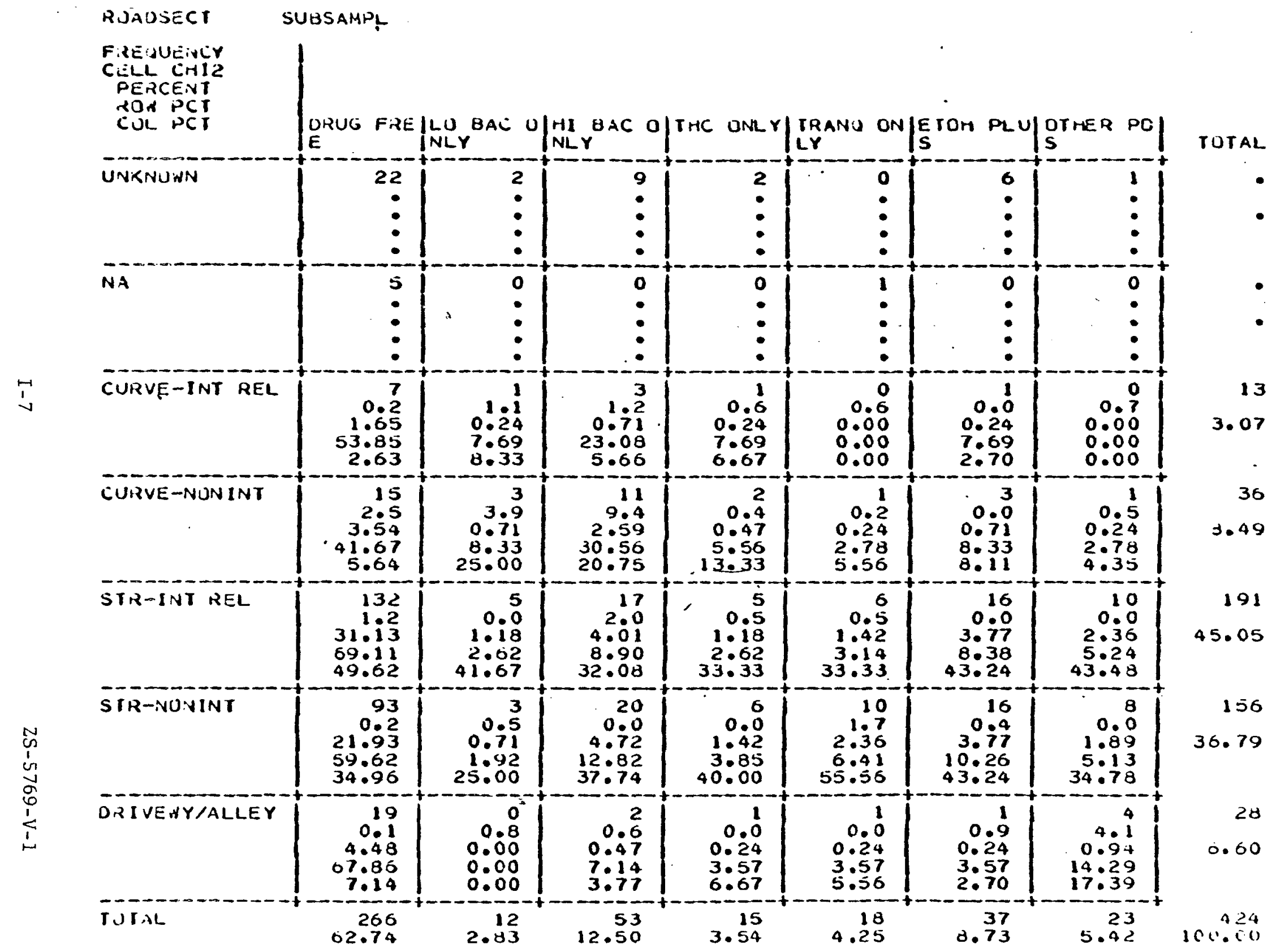


TABLE I - 7. - ROAD TYPE BY SUBSAMPL

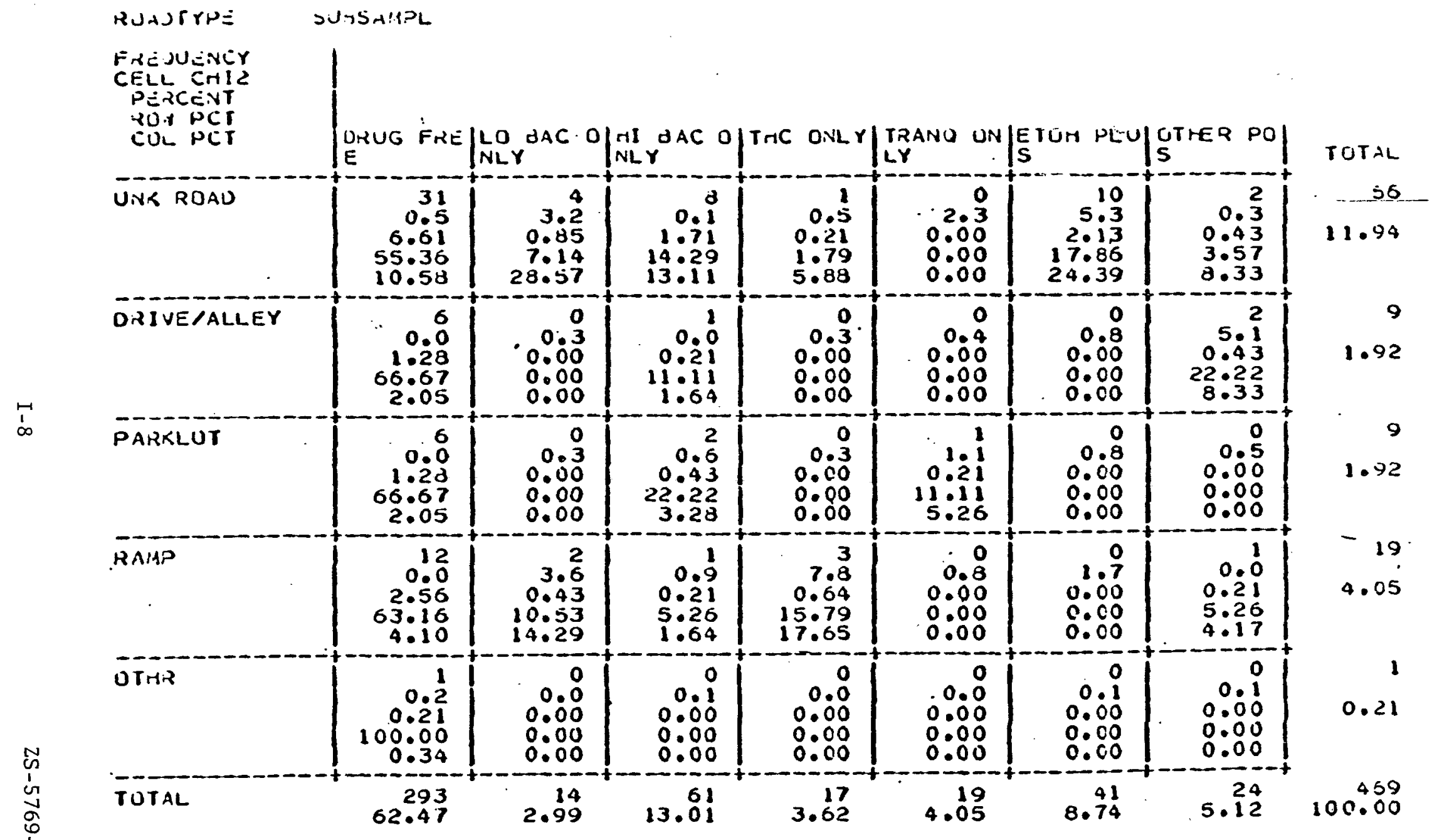


TABLE I - 7. - (CONTINUED)

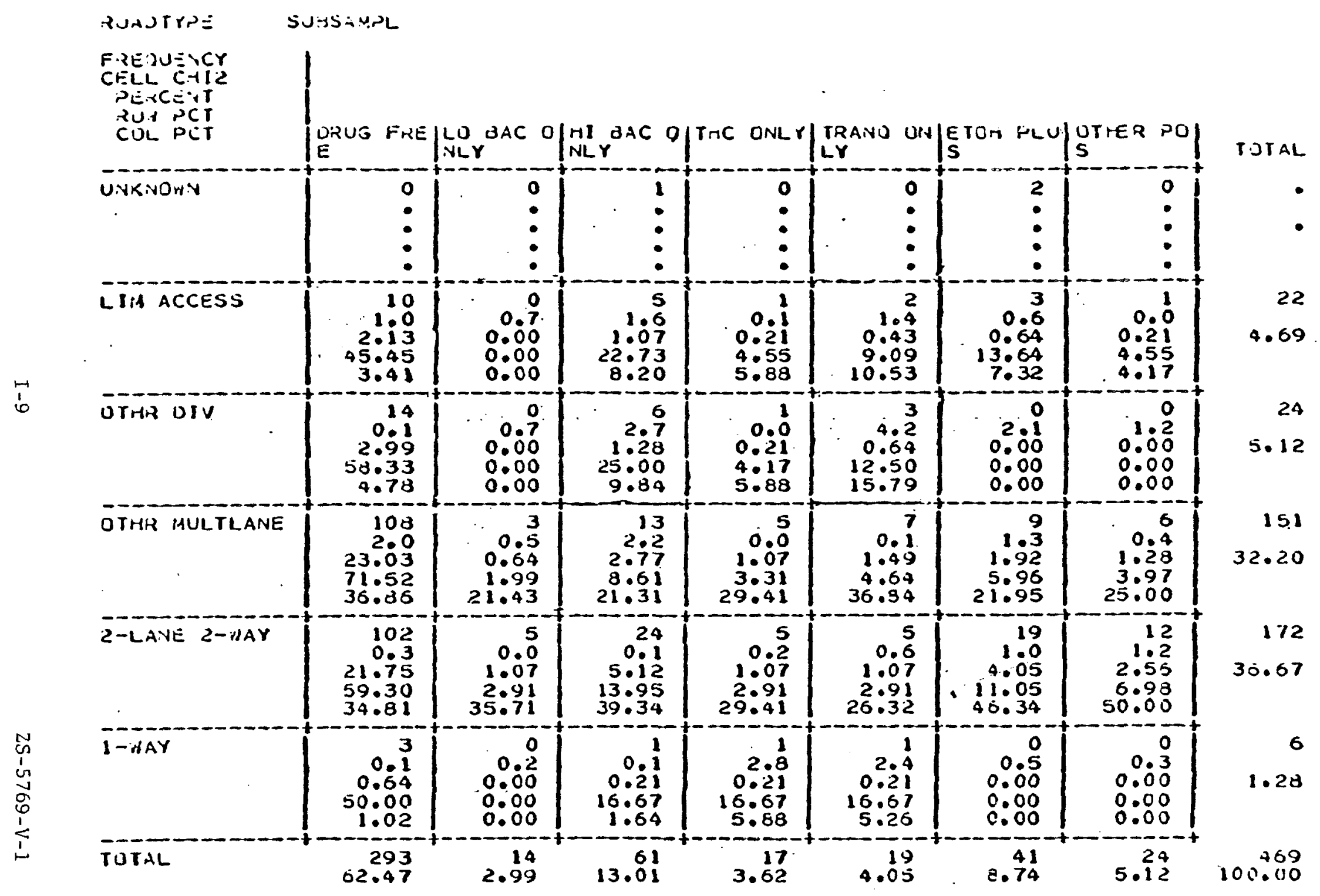


TABLE I-8. - SEASON BY SUBSAMPL

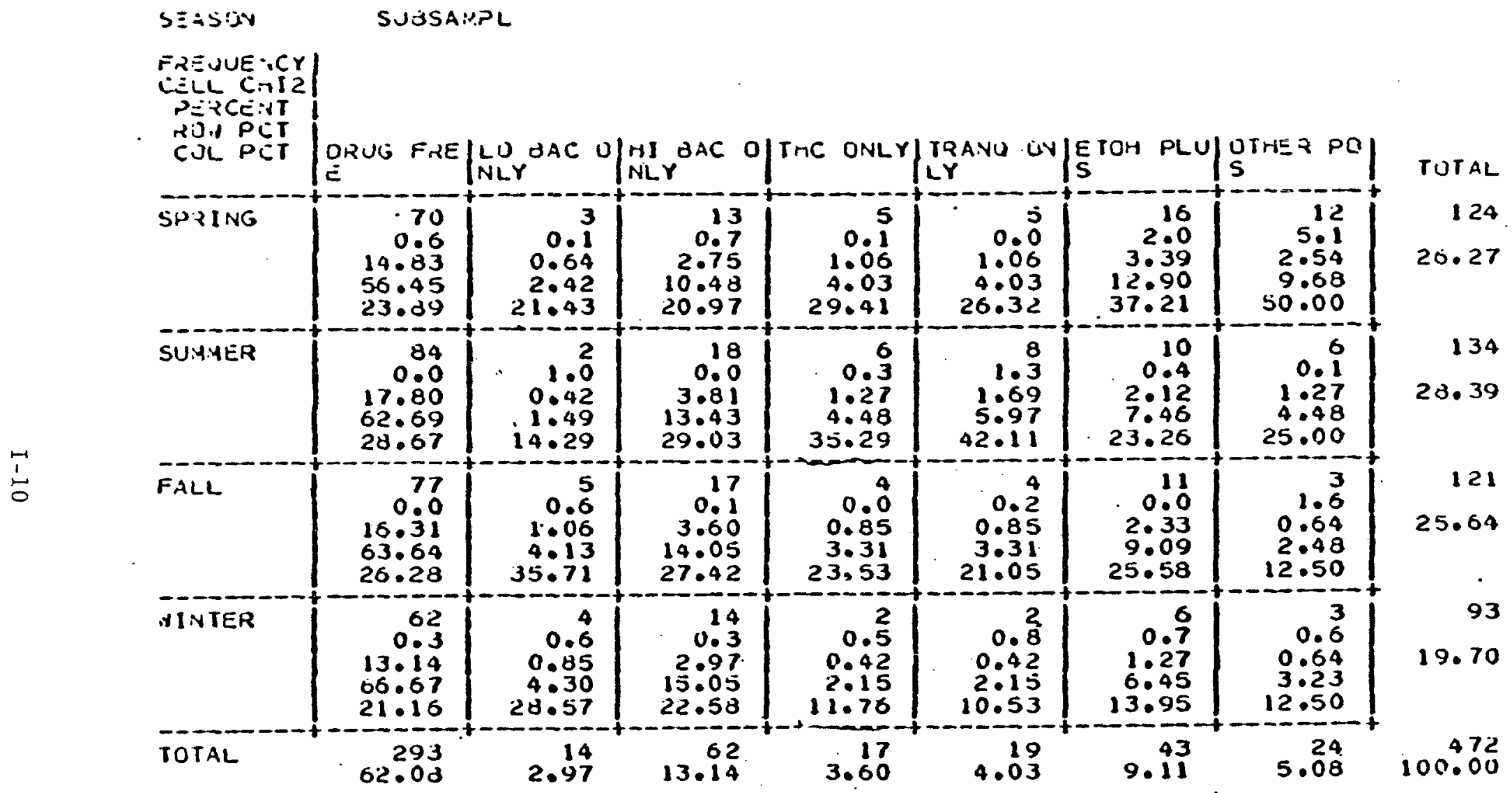


TABLE I-9. - SEX BY SUBSAMPL

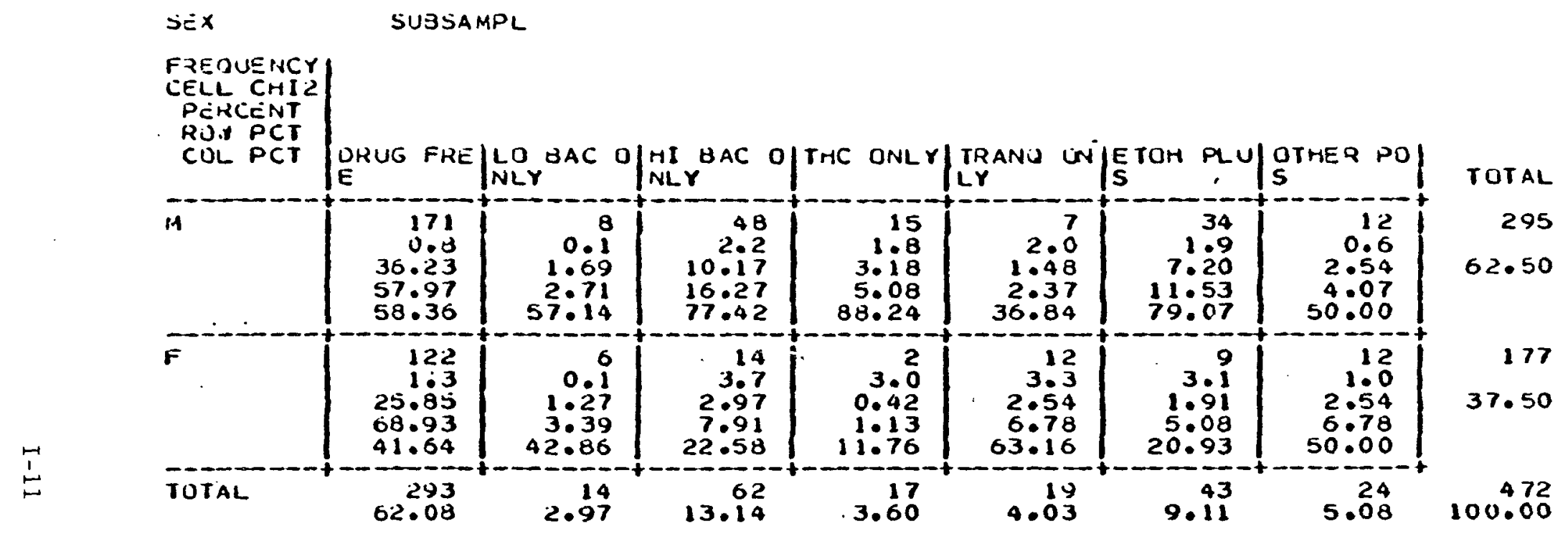


TABLE I-10. - TIME OF DAY BY SUBSAMPL

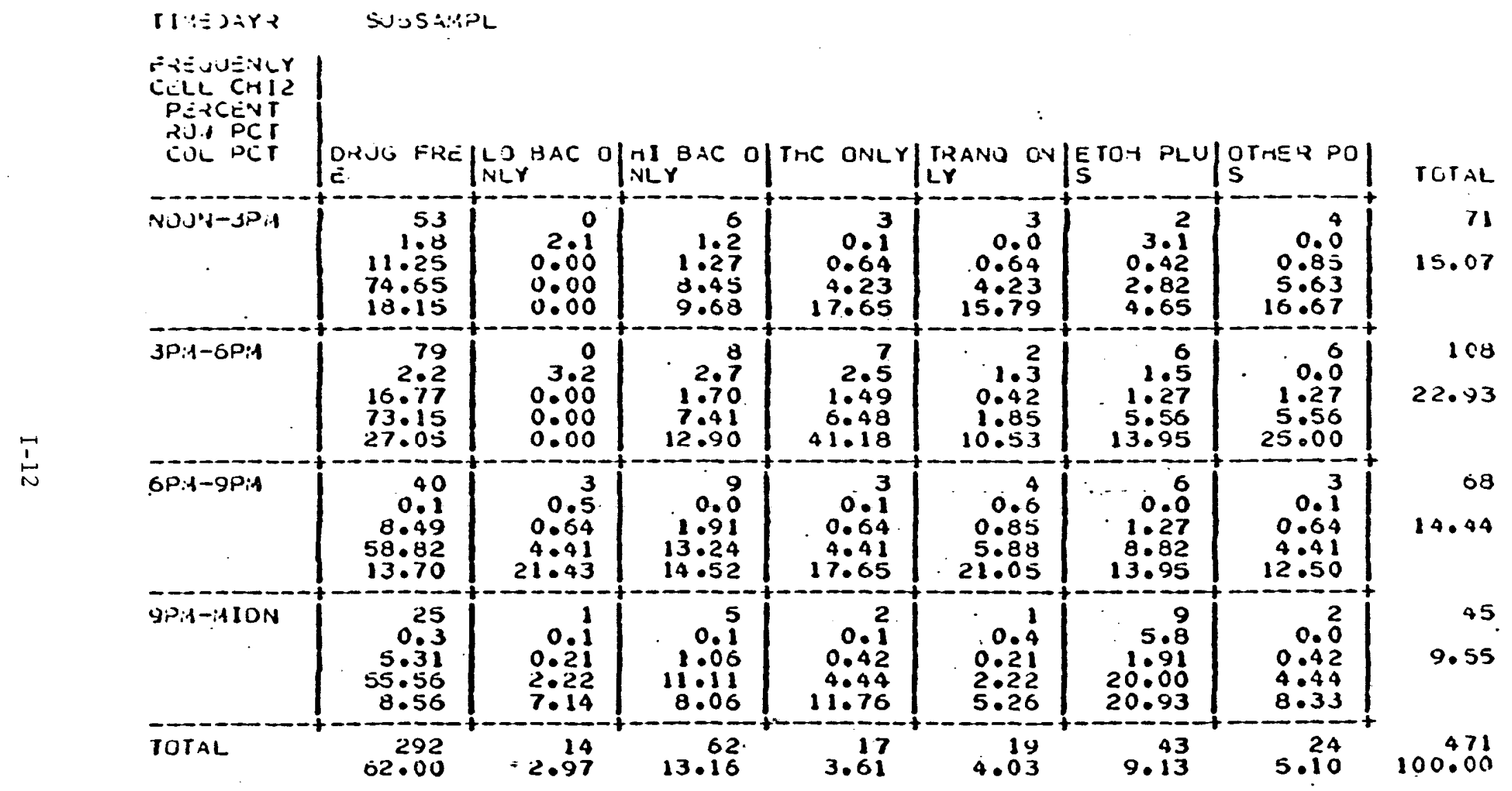


TABLE I-10. - (CONTINUED)

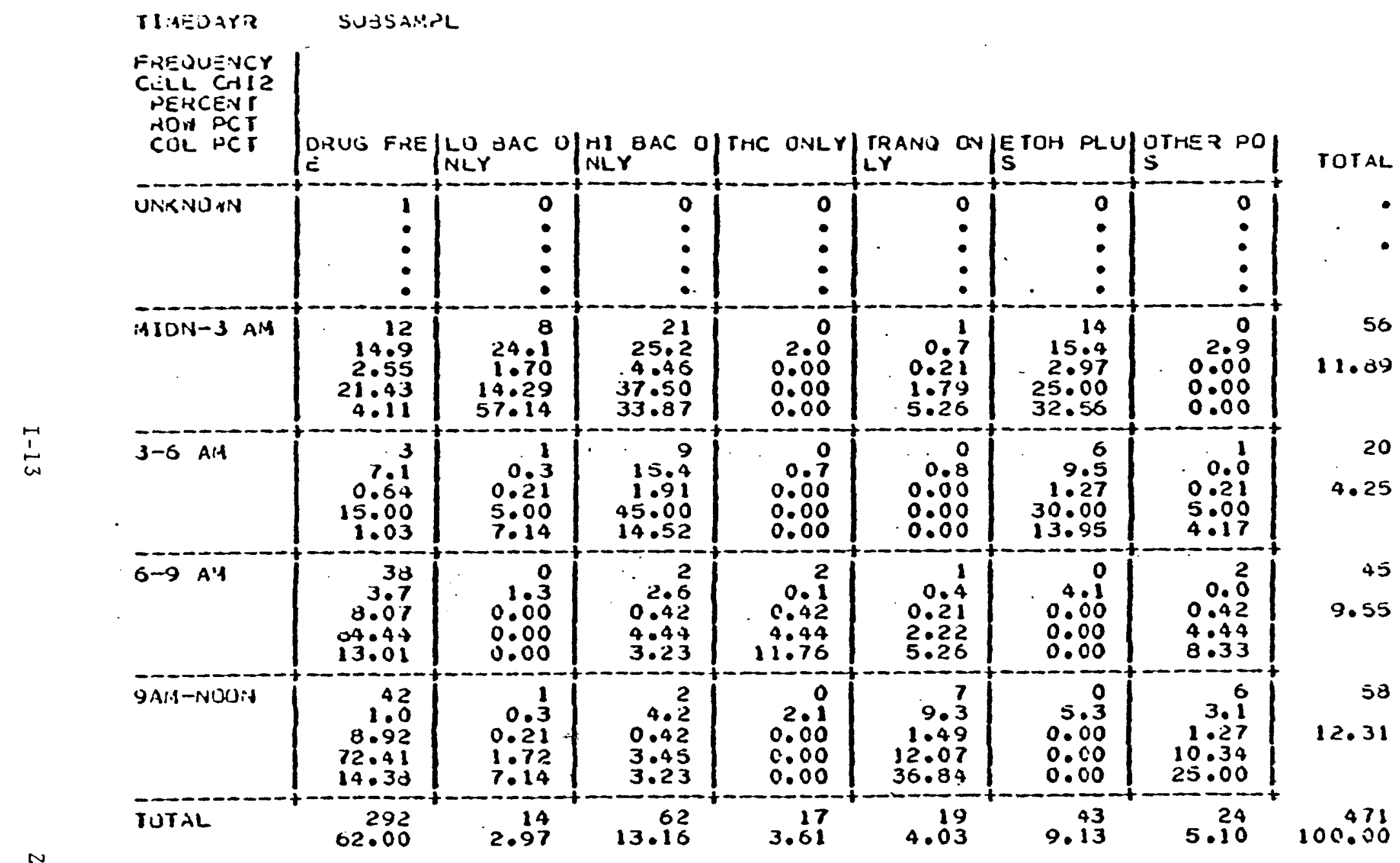


TABLE I-11: - VEHICLE TYPE BY SUBSAMPL

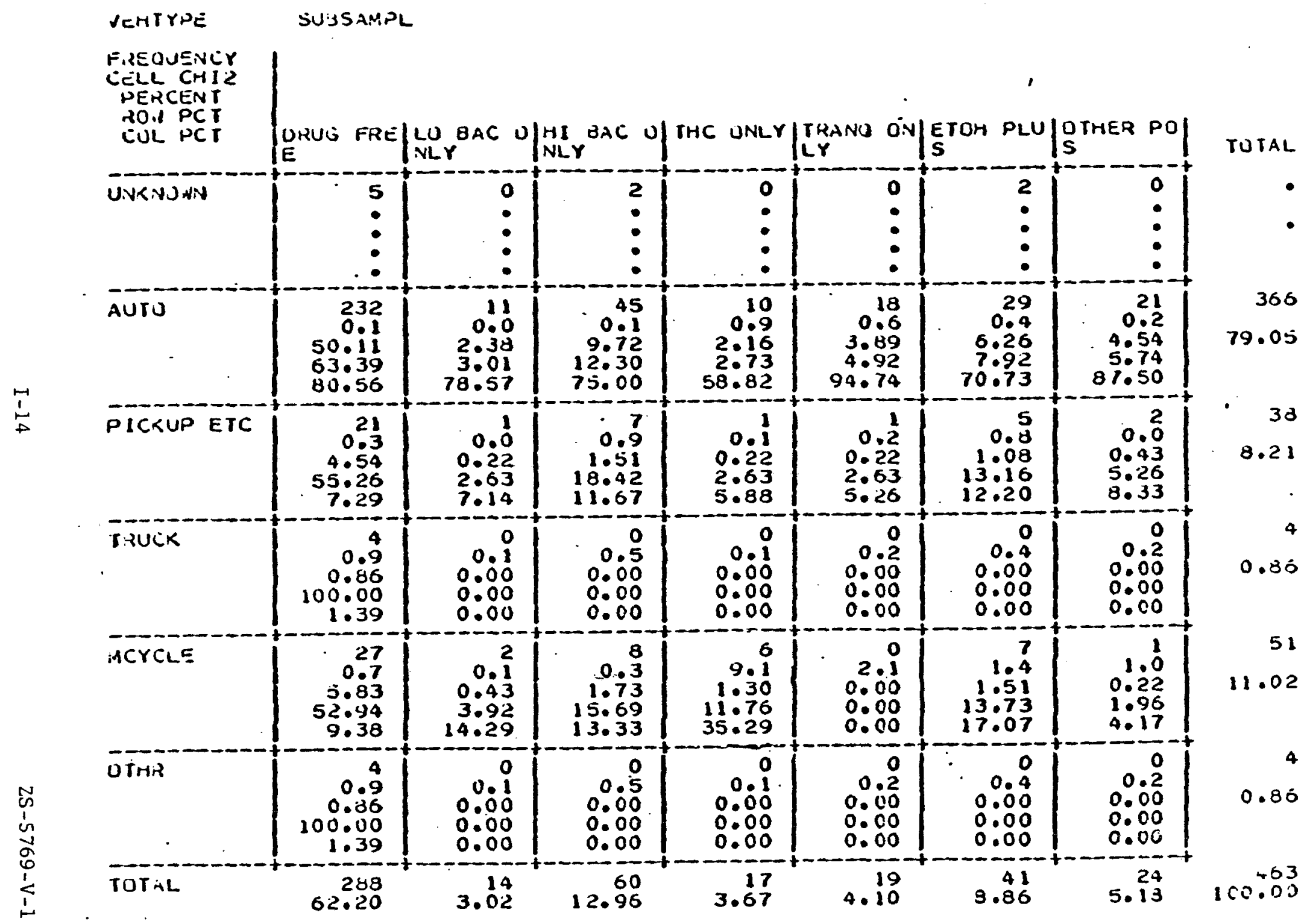


TABLE I-12. - WEATHER BY SUBSAMPL

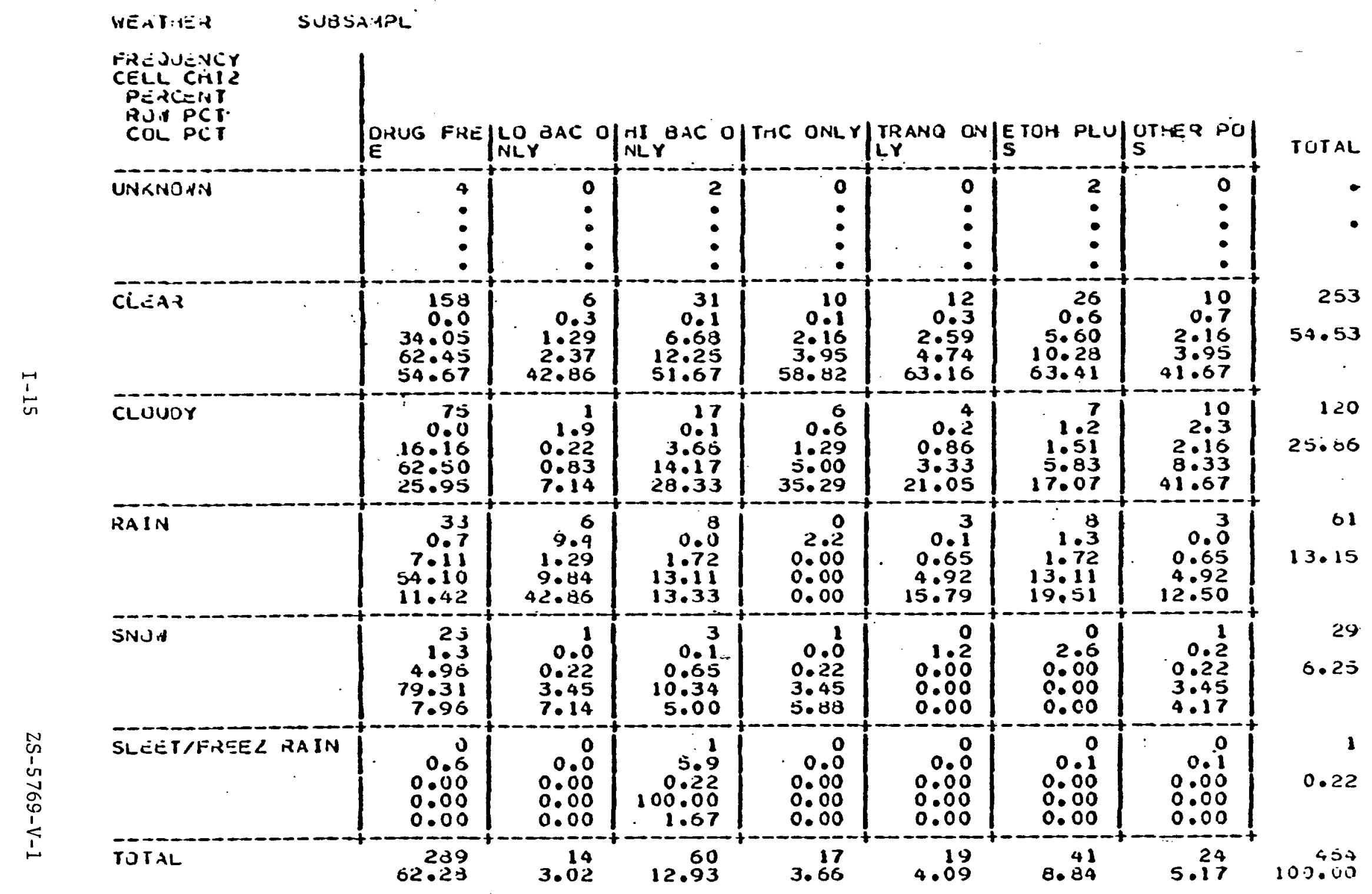




\section{APPENDIX J}

REPLICATION OF PERCHONOK ANALYSES

Replication of Analyses in Kenneth Perchonok's 1978 report, Identification of Specific Problems and Countermeasures

Targets for Reducing Alcohol Related Casualties

(U.S. Department of Transportation, National Highway

Traffic Safety Administration, Report DOT-HS-803716.) 
Basic questions this study addressed concern the relationships of alcohol and drugs to collision types, driver responsibility for crashes, and driver behavioral exrors. To do this, the original proposal and subsequent contract specified that the data analyses would include the use of Kenneth Perchonok's "causal structure," a coding scheme for classifying key details of crashes. The resulting analyses provide a partial replication of Perchonok's 1978 study of alcohol-related accidents. (Perchonok's study used police indications of alcohol involvement, while this study identified drinking drivers with blood tests.)

\section{Coding Perchonok's "Causal Structure"}

Before Perchonok's method could be applied in this study, a coding manual clearly describing the concepts and defining the terms was needed, to insure coding reliability. Consequently, that coding manual was produced in this project. Before describing the procedures in creating the manual, a brief description of the Perchonok analytic scheme is appropriate.

Overview of Perchonok's system. Perchonok's scheme is basically a method to describe a traffic accident in terms of what happened, how it happened, and why it happened, particularly during the last few second when it was still possible to avoid the crash. While describing more than causes, the causes it does examine are the most immediate ones, particularly any driver errors that produced the crash.

The scheme conceives an accident as comprising two basic events. The first is the Primary Event, * the accident-defining collision between vehicles, a rollover, or some other happening. The second is the Critical Event, which describes the action of a vehicle, pedestrian, or some other object which occurred momentarily before the crash and after which a crash

*Primary Event is our term, which seemed to more accurately label the variable which Perchonok (1978) called the "Target." 
was virtually unavoidable. In addition to these basic events, sometimes a Prior Event is also coded to record significant actions preceding the Critical Event.

Every accident has just one Primary Event and just one Critical Event, but they may be described differently from the perspective of each vehicle in an accident. Perchonok's scheme is set up to code a crash from the perspective of any one or all vehicles in the accident, according to the needs of the research. In a two-vehicle crash, for example, the accident may first be coded from the perspective of vehicle $A$, then coded again from the perspective of vehicle $B$. The vehicle whose perspective is being used in any coding is the Subject Vehicle, and whatever it impacts is called the Target. The paths and locations of the Subject and Target just prior to the Critical Event are also coded.

The Critical Event may be considered the most immediate "cause" of an accident, e.g., one vehicle crosses the road centerline into the path of an oncoming vehicle. More explanatory as a "cause," however, is the Critical Reason, which tells what the subject driver did or did not do to effect the Critical Event. If a Prior Event is coded, the Prior Reason explains why that event happened. Perchonok's system also included a kind of summary variable, Culpability. Unlike the other variables, this one is basically a rating scale, by which the coder assesses the driver's responsibility for the accident.

In summary, the following are the basic variables of Perchonok's system:
(a) Primary Event
(b) Critical. Event
(c) Subject Path
(d) Target Location
(e) Target Path
(f) Critical Reason
(g) Culpability 
There are, in addition, several other variables to record more specific details of the Critical Event and Critical Reason, as well as Culpable Behavior. These, like the Prior Event and Prior Reason, are used only when applicable. These subordinate variables were not used in this study.

Developing the coding manual. A principle adopted in creating the manual was to keep the coding scheme as faithful to Perchonok's original conceptions as possible, with modifications only as needed to eliminate inconsistencies or to provide supplementary information. (Some modifications were recommended by Perchonok on the basis of his past experience with the system.)

The procedure used was as follows. First, all available previous reports, papers, and notes in which Perchonok described the coding scheme were reviewed to glean any descriptions or interpretations of the variables in the coding scheme. These became the basis for writing the first draft of a coding manual in which all terms were defined, with explanatory discussions as needed for some of the more difficult concepts. An interative process was then followed, in which the coding manual was used to recode accident cases from Perchonok's 1978 study, and modifications to the manual were made where discrepancies with the 1978 coding revealed definitional problems. The procedure provided empirical assurance that the coding manual produced coding that was consistent with that in Perchonok's 1978 study. Final modifications were made after Perchonok reviewed the manual.

Coding reliability. Intercoder agreement was checked four times during the study, at intervals from the beginning. to the end of the coding. At these times, each coder independently recoded cases of the other coder, and agreement between them was determined.* The results (Table $J-1$ ) showed that initially intercoder agreement was somewhat low, but there was a gradual increase over time. Considering 80 per cent agreement as a minimum acceptable

*Agreement was expressed in per cents. The method is described in an appendix to the coding manual in Appendix $C$ of this report. 
TABL: J-1

Coding Reliability -- Degree of Agreement Between Coders on Cases From This Study

Basic Variables

Primary Event

Critical Event

Subject Path

Target Location

Target Path

Critical Reason

Culpability

Culpability Correlation*
Set 1

(25 Cases)

$92 \%$

$79 \%$

$92 \%$

$83 \%$

$73 \%$

$63 \%$

$73 \%$

0.92
Set 2 (25 Cases) (25 Cases)

$100 \%$
$77 \%$
$89 \%$
$89 \%$
$90 \%$
$73 \%$
$81 \%$
0.82

$100 \%$

$77 \%$

$89 \%$

$89 \%$

$90 \%$

$73 \%$

0.82

$100 \%$
$80 \%$
$84 \%$
$88 \%$
$94 \%$
$80 \%$
$80 \%$
0.92

Set 4

(25 Cases)

$100 \%$

$92 \%$

$92 \%$

$84 \%$

$90 \%$

$80 \%$

$72 \%$

0.93

Subordinate Variables

\begin{tabular}{|c|c|c|c|c|c|}
\hline Speed Change & & $(50 \%)$ & $(50 \%)$ & $(80 \%)$ & $(100 \%)$ \\
\hline Direction Change & & $88 \%$ & $92 \%$ & $78 \%$ & $86 \%$ \\
\hline Direction & & $88 \%$ & $88 \%$ & $96 \%$ & $86 \%$ \\
\hline Information Failure Type & & $17 \%$ & $40 \%$ & $50 \%$ & $22 \%$ \\
\hline Control Failure Type & Critical & $57 \%$ & $(100 \%)$ & $(80 \%)$ & $(100 \%)$ \\
\hline Logistic Type & Reasons & $(67 \%)$ & $(0 \%)$ & $(--)$ & $(40 \%)$ \\
\hline Critical Source & & $73 \%$ & $80 \%$ & $83 \%$ & $74 \%$ \\
\hline Critical Reason Basis & & $63 \%$ & $70 \%$ & $81 \%$ & $80 \%$ \\
\hline Culpable Behavior & & $74 \%$ & $63 \%$ & $86 \%$ & $67 \%$ \\
\hline OVERALL & & $72 \%$ & $78 \%$ & $82 \%$ & $84 \%$ \\
\hline
\end{tabular}

Figures in parenthesis involve 3 or fewer cases.

*Here, coder agreement is determined by Pearson $r$, treating culpability as a rating scale. 
standard, and 90 per cent as a standard normally to be sought, it can be seen that some variables were coded with acceptable reliability, while others were not. Generally, the basic variables of the Perchonok scheme had higher reliabilities than the subordinate variables.

of the basic variables in the system, Critical Reason most directly pertains to driver errors or failures. Unfortunately, it had the lowest reliability of the basic variables in the Perchonok scheme, attaining the marginal reliability of 80 per cent only after the coders had extensive experience. Three subordinate variables are intended to describe the particular kind of "information failure," "control failure," or "logistic" error made by drivers. As Table $J-1$ shows, however, the coding reliability of these variables was unacceptable, with the possible exception of Control Failure Type. In large part, these problems result from the difficulty in learning just what the driver did or did not do just prior to the Critical Event.

As a final check on coding reliability, the same 100 cases used in Table J-1 were submitted to Perchonok to code independently. Table J-2 shows that Perchonok generally agreed somewhat less with each coder than they did with each other. Notice, however, that the trend of increasing agreement with successive cases appears here also.

Determining collision type. In Perchonok's (1978) study, nine collision types were distinguished in the analysis, and these met the requirement of describing the particular role of the driver's vehicle. These types are defined as combinations of the variables Critical Event, Subject Path, Target Location, Target Path, Direction Change and Speed Change. Exactly how these variables are combined for the collision types is detailed in Appendix $D$. Figure J-1 shows schematic diagrams of the nine types. 
TABLE $J-2$

Coding Agreement Between Perchonok and Coders

Basic Variables

Primary Event

Critical Event

Subject Path

Target Location

Target Path

Critical Reason

Culpability

Culpability Correlation*
Set 1 Coder 1 Coder

$\begin{array}{ll}84 \% & 92 \% \\ 64 \% & 56 \% \\ 80 \% & 84 \% \\ 88 \% & 84 \% \\ 75 \% & 88 \% \\ 56 \% & 56 \% \\ 64 \% & 56 \%\end{array}$

0.74

0.59
Set 2 $100 \% \quad 100 \%$

$88 \% \quad 80 \%$

$80 \% \quad 88 \%$

$92 \% \quad 80 \%$

$80 \% \quad 83 \%$

$76 \%$

$64 \%$

0.56
Coder 1 Set 3

$92 \%$

$92 \%$
$72 \%$
$80 \%$

$80 \%$

$80 \%$

$65 \%$

$52 \%$

$68 \%$

0.83

$92 \%$
$84 \%$
$88 \%$
$80 \%$
$71 \%$
$56 \%$
$68 \%$

0.83

Subordinate Variables

$\stackrel{4}{1}$

Speed Change
Direction Change

Direction

Information Failure Type

Control Failure

$$
\text { Type }
$$

Logistic Type

Critical Source

Critical Reason

Basis

Culpable Behavior

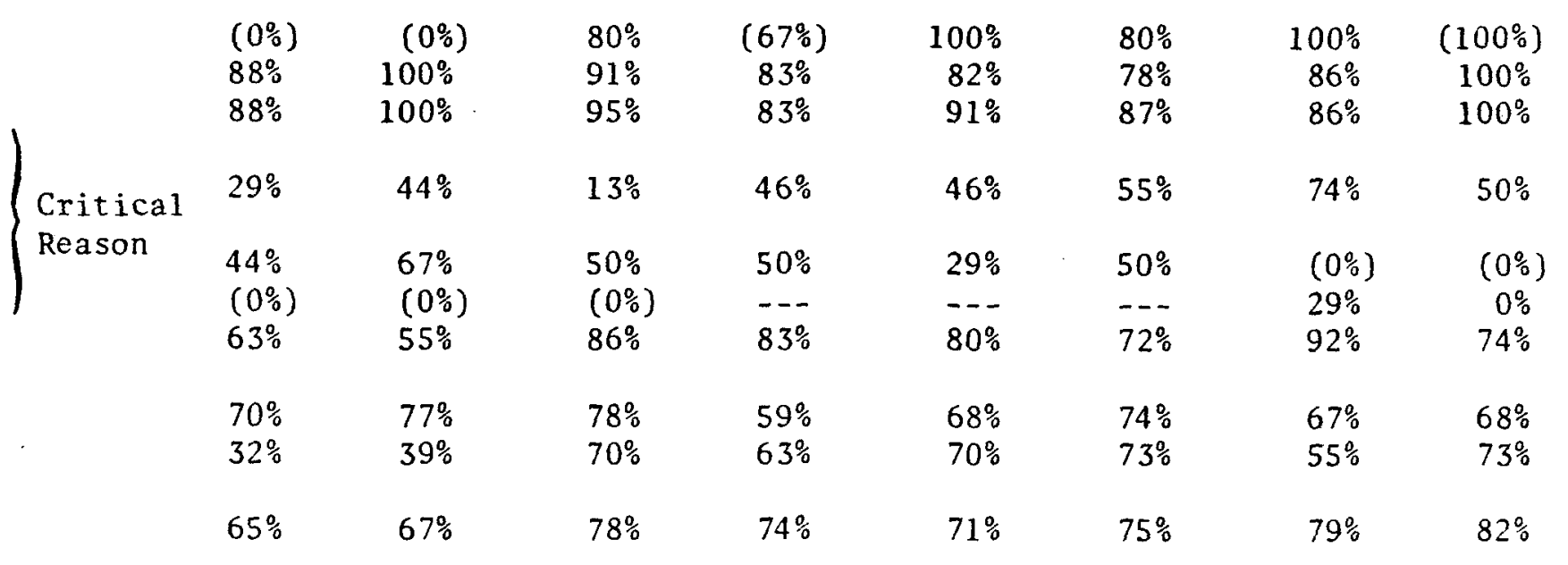

OVERALL

Figures in parenthesis involve $\leq 3$ cases. 
CLASS R

reAR END

STATIONARY TARGET AMEAD

INTERSECTING PATH

- CONTINUE

INTERSECTING PATH

- START

PARALLEL OPPOSITE

- lateral move

PARALLEL OPPOSITE

- LEFT TUAN

PARALLEL SAME

- Lateral move

REARWARD

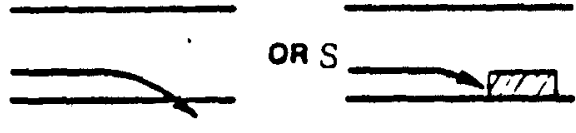

$S \longrightarrow$ (EXCEPT TAIL GATING)
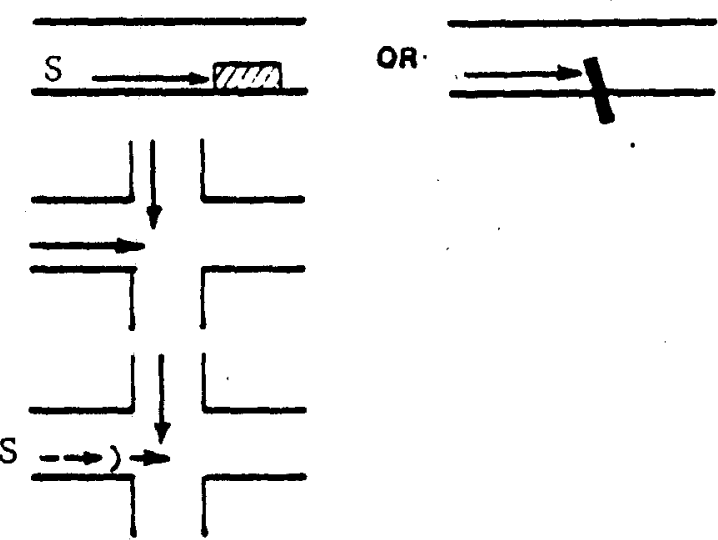

$\mathrm{S}$
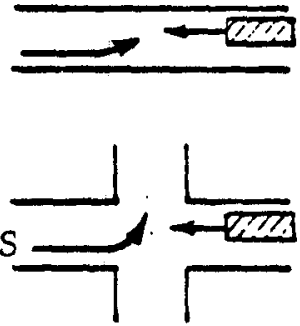

$\mathrm{S}$

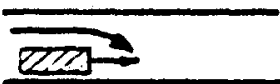

ANY BACKING-UP

FIGURE J-1 PARTIAL SCHEMATICS OF PERCHONOK COLLISION TYPES

$(S=$ Subject vehicle) 
For the data sets used in Table $\mathrm{J}-1$, the collision types were formed from each coder's component variable codes. Through the four data sets, the intercoder reliabilities were: $53 \%, 73 \%, 81 \%$, and $69 \%$. These were mostly below the standard considered desirable.

Results

Replications were made of two key analyses in Perchonok's 1978 study, pertaining respectively to collision types and to Critical Reasons.

Since Perchonok analyzed the crashes of culpable drivers only, it was necessary to do that here also. Perchonok reported that 95 per cent of his drinking drivers were culpable, compared to 60 per cent of the "normal" drivers. These high levels are closer to the 87 per cent and 43 per cent that were found in this study for the drivers judged culpable or culpable/contributory. Consequently, drivers within both of those categories were selected for the replication analysis.

\section{Collision type. Table J-3 compares Perchonok's results with those} of this study. Generally, the agreement is high. The largest discrepancies are that Perchonok found substantially fewer Class R (e.g. road departure) crashes and more rear-end (striking) collisions than did this study. Perchonok's more rural sample might have been expected to produce more Class $\mathrm{R}$ crashes, but the lower severity of his accidents would reduce the proportion in comparison with the injured drivers of this study. On the other hand, rear-end crashes would be expected to decrease in rural areas, but increase in a sample of less severe accidents.

If one examines the indications of whether any collision type was more common among the sober or the alcohol-involved drivers, it can be seen that the two studies gave similar results. For example, the stationary-targetahead type was found proportionately more among the alcohol-involved, in both studies. 
TABLE J-3. - REPLICATION OF PERCHONOK'S COLLISION TYPE ANALYSIS (Based on high-culpability drivers only)

\begin{tabular}{|c|c|c|c|c|}
\hline \multirow[b]{2}{*}{$\begin{array}{c}\text { Perchonok's } \\
\text { Collision Types } \\
\end{array}$} & \multicolumn{2}{|c|}{ "Sober" Drivers } & \multicolumn{2}{|c|}{ Al cohol-Involved } \\
\hline & $\begin{array}{c}\text { This } \\
\text { study } \\
\text { (drugfree) } \\
\end{array}$ & $\begin{array}{l}\text { Perchonok } \\
\text { ("normal s") } \\
\end{array}$ & $\begin{array}{c}\text { This } \\
\text { study } \\
\text { (alc.-only) } \\
\end{array}$ & $\begin{array}{l}\text { Perchonok } \\
\text { ("Drinkers") }\end{array}$ \\
\hline Class $R$ & $28.7 \%$ & $18.1 \%$ & $53.0 \%$ & $41.7 \%$ \\
\hline Rear end & 10.4 & 17.8 & 4.5 & 13.9 \\
\hline $\begin{array}{l}\text { Stationary Target } \\
\text { Ahead }\end{array}$ & 3.5 & 4.1 & 4.5 & 7.6 \\
\hline $\begin{array}{l}\text { Intersecting Path - } \\
\text { Continue }\end{array}$ & 8.7 & 8.5 & 1.5 & 4.1 \\
\hline $\begin{array}{l}\text { Intersecting Path - } \\
\text { Start }\end{array}$ & 7.8 & 6.5 & 0 & 0.7 \\
\hline $\begin{array}{c}\text { Parallel Opposite - } \\
\text { Lateral Move }\end{array}$ & 3.5 & 5.2 & 4.5 & 6.6 \\
\hline $\begin{array}{l}\text { Parallel Opposite - } \\
\text { Left Turn }\end{array}$ & 5.2 & 5.9 & 1.5 & 2.5 \\
\hline $\begin{array}{l}\text { Parallel Same - } \\
\text { Lateral Move }\end{array}$ & 0 & 2.3 & 1.5 & 1.5 \\
\hline Rearward & 0 & 3.2 & 1.5 & 1.6 \\
\hline Other & 32.2 & 28.4 & 27.3 & 19.7 \\
\hline Total & $100.0 \%$ & $100.0 \%$ & $100.0 \%$ & $100.0 \%$ \\
\hline Total drivers & 115 & 1,597 & 66 & 2,863 \\
\hline Type unknown & 6 & $?$ & 2 & $?$ \\
\hline
\end{tabular}


Critical Reasons. Before presenting the results, Perchonok's Critical Reasons variable needs a brief description*. The reasons explain the cause of an accident from the perspective of each driver. They are coded into one of the following mutually-exclusive categories:

(a) External Influence (E.I.) - Another vehicle or agent is the cause of the Critical Event.

(b) Driver Alleged E.I. - Unsubstantiated driver claim that another vehicle or agent caused the accident.

(c) Vehicle Breakdown - Vehicle malfunction or failure.

(d) Driver Breakdown - Driver became physically unable to control vehicle, e.g., fell asleep, "blacked out."

(e) Driver Information Failure (IF) - Driver failed to acquire and use needed information.

(f) Driver Control Failure (CF) - Driver lost control of vehicle.

(g) IF or CF - May have been either Information Failure or Control Failure; a vague category often applied to road departure crashes when the reason for the accident is unclear.

(h) Other/Unclear - All other possibilities.

It should be noted that the coders indicated that their judgements of Critical Reasons were based on inference in 28 per cent of the cases.** Such inferences were made after reviewing all relevant facts in the case

\footnotetext{
*See Coding Manual (Appendix C) for details.

** Judging whether an inference was made was not a highly reliable judgment. See Critical Reason Basis in Table J-I
} 
reports. When a Critical Reason was not inferred, it was based on some specific statement in the police report or driver interview identifying the reason for the accident. So as not to simply pass on an inference of the reporting police officer, the coders were instructed to give credence to an officer's statement of cause only if he referred to some objective, observable fact.

The results in Table $\mathrm{J}-4$ reveal a fair degree of agreement between Perchonok's results and ours for the "sober" drivers. Among the alcoholinvolved drivers, however, there are some large differences. That Perchonok's "drinkers" did not exhibit Driver Alleged External Influences is easily explained; Perchonok did not use that category. (In the absence of driver interviews, it may not have been useful.) Other differences are less readily explained, however: our alcohol-involved had nearly six times as many Driver Breakdowns as had Perchonok's, while his group had over twice the Information Failures of ours. A major factor accounting for the differences may be the fact that this study used driver interviews and Perchonok's did not. On the one hand, this would require Perchonok's data to be based more on inference. (He reported that Information Failures, Control Failures, IF-CF, and a seldom-used category called Logistic, were inferred 73 per cent of the time.) On the other hand, driver interviews enable drivers to offer rationalizations for their accidents, which necessarily will affect the coding of Critical Reasons.

If the two studies are compared in another way, their resultts are more similar. Ignoring Driver-Alleged External Influence, the proportions of the drugfree Critical Reasons relative to the alcohol-involved are nearly always in the same direction. For example, both studies found higher proportions of Driver Breakdown among the alcohol-involved than among the sober. The only exception to this tendency is in Control Failure, and there the results are basically the same. 
TABLE $J-4$ - REPLICATION OF PERCHONOK'S CRITICAL REASON ANALYSIS (Based on high-culpability drivers only)

\begin{tabular}{|c|c|c|c|c|}
\hline \multirow[b]{2}{*}{ Critical Reason } & \multicolumn{2}{|c|}{ "Sober" Drivers } & \multicolumn{2}{|c|}{ Alcohol - Involved } \\
\hline & $\begin{array}{c}\text { This } \\
\text { study } \\
\text { (drugfree) } \\
\end{array}$ & $\begin{array}{c}\text { Perchonok } \\
\text { ("norma1s") } \\
\end{array}$ & $\begin{array}{c}\text { This } \\
\text { study } \\
\text { (a1c. on } 1 y) \\
\end{array}$ & $\begin{array}{c}\text { Perchonok } \\
\text { ("Drinkers") }\end{array}$ \\
\hline $\begin{array}{l}\text { External } \\
\quad \text { Influence (E.I.) }\end{array}$ & $7.3 \%$ & $6.8 \%$ & 0 & $3.2 \%$ \\
\hline Driver-Alleged E.I.* & 5.5 & - & 19.3 & -- \\
\hline Vehicle Breakdown & 0.9 & 4.3 & 0 & 1.8 \\
\hline Driver Breakdown & 7.3 & 0.4 & 15.8 & 2.8 \\
\hline $\begin{array}{l}\text { Dr. Information } \\
\text { Failure (IF) }\end{array}$ & 47.7 & 55.5 & 19.3 & 41.6 \\
\hline $\begin{array}{l}\text { Dr. Control } \\
\text { Failure (CF) }\end{array}$ & 19.3 & 18.8 & 19.3 & $20 ! 1$ \\
\hline Indistinct IF or $\mathrm{CF}$ & 6.4 & 10.4 & 22.8 & 27.3 \\
\hline Other/Unclear & 5.5 & 3.8 & 3.5 & 3.1 \\
\hline Total\% & $100.0 \%$ & $100.0 \%$ & $100.0 \%$ & $100.0 \%$ \\
\hline Total drivers & 109 & 1,597 & 57 & 2,863 \\
\hline
\end{tabular}

*Perchonok's original system did not include this reason. 
It is worth noting that lower rates of Information Failure among the alcohol-involved were also found by Perchonok in two earlier studies (1972, 1975; * all three studies were of Western New York accidents. (They may have included some of the same accidents.)

Great caution should be used in attributing meaning to these results, for several problems were revealed in coding the data. The reliability of the general Critical Reasons category was substandard, and specific Critical Reasons, such as types of Information Failure, were even less reliable. Coding in a number of cases was based on inference, and the coders even had difficulty in agreeing whether they had used inference or not. Even if reliable, the category of Information Failure/Control Failure, the most frequent "cause" of high-BAC crashes, simply acknowledges that the crash may have been either an Information Failure or Control Failure. (Perchonok [1978] gave this the label of "tracking error".) Finally, serious questions are raised about the veracity of the causal information derived from the drivers, for the alcohol-involved ones in this study reported more Vehicle Breakdowns and considerably more unsubstantiated instances of being forced into an accident by a noncrash vehicle or other agent.

*Ziedmân, Moskowitz, and Niemann (1980) reported that the reverse was found in Perchonok's 1972 study, but that does not seem correct. 